\title{
Satellite cells and skeletal muscle characteristics in sarcopenia
}

Citation for published version (APA):

Verdijk, L. (2009). Satellite cells and skeletal muscle characteristics in sarcopenia. [Doctoral Thesis, Maastricht University]. Datawyse / Universitaire Pers Maastricht. https://doi.org/10.26481/dis.20091016lv

Document status and date:

Published: 01/01/2009

DOI:

10.26481/dis.20091016lv

Document Version:

Publisher's PDF, also known as Version of record

\section{Please check the document version of this publication:}

- A submitted manuscript is the version of the article upon submission and before peer-review. There can be important differences between the submitted version and the official published version of record.

People interested in the research are advised to contact the author for the final version of the publication, or visit the DOI to the publisher's website.

- The final author version and the galley proof are versions of the publication after peer review.

- The final published version features the final layout of the paper including the volume, issue and page numbers.

Link to publication

\footnotetext{
General rights rights.

- You may freely distribute the URL identifying the publication in the public portal. please follow below link for the End User Agreement:

www.umlib.nl/taverne-license

Take down policy

If you believe that this document breaches copyright please contact us at:

repository@maastrichtuniversity.nl

providing details and we will investigate your claim.
}

Copyright and moral rights for the publications made accessible in the public portal are retained by the authors and/or other copyright owners and it is a condition of accessing publications that users recognise and abide by the legal requirements associated with these

- Users may download and print one copy of any publication from the public portal for the purpose of private study or research.

- You may not further distribute the material or use it for any profit-making activity or commercial gain

If the publication is distributed under the terms of Article $25 \mathrm{fa}$ of the Dutch Copyright Act, indicated by the "Taverne" license above, 
Satellite cells and skeletal muscle

characteristics in sarcopenia 


\section{ilứlín}

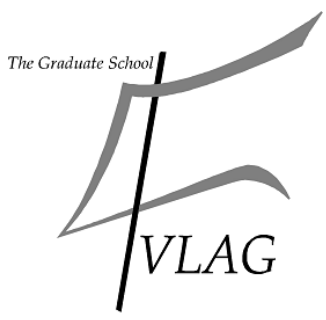

The studies presented in this thesis were performed within the NUTRIM School for Nutrition, Toxicology and Metabolism which participates in the Graduate School VLAG (Food Technology, Agrobiotechnology, Nutrition and Health Sciences), accredited by the Royal Netherlands Academy of Arts and Sciences.

Cover design: Datawyse, Universitaire Pers Maastricht / Lex Verdijk

Cover photos: Fraser Gunn, Tekapo, New Zealand

Printed by: Datawyse, Universitaire Pers Maastricht

(C) Lex B Verdijk, Maastricht 2009

ISBN 978-90-5278-861-6 


\title{
Satellite cells and skeletal muscle characteristics in sarcopenia
}

\author{
PROEFSCHRIFT
}

Ter verkrijging van de graad van doctor aan de Universiteit Maastricht

op gezag van de Rector Magnificus Prof. mr. G.P.M.F. Mols volgens het besluit van het College van Decanen, in het openbaar te verdedigen

op vrijdag 16 oktober 2009 om 10:00 uur

door

\section{Lex Berti Verdijk}

geboren te Vierlingsbeek op 10 februari 1979

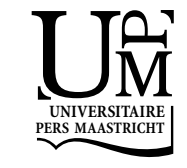




\section{Promotor}

Prof. dr. H. Kuipers

\section{Copromotores}

Dr. L.J.C. van Loon

Dr. H.H.C.M. Savelberg

\section{Beoordelingscommissie}

Prof. dr. ir. A.M.W.J. Schols (voorzitter)

Prof. dr. ir. C.P.G.M. de Groot (WUR, Wageningen)

Dr. M.K.C. Hesselink

Prof. dr. F. Kadi (Örebro University, Örebro, Sweden)

Prof. dr. H.P. Sauerwein (em. Hoogleraar AMC/UvA, Amsterdam)

Financial support for the publication of this thesis was granted by DSM Food Specialties, Philips Healthcare, and Medische laboratoria dr. Stein \& Collegae, and is gratefully acknowledged. 


\section{Table of contents}

Chapter 1

Introduction

Chapter 2

One-repetition maximum strength test represents a valid means to assess leg strength in vivo in humans

Chapter 3

Satellite cell content is specifically reduced in type II skeletal muscle fibers in the elderly

\section{Chapter 4}

Muscle fiber type characteristics are predictive of skeletal muscle mass and strength in healthy, elderly males

Chapter 5

Skeletal muscle hypertrophy following resistance training is accompanied by a fiber type-specific increase in satellite cell content in elderly men

\section{Chapter 6}

Protein supplementation before and after exercise does not further augment skeletal muscle hypertrophy after resistance training in elderly men

Chapter 7

General discussion

Summary

Samenvatting

Dankwoord

Curriculum vitae 



\title{
Chapter 1
}

\author{
Introduction
}



The primary function of skeletal muscle is to produce the forces that are needed to generate movement of the body. Muscle strength and muscle power are largely dependent on muscle mass. Consequently, skeletal muscle mass represents a major determinant of functional performance. Furthermore, as skeletal muscle tissue comprises $\sim 70 \%$ of body cell mass, it plays a major role in glucose, fat, and protein metabolism. Even with healthy aging, there is a gradual, progressive decline in muscle mass with an advancing age. The latter leads to the loss of muscle strength and, as such, a decline in functional performance. The loss of muscle mass and function with aging has been termed sarcopenia. Sarcopenia is recognized as an important factor in determining the ability of elderly people to live independently, and is associated with a reduction in the quality of life (69). Given the global changes in population demographics and the increased life expectancy, sarcopenia is becoming a major health care and socio-economic problem. The detrimental consequences of sarcopenia necessitate the development of interventional strategies to improve muscle mass and function in the elderly. Throughout the lifespan, skeletal muscle tissue appears to retain at least part of its remarkable capacity to adapt to changes in physiological demands. Resistance type exercise training represents the most effective interventional strategy to improve skeletal muscle mass and strength, even in the very old. However, the exact pathways by which physical activity induces the skeletal muscle adaptive response, as well as the specific mechanisms underlying the process of sarcopenia itself remain to be elucidated.

In this thesis, age-related changes in muscle mass and strength are studied on a whole-body, limb, and myocellular level. Specific attention is given to the potential role of myonuclei and satellite cells (or skeletal muscle stem cells) in the etiology of sarcopenia and in the skeletal muscle adaptive response to intervention programs designed to counteract the loss of muscle mass and function in the elderly.

\section{Aging and sarcopenia}

Population demographics show that in Western societies, the number of people aged 65 years and over will rise by $70-100 \%$ over the next 40 years; from 61 million up to 103 million in Europe (28) and from 46 million to 108 million in the United States (104). In The Netherlands, similar trends are observed, with an expected rise in the number of people aged 65 years and over from 2.4 to 4.2 million between 2007 and 2040 (16). As such, the proportion of elderly in the population will increase from $\sim 15 \%$ to more than $25 \%$ within the next 40 years.

With aging, there is a gradual but progressive loss of skeletal muscle mass and function, which is referred to as sarcopenia. The term sarcopenia was first introduced by Rosenberg (89) in an attempt to draw more attention 
towards the clinical importance of the progressive decline in muscle tissue as a cause of reduced functional performance in the elderly. The word stems from the Greek language and literally means poverty (penia) of flesh (sarco). Sarcopenia is not associated with any specific disease state and is, therefore, distinct from cachexia and/or muscle wasting as observed in diseases like cancer, human immunodeficiency virus (HIV), or chronic obstructive pulmonary disease (COPD) (94). With normal human growth and development, skeletal muscle mass increases until the third decade and then remains relatively stable until the age of 40-50 years. Thereafter, a gradual but progressive decline is observed, with the loss of skeletal muscle mass predominantly located in the extremities. Baumgartner et al. (5) defined sarcopenia as an appendicular skeletal muscle mass value (sum of lean tissue mass in the arms and the legs) of at least 2 standard deviations below the gender-specific mean for healthy, young adults. Using this criterion, the prevalence of sarcopenia in a population-based sample of people above the age of 60 years was shown to be $\sim 25 \%$, and up to $\sim 50 \%$ in individuals aged 80 years and over. Similar findings were reported by Ianuzzi et al. (50) and Janssen et al. (52). For regional muscle volume and/or cross-sectional area of specific muscles or muscle groups, cross-sectional studies have shown decreases of $\sim 4-11 \%$ per decade between the ages $20-85$ years, with a more predominant decline in the lower extremities $(24,53,73,74,97)$. Longitudinal data support these findings by showing similar, or even larger declines after 5-12 years of follow-up in the elderly $(35,39)$.

\section{Consequences of sarcopenia}

Muscle mass has been shown to be a major determinant of muscle strength $(36,63)$. The strong correlation between muscle mass (total thigh muscle cross-sectional area) and muscle strength (one-repetition maximum leg press strength) is depicted in Figure 1.1. In line with the age-related loss of skeletal muscle mass, muscle strength starts to decline after the $3^{\text {rd }}$ decade, with a more rapid decline after the $5^{\text {th }}$ decade $(70,74)$. Lower extremity muscle mass and strength are closely linked to functional performance and mobility in the elderly. Fiatarone et al. (31) observed an inverse correlation between quadriceps muscle strength and $6 \mathrm{~m}$ walking time, the number of steps needed to walk $6 \mathrm{~m}$, and chair rise time. Likewise, Visser et al. (106) reported that a reduced thigh muscle area is associated with decreased lower extremity functional performance. Data from the New Mexico Elder Health Survey showed that the age-related decline in muscle mass and strength can result in serious functional impairment. The presence of sarcopenia was associated with a 2-4 times higher risk of balance abnormalities, the need to use a cane while walking, the prevalence of 3 or more disabilities in daily functioning, and/or having fallen once or more over the past year (5). In addition, the loss of muscle mass and strength with aging is also 
accompanied by a decline in endurance capacity and increased fatigability (33). Eventually, advanced muscle weakness results in the inability to perform activities of daily living, an increased fall risk, the loss of independence, a greater need for institutionalization, and a higher mortality $(8,24,29,52,86)$. As such, sarcopenia imposes a major burden on health care costs in Western societies. In 2000, the health care costs directly attributable to sarcopenia were estimated to be $1.5 \%$ of total health care expenditures (i.e. 18.5 billion dollar) in the United States (54).

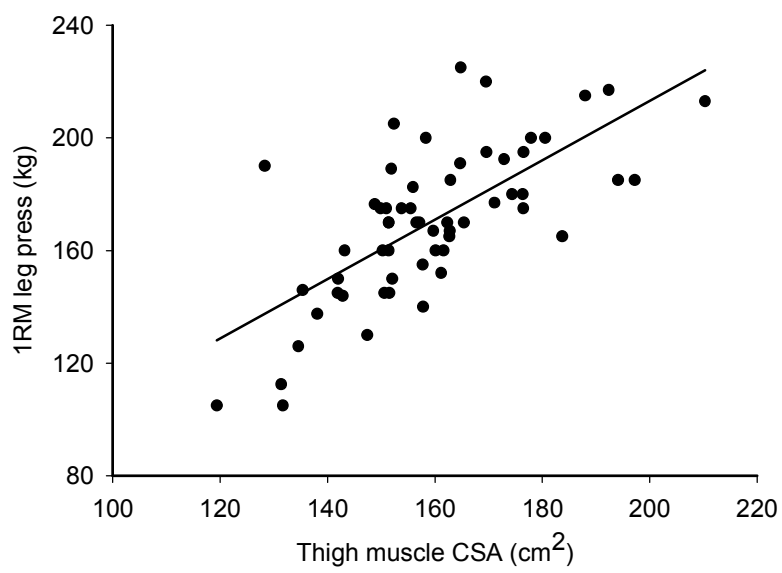

Figure 1.1 Correlation between total thigh muscle cross-sectional area (CSA) measured by CT scan and one-repetition maximum (1RM) leg press strength $(n=60, r=0.70$, Verdijk 2008, unpublished observations).

Furthermore, it should be realized that skeletal muscle tissue represents a major metabolic organ, playing an important role in glucose, fat and protein metabolism. Consequently, sarcopenia is generally associated with an increased risk of developing chronic metabolic diseases, like type 2 diabetes, obesity, osteoporosis, and cardiovascular disease $(29,80)$. Taken together, the detrimental consequences of sarcopenia underline the importance of designing strategies that can effectively delay and/or reverse the loss of muscle mass with aging. Before describing such potential interventions to prevent or limit the loss of muscle mass with aging, the muscular features that characterize sarcopenia will be addressed and some of the mechanisms underlying the changes in muscle tissue with aging will be identified.

\section{Age-related changes in muscle characteristics}

From approximately the fourth decade, whole-body lean tissue mass progressively declines with increasing age. This loss of skeletal muscle mass is not uniformly distributed over the different body regions. First of all, the 
decline seems to be larger in the extremities when compared with the trunk $(6,39)$. Furthermore, leg muscles have been reported to be affected to a greater extent than arm muscles $(39,53)$, which might explain the apparent loss of mobility with aging. In addition, different muscle groups are affected differently throughout the aging process, which is probably due to their functional and/or structural diversity $(3,63)$. Besides the apparent decrease in whole-body and regional lean mass and muscle cross-sectional area, qualitative changes at the level of the entire muscle include an increase in connective tissue content and fat infiltration $(43,72)$.

On the level of the muscle fiber, Lexell et al. (73) clearly show that both type I and type II muscle fibers are lost with aging. Some studies have shown an increased proportion of type I muscle fibers at a more advanced age, implying the predominant loss of type II muscle fibers $(25,71)$. In contrast, others report no changes in muscle fiber type composition, both in cross-sectional (48) and in longitudinal studies $(3,35)$. Furthermore, fiber type grouping (73) and decreased capillarization (35) have been observed in elderly muscle tissue. By far the most consistent is the observation of specific type II muscle fiber atrophy with aging. In contrast to the type I muscle fibers, type II muscle fiber size is $25-50 \%$ lower in the elderly when compared with the young $(25,44,64,71-73,98)$. It should be noted that the majority of studies included biopsy samples taken from the vastus lateralis muscle. Changes in muscle fiber size with aging probably depend on the location of the muscle and on the functional demands placed on it. Although type II muscle fiber atrophy has also been observed in the masseter (62) and the biceps brachii muscles (64), generalization of these findings to other muscle groups of the human body should be performed with great caution. As mentioned above, the decrease in muscle mass, resulting from the loss and atrophy of the muscle fibers, is a major determinant of the age-related loss of muscle strength. In addition, qualitative changes in skeletal muscle tissue seem to contribute to the loss of functional capacity. This age-related change in muscle quality leads to a decline in specific force, i.e. muscle strength corrected for muscle mass. Specific force has been shown to be reduced at the level of the entire muscle $(63,83)$ and at muscle fiber level at a more advanced age (38). The qualitative changes underlying a decline in muscle force include specific type II muscle fiber atrophy, increased connective tissue content, greater fat infiltration, greater hydration level of lean tissue, reduced myofibrillar protein concentration, and impaired neuromuscular drive $(4,9,22,27,43,61,72)$. The relative importance of these qualitative changes for the functional consequences of sarcopenia remains to be determined. 


\section{Etiology of sarcopenia}

It is generally acknowledged that sarcopenia forms a complex, multifactorial process. Although the exact cellular and/or molecular mechanisms underlying sarcopenia are still a matter of debate, a number of possible explanations have been suggested in the literature. The following is a summary of the etiological factors that are generally thought to be responsible for the loss of muscle mass with aging $(24,26,29,40,58,80$, 93, 105, 107).

From the most basic point of view, any loss of muscle mass stems from a structural imbalance between muscle protein synthesis and muscle protein breakdown. Though initial studies have suggested that there might be an age-related reduction in basal muscle protein synthesis, most recent data indicate that basal muscle protein turnover rates do not differ between young and elderly adults when corrected for total muscle mass $(80,107,108)$. Furthermore, a subclinical inflammatory state (with increased levels of TNF $\alpha$, NF-KB and IL-6 in the elderly) has been suggested to lead to increased muscle protein catabolism $(21,24,58,93)$. However, as opposed to specific disease states (e.g. rheumatoid arthritis, HIV, cancer, COPD), whole-body protein breakdown rates do not seem to differ between healthy young and elderly subjects (84). As basal muscle protein synthesis and/or whole-body breakdown rates do not seem to differ between the young and elderly, most research groups now hypothesize that the loss of muscle mass with aging is, at least partly, attributed to a blunted muscle protein synthetic response to the main anabolic stimuli, i.e. protein intake and/or physical activity (107). In accordance, recent studies show a reduced sensitivity and responsiveness to the anabolic properties of protein or amino acid ingestion in the elderly $(21,60)$. Furthermore, the increase in muscle protein synthesis rate observed following a single bout of resistance type exercise has been shown to be attenuated in the elderly when compared with the young (65, 68). The mechanisms responsible for this apparent anabolic resistance to food intake and/or physical activity remain to be elucidated.

Decreased systemic and/or local concentrations of testosterone, estrogen, growth hormone (GH) and/or insulin like growth factor (IGF)-1 have also been implicated as potential contributing factors to the etiology of sarcopenia $(59,93,107)$. Since IGF-1 is also locally synthesized in skeletal muscle tissue, it remains to be determined whether its reduced hormone concentration might lead to muscle atrophy, or vice versa. Next to the endocrine aspects, neurologic alterations might contribute to the loss of muscle mass and function with aging. Age-related changes in motor unit activation and/or co-activation might negatively affect force generating capacity. In addition, the loss of motor neurons from the spinal cord is considered an important factor in the loss of muscle fibers at a more advanced age. Furthermore, surviving motor neurons can re-innervate the 
denervated muscle fibers, resulting in the histological observation of fiber type grouping $(24,105)$. The loss of motor neurons might partly be attributed to apoptosis, resulting from oxidative damage. Likewise, DNA deletion mutations induced by reactive oxygen species probably result in the loss of myonuclei and/or mitochondria, resulting in mitochondrial dysfunction. The latter has been suggested to contribute to muscle fiber atrophy and to the reduced muscle oxidative capacity observed in elderly muscle $(58,80,107)$.

In addition to the above mentioned aspects, there are 2 important etiological factors that are related to lifestyle changes: a less than optimal nutrition and physical inactivity at a more advanced age. With aging, food intake has been shown to decline progressively, due to decreased energy expenditure, reduced taste sensation, and/or social isolation. The resulting decline in protein intake seems to be the most important nutritional factor that can contribute to the loss of muscle mass with aging $(26,29,58,107)$. The current recommended dietary allowance (RDA) for protein intake in the elderly is set at $0.8 \mathrm{~g} / \mathrm{kg} / \mathrm{d}(85,103)$. However, the adequacy of the RDA for maintaining and/or improving skeletal muscle mass in the elderly has been a matter of scientific debate for many years. Campbell et al. (12) recently suggested that the current RDA meets the minimum dietary needs of virtually all elderly. However, in a 14 week dietary control study, the same authors showed that intake of the RDA is marginally inadequate to increase skeletal muscle mass following resistance type exercise training (14), and results in a reduction in quadriceps cross-sectional area in sedentary elderly men and women (15). In contrast, when habitual dietary protein intake is modestly above the current RDA, resistance type exercise training induces an increase in muscle mass and strength. Further increasing protein intake does not seem to augment these beneficial effects $(11,13,51)$. Although specific guidelines for dietary protein intake in the elderly remain to be established, it seems evident that habitual protein under-nutrition may contribute to the loss of muscle mass observed with aging.

Furthermore, an increase in age is generally associated with the adoption of a more sedentary lifestyle, which reduces the anabolic stimuli related to mechanical loading $(24,80,107)$. Moreover, there appears to be an ongoing downward spiral in which physical inactivity leads to reduced muscle mass, resulting in a further decline in habitual physical activity levels, and so on. As such, sedentary elderly have been reported to show a faster decline in muscle mass compared with their physically active peers (24). However, even in elderly with a life-long history of exercise training, muscle mass declines with an advancing age. In particular, elderly weightlifters show remarkably little change in muscle fiber size and lean mass when compared with (sedentary) young, healthy adults (64). Yet, these active elderly still have shown a decline in muscle mass when compared with young, resistance 
type exercise-trained athletes. Thus, the general consensus is that sarcopenia is not merely a consequence of disuse, but also represents the result of aging per se.

In summary, many mechanisms have been proposed to underlie the agerelated loss of muscle mass. The relative importance of each of these factors, as well as their interaction, remains to be established. Furthermore, the exact molecular and cellular (signaling) pathways that explain the proposed relation between the above mentioned etiological factors and the progressive decline in muscle mass and strength are still poorly understood. Establishing the physiological and molecular mechanisms responsible for the loss of muscle mass would provide valuable information to define more effective exercise, nutritional, and/or pharmacological intervention strategies to prevent and/or treat sarcopenia.

\section{Interventions for sarcopenia}

Most intervention studies that aim to increase skeletal muscle mass and improve muscle function in the elderly have focused on some of the proposed etiological factors of sarcopenia; i.e. endocrine changes, physical activity, and/or nutrition $(8,24,29,49,58,107)$. With respect to hormonal interventions, testosterone administration has been shown to be most effective, resulting in greater muscle mass and muscle strength $(58,99)$. However, several attempts are currently being made to stimulate anabolic and/or inhibit catabolic pathways by modulating systemic availability and/or local expression of specific hormones, such as GH and IGF-1 $(40,75)$. The long-term efficacy and safety of hormone administration, or pharmacological interventions in general, remain to be determined $(8,59)$.

Nutritional interventions have mainly focused on increasing the dietary protein intake and/or the ingestion of specific protein or (essential) amino acid mixtures thought to augment muscle anabolism. The potential of food ingestion to stimulate muscle protein accretion has been well established (88, 109). Moreover, post-exercise amino acid/protein administration has been shown to substantially augment net muscle protein accretion following exercise $(7,65,66,102)$. However, long-term intervention studies have generally failed to observe any surplus benefits of protein supplementation in the elderly, either as a separate interventional strategy or as an adjunct to prolonged exercise training $(32,41,51)$. Yet, data on long-term interventions are relatively scarce, and the efficacy of timed protein supplementation regimens designed to augment the skeletal muscle adaptive response to exercise training forms a promising field for further work in this area.

Prolonged resistance type exercise training has proven the most effective interventional strategy to counteract sarcopenia (49). Frontera et al. (37) were amongst the first to show that elderly are still capable of increasing skeletal muscle mass and strength in response to resistance type exercise 
training. Numerous studies have since confirmed the substantial clinical benefits of resistance type exercise training in various elderly subpopulations, even in nonagenarians $(17,31,32,46,67,92)$. The benefits of resistance type exercise training generally include an increase in wholebody lean tissue mass, greater cross-sectional area of the trained muscle group, muscle fiber hypertrophy, and substantial gains in muscle strength. Furthermore, some studies also assessed the functional outcome in terms of activities of daily living and report improved walking speed and stair climbing power $(31,32)$. Notably, improvements in other health parameters, like insulin sensitivity, blood pressure and body weight, have also been reported $(49,111)$. Endurance type exercise training has been shown to improve oxidative capacity in elderly adults $(29,34)$, but does not increase absolute muscle mass. Therefore, resistance type exercise training is currently considered required in the effective prevention and/or treatment of sarcopenia and should, as such, be implemented in physical activity programs aiming to improve health and functional performance in the elderly population.

The above findings clearly indicate that skeletal muscle tissue in the elderly is still capable of adapting to functional overload by inducing muscle hypertrophy, increasing muscle strength, and improving muscle function. However, it seems that the response in the elderly is limited and/or delayed when compared with younger adults $(67,110)$. The latter may be related to the attenuated exercise-induced muscle protein synthetic response in elderly versus young adults (68). This could be partially explained by an age-related impairment in anabolic hormone action, myogenic gene expression, and/or anabolic signaling $(30,42,68,98,112)$. More work is needed to extend our knowledge on these and other potential mechanisms to assess why elderly respond differently to anabolic stimuli when compared with healthy, young adults.

\section{Satellite cells, myonuclei and sarcopenia}

Recently, there has been a renewed interest in the potential regulatory role of skeletal muscle satellite cells in the skeletal muscle adaptive response to resistance type exercise training and/or other interventions that induce skeletal muscle hypertrophy $(77,81)$. Satellite cells are essential for myofiber maintenance, growth, and regeneration (45). As such, changes in satellite cells have been implicated in the loss of muscle mass with aging. The current knowledge on the proposed role of satellite cells in the etiology of sarcopenia is described in more detail below.

Skeletal muscle tissue is composed of thousands of muscle fibers. Throughout myogenesis, each muscle fiber is generated by fusion of numerous myoblasts. As such, skeletal muscle fibers contain multiple nuclei (or myonuclei). According to the myonuclear domain theory $(2,19)$, each 
myonucleus controls gene expression over a finite volume of cytoplasm, known as the myonuclear domain. Therefore, changes in the size of a muscle fiber will theoretically be associated with a change in the size of the myonuclear domain and/or a change in the number of myonuclei within the muscle fiber. In accordance, muscle fiber atrophy has been associated with both a decline in myonuclear domain size $(1,82)$, and a decline in myonuclear content $(1,10)$. Likewise, muscle hypertrophy is associated with an increase in myonuclear domain size (56), and an increase in myonuclear number (57). In addition to the latter, there is a constant need for new myonuclei throughout the lifespan, to accomplish growth and to replace myonuclei that are lost following injury or apoptosis. However, myonuclei are post-mitotic and, as such, unable to account for the incorporation of new myonuclei. Therefore, the ability of skeletal muscle tissue to adapt to various physiological demands largely depends on a small population of skeletal muscle stem cells, termed satellite cells (45).

Satellite cells were first described by Mauro in 1961 (76). They owe their name to their localization under the basement membrane, but outside the plasma membrane of the muscle fiber. In adult skeletal muscle, satellite cells normally reside in a quiescent state in their niche below the basement membrane. Upon activation, satellite cells start to proliferate. Subsequently, they either differentiate to form new myonuclei, or return to quiescence thereby replenishing the resident satellite cell pool through self-renewal (23, $45,113)$. Interestingly, satellite cells seem to represent the only source for the generation of newly formed myonuclei in vivo $(2,78,79)$. Thus, satellite cells are essential for maintenance, repair, and growth of skeletal muscle tissue. Figure 1.2 shows a scheme of the theoretical adaptation of myonuclear and satellite cell content associated with muscle fiber atrophy and hypertrophy.

Given their importance in the regulation of skeletal muscle mass, satellite cells might play a prominent role in the mechanisms underlying muscle wasting conditions. Moreover, their ability to provide additional myonuclei underlines their importance in skeletal muscle maintenance and hypertrophy. As such, the interest in satellite cells in relation to sarcopenia has increased rapidly over the past 20 years. One of the first questions to be answered was how the satellite cell pool changes throughout life. During postnatal growth and development, up to $15 \%$ of the myonuclei are satellite cells (101). In adults, skeletal muscle satellite cells comprise only $1-5 \%$ of all myonuclei $(25,57,87)$. 
A
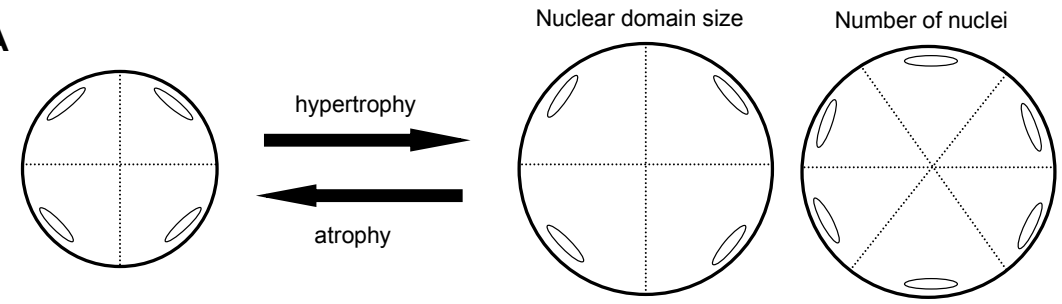

B

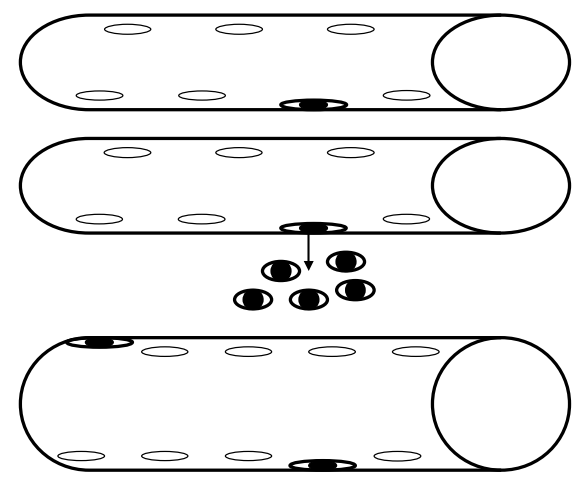

Quiescent SC

SC activation and proliferation

SC differentiation

New myonuclei

Fiber growth

Fiber repair

Return to quiescence

Figure 1.2 Myonuclei and satellite cells in the skeletal muscle adaptive response. A: crosssection of a muscle fiber containing several myonuclei. Muscle hypertrophy is associated with an increase in myonuclear domain size (due to increased protein synthesis induced by the existing myonuclei) and/or an increase in the number of myonuclei. In contrast, atrophy is associated with a reduced myonuclear number and/or domain size. B: longitudinal section of a muscle fiber containing several myonuclei and a satellite cell. Skeletal muscle satellite cells normally lie quiescent between the basal lamina and the plasma membrane of the associated myofiber. Upon injury or mechanical loading, satellite cells are activated and start to proliferate. Following differentiation, new myonuclei will be incorporated into the myofiber to achieve hypertrophy. In addition, part of the proliferated satellite cells will return to quiescence to replenish the satellite cell pool. Alternatively, differentiated cells can fuse together to generate new myofibers in case of significant myofiber damage (not shown). Reprinted from Ageing Res Rev, Snijders T, Verdijk LB, van Loon LJC, The impact of sarcopenia and exercise training on skeletal muscle satellite cells, in press, (C) (2009), with permission from Elsevier.

In animal studies, the number of satellite cells was shown to decline with an increasing age. The latter has been proposed to result in the loss of myonuclei, triggering muscle fiber atrophy (10). Likewise, Shefer et al. (96) suggested that the loss of satellite cells would cause loss of myogenic potential, leading to a reduction in regenerative capacity and impaired myofiber maintenance. These studies suggest that a decline in satellite cell content contributes to the age-related loss of muscle mass. However, studies performed on human muscle tissue have been less consistent. Some authors report a decline in satellite cell content in the elderly versus the young, with 
no apparent decline in myonuclear content $(55,87)$. In contrast, others failed to report significant differences in both satellite cell and myonuclear content between young and elderly men and women $(25,47,91)$. So far, the apparent discrepancy in the literature remains unresolved.

Rosenblatt et al. (90) showed that satellite cell activity and incorporation of myonuclei derived from satellite cells are required for loading-induced hypertrophy in adult rat muscle. In humans, the number of satellite cells was shown to be increased $24 \mathrm{~h}$ after a single exercise session (25), implying that activation and proliferation of satellite cells occurs within a short time period after mechanical loading. However, studies evaluating the long-term adaptive response to exercise intervention in humans have not provided conclusive data. In healthy young men, muscle fiber size and satellite cell content have been reported to increase in response to resistance type exercise training, with no changes in the number of myonuclei per muscle fiber (56). In contrast, other studies report that muscle fiber hypertrophy is accompanied by an increase in both myonuclear and satellite cell content, suggesting successful incorporation of satellite cell progeny $(57,100)$. Similar inconsistencies have been reported in the elderly. Following endurance type exercise training in elderly males, a moderate increase in muscle fiber size was accompanied by an increase in satellite cell content, but no change in myonuclear content (18). Furthermore, an increase in satellite cell content was only reported in the exercised leg after unilateral strength training (92), underlining the importance of mechanical loading for inducing satellite cell proliferation in the elderly. In contrast, significant muscle fiber hypertrophy following resistance type exercise training has also been observed without apparent accompanying changes in myonuclear and/or satellite cell content (47). The factors underlying the apparent discrepant findings are presently unclear.

Aside from age-related changes in the skeletal muscle satellite cell pool size, there might be an age-related impairment in the ability of satellite cells to become active, proliferate and/or differentiate in response to anabolic stimuli. Such an impairment in satellite cell functioning has been suggested to contribute to the age-related loss of muscle mass and/or to a reduction in the regenerative potential of skeletal muscle tissue. Early studies have shown a potential delay in the in vitro cell cycle entry (i.e. activation) of satellite cells from aged animals (95). However, subsequent satellite cell proliferation appeared to progress normally. Furthermore, Conboy et al. (20) have shown that satellite cell activation can be normalized by exposing aged muscle to a young systemic environment. These findings suggest that the intrinsic regenerative potential of satellite cells is not altered with age. Age-related changes in the interplay between satellite cells and their surrounding milieu are more likely to play a key role in the blunted activation of satellite cells with aging. 
In summary, both a decline in the number of satellite cells and reduced sensitivity to the stimuli leading to the activation, proliferation and differentiation of satellite cells might be of key importance in understanding the molecular mechanisms responsible for the age-related loss of muscle mass. Although aged skeletal muscle tissue seems to retain at least part of its ability for adaptation, considerable discrepancy exists in the literature. Agerelated changes in satellite cell content and in the response of satellite cells to exercise or other anabolic interventions in the elderly remain far from being elucidated. Since much of the available information stems from specific animal models and cell culture experiments, part of the inconsistency reported in the literature may be attributable to differences in the species or models studied. Additionally, differences in subjects' age, gender, and training background, are likely to modulate the process of muscle mass loss with aging, resulting in considerable inter-individual variability. The different function and/or mode of action of the specific muscle groups under investigation might also explain at least some of the inconsistency. Muscle fiber atrophy with aging has been shown to be largely confined to the type II muscle fibers. In addition, the skeletal muscle adaptive response to altered use or, more specifically, to exercise intervention, has generally been shown to be muscle fiber type-specific. As such, it is very likely that the effects of aging and/or exercise intervention on satellite cells are also muscle fiber type-specific. Such fiber type-specificity might be the key issue linking the above mentioned variables (i.e. differences in species, age, training background, etc) to the reported inconsistency regarding age-related differences in satellite cell content. However, muscle fiber type-specific data on satellite cell content are completely lacking for human muscle.

To provide a better insight into the potential role of satellite cells in agerelated skeletal muscle atrophy and exercise induced muscle hypertrophy, it seems imperative to evaluate muscle fiber characteristics in a fiber typespecific manner. Specific human in vivo studies are needed to explore the fiber type-specific changes in satellite cell content that might occur with aging, and in response to exercise and/or nutritional intervention in the elderly. Integrating such analyses with fiber type-specific data on muscle fiber composition, size, and myonuclear content could reveal important mechanistic concepts of sarcopenia and provide new leads for the development of effective exercise, nutritional, and/or pharmacological interventions to prevent and/or reverse the progressive loss of muscle mass and function with aging. Therefore, in the present thesis we aim to investigate age-related changes in skeletal muscle mass, strength, and muscle fiber type-specific composition, size, and satellite cell content, and the adaptive response of these variables to resistance type exercise training in the elderly. 


\section{Thesis outline}

This thesis describes a series of studies in which the age-related changes in muscle mass and strength are studied on a whole-body, limb, and myocellular level. In Chapter 2, we determine the validity of one-repetition maximum (1RM) strength testing to determine leg muscle strength. Therefore, 1RM testing for leg extension strength is compared to gold standard dynamometry testing. In chapter 3 , we confirm our hypothesis that type II muscle fiber atrophy in the elderly is associated with a fiber typespecific decline in satellite cell content. In chapter 4, we present correlations between whole-body muscle mass and strength, and specific muscle fiber characteristics in the elderly. Chapters 5 and 6 discuss the results of a longterm exercise intervention program. In chapter 5 , we assess whether the agerelated muscle fiber type-specific changes can be reversed following 3 months of resistance type exercise training in healthy, elderly men. In chapter 6, we test our hypothesis that the gain in muscle mass and strength following prolonged resistance type exercise training can be further augmented by timed protein supplementation prior to and immediately after each exercise bout. In chapter 7 , we finally discuss the outcome of the studies described in chapters 2-6 and provide general conclusions. In addition, the implications of this thesis are discussed and future research aims are identified to extend on the knowledge currently available regarding the proposed role of satellite cells in the etiology of sarcopenia, and in the mechanisms associated with skeletal muscle hypertrophy in response to different interventional strategies to prevent and/or treat the progressive loss of skeletal muscle mass and function with aging. 


\section{References}

1. Allen DL, Linderman JK, Roy RR, Grindeland RE, Mukku V, Edgerton VR. Growth hormone/IGF-I and/or resistive exercise maintains myonuclear number in hindlimb unweighted muscles. J Appl Physiol 1997;83:1857-61.

2. Allen DL, Roy RR, Edgerton VR. Myonuclear domains in muscle adaptation and disease. Muscle Nerve 1999;22:1350-60.

3. Aniansson A, Hedberg M, Henning GB, Grimby G. Muscle morphology, enzymatic activity, and muscle strength in elderly men: a follow-up study. Muscle Nerve 1986;9:585-91.

4. Balagopal P, Rooyackers OE, Adey DB, Ades PA, Nair KS. Effects of aging on in vivo synthesis of skeletal muscle myosin heavy-chain and sarcoplasmic protein in humans. Am J Physiol 1997;273:E790-800.

5. Baumgartner RN, Koehler KM, Gallagher D, et al. Epidemiology of sarcopenia among the elderly in New Mexico. Am J Epidemiol 1998;147:755-63.

6. Baumgartner RN, Stauber PM, McHugh D, Koehler KM, Garry PJ. Cross-sectional age differences in body composition in persons $60+$ years of age. J Gerontol A Biol Sci Med Sci 1995;50:M307-16.

7. Biolo G, Tipton KD, Klein S, Wolfe RR. An abundant supply of amino acids enhances the metabolic effect of exercise on muscle protein. Am J Physiol 1997;273:E122-9.

8. Borst SE. Interventions for sarcopenia and muscle weakness in older people. Age Ageing 2004;33:548-55.

9. Bottinelli R, Reggiani C. Human skeletal muscle fibres: molecular and functional diversity. Prog Biophys Mol Biol 2000;73:195-262.

10. Brack AS, Bildsoe H, Hughes SM. Evidence that satellite cell decrement contributes to preferential decline in nuclear number from large fibres during murine age-related muscle atrophy. J Cell Sci 2005;118:4813-21.

11. Campbell WW, Crim MC, Dallal GE, Young VR, Evans WJ. Increased protein requirements in elderly people: new data and retrospective reassessments. Am J Clin Nutr 1994;60:501-9.

12. Campbell WW, Johnson CA, McCabe GP, Carnell NS. Dietary protein requirements of younger and older adults. Am J Clin Nutr 2008;88:1322-9.

13. Campbell WW, Leidy HJ. Dietary protein and resistance training effects on muscle and body composition in older persons. J Am Coll Nutr 2007;26:696S-703S.

14. Campbell WW, Trappe TA, Jozsi AC, Kruskall LJ, Wolfe RR, Evans WJ. Dietary protein adequacy and lower body versus whole body resistive training in older humans. J Physiol 2002;542:631-42.

15. Campbell WW, Trappe TA, Wolfe RR, Evans WJ. The recommended dietary allowance for protein may not be adequate for older people to maintain skeletal muscle. J Gerontol A Biol Sci Med Sci 2001;56:M373-80.

16. CBS. Kerncijfers van de bevolkingsprognose, 2006-2050. http://statline.cbs.n1/StatWeb/publication/?VW=T\&DM=SLNL\&PA=03766ned\&D1 $=\mathrm{a} \& \mathrm{D} 2=0 \& \mathrm{D} 3=1,4,14$, 24,34,1\&HD=081023-0916\&HDR=G1,G2\&STB=T. 2007.

17. Charette SL, McEvoy L, Pyka G, et al. Muscle hypertrophy response to resistance training in older women. J Appl Physiol 1991;70:1912-6.

18. Charifi N, Kadi F, Feasson L, Denis C. Effects of endurance training on satellite cell frequency in skeletal muscle of old men. Muscle Nerve 2003;28:87-92.

19. Cheek DB. The control of cell mass and replication. The DNA unit--a personal 20-year study. Early Hum Dev 1985;12:211-39.

20. Conboy IM, Conboy MJ, Wagers AJ, Girma ER, Weissman IL, Rando TA. Rejuvenation of aged progenitor cells by exposure to a young systemic environment. Nature 2005;433:760-4. 
21. Cuthbertson D, Smith K, Babraj J, et al. Anabolic signaling deficits underlie amino acid resistance of wasting, aging muscle. Faseb J 2005;19:422-4.

22. D'Antona G, Pellegrino MA, Adami R, et al. The effect of ageing and immobilization on structure and function of human skeletal muscle fibres. J Physiol 2003;552:499-511.

23. Dhawan J, Rando TA. Stem cells in postnatal myogenesis: molecular mechanisms of satellite cell quiescence, activation and replenishment. Trends Cell Biol 2005;15:66673.

24. Doherty TJ. Invited review: Aging and sarcopenia. J Appl Physiol 2003;95:1717-27.

25. Dreyer HC, Blanco CE, Sattler FR, Schroeder ET, Wiswell RA. Satellite cell numbers in young and older men 24 hours after eccentric exercise. Muscle Nerve 2006;33:24253.

26. Dreyer HC, Volpi E. Role of protein and amino acids in the pathophysiology and treatment of sarcopenia. J Am Coll Nutr 2005;24:140S-145S.

27. Edstrom E, Altun M, Bergman E, et al. Factors contributing to neuromuscular impairment and sarcopenia during aging. Physiol Behav 2007;92:129-35.

28. Eurostat. Populations and Social Conditions: People by Age Classes. http://epp.eurostat.cec.eu.int 2006.

29. Evans W. Functional and metabolic consequences of sarcopenia. J Nutr 1997;127:998S1003S.

30. Favier FB, Benoit H, Freyssenet D. Cellular and molecular events controlling skeletal muscle mass in response to altered use. Pflugers Arch 2008;456:587-600.

31. Fiatarone MA, Marks EC, Ryan ND, Meredith CN, Lipsitz LA, Evans WJ. Highintensity strength training in nonagenarians. Effects on skeletal muscle. Jama 1990;263:3029-34.

32. Fiatarone MA, O'Neill EF, Ryan ND, et al. Exercise training and nutritional supplementation for physical frailty in very elderly people. $\mathrm{N}$ Engl $\mathrm{J}$ Med 1994;330:1769-75.

33. Fleg JL, Lakatta EG. Role of muscle loss in the age-associated reduction in VO2 max. $\mathrm{J}$ Appl Physiol 1988;65:1147-51.

34. Freyssenet D, Berthon P, Denis C, Barthelemy JC, Guezennec CY, Chatard JC. Effect of a 6-week endurance training programme and branched-chain amino acid supplementation on histomorphometric characteristics of aged human muscle. Arch Physiol Biochem 1996;104:157-62.

35. Frontera WR, Hughes VA, Fielding RA, Fiatarone MA, Evans WJ, Roubenoff R. Aging of skeletal muscle: a 12-yr longitudinal study. J Appl Physiol 2000;88:1321-6.

36. Frontera WR, Hughes VA, Lutz KJ, Evans WJ. A cross-sectional study of muscle strength and mass in 45- to 78-yr-old men and women. J Appl Physiol 1991;71:644-50.

37. Frontera WR, Meredith CN, O'Reilly KP, Knuttgen HG, Evans WJ. Strength conditioning in older men: skeletal muscle hypertrophy and improved function. J Appl Physiol 1988;64:1038-44.

38. Frontera WR, Suh D, Krivickas LS, Hughes VA, Goldstein R, Roubenoff R. Skeletal muscle fiber quality in older men and women. Am J Physiol Cell Physiol 2000;279:C611-8.

39. Gallagher D, Ruts E, Visser M, et al. Weight stability masks sarcopenia in elderly men and women. Am J Physiol Endocrinol Metab 2000;279:E366-75.

40. Giovannini S, Marzetti E, Borst SE, Leeuwenburgh C. Modulation of GH/IGF-1 axis: Potential strategies to counteract sarcopenia in older adults. Mech Ageing Dev 2008;129:593-601.

41. Godard MP, Williamson DL, Trappe SW. Oral amino-acid provision does not affect muscle strength or size gains in older men. Med Sci Sports Exerc 2002;34:1126-31.

42. Goldspink G. Impairment of IGF-I gene splicing and MGF expression associated with muscle wasting. Int J Biochem Cell Biol 2006;38:481-9. 
43. Goodpaster BH, Carlson CL, Visser M, et al. Attenuation of skeletal muscle and strength in the elderly: The Health ABC Study. J Appl Physiol 2001;90:2157-65.

44. Grimby G. Muscle performance and structure in the elderly as studied cross-sectionally and longitudinally. J Gerontol A Biol Sci Med Sci 1995;50 Spec No:17-22.

45. Hawke TJ, Garry DJ. Myogenic satellite cells: physiology to molecular biology. J Appl Physiol 2001;91:534-51.

46. Hikida RS, Staron RS, Hagerman FC, et al. Effects of high-intensity resistance training on untrained older men. II. Muscle fiber characteristics and nucleo-cytoplasmic relationships. J Gerontol A Biol Sci Med Sci 2000;55:B347-54.

47. Hikida RS, Walsh S, Barylski N, Campos G, Hagerman FC, Staron RS. Is hypertrophy limited in elderly muscle fibers? A comparison of elderly and young strength-trained men. Basic Appl. Myol. 1998;8:419-427.

48. Hortobagyi T, Zheng D, Weidner M, Lambert NJ, Westbrook S, Houmard JA. The influence of aging on muscle strength and muscle fiber characteristics with special reference to eccentric strength. J Gerontol A Biol Sci Med Sci 1995;50:B399-406.

49. Hunter GR, McCarthy JP, Bamman MM. Effects of resistance training on older adults. Sports Med 2004;34:329-48.

50. Iannuzzi-Sucich M, Prestwood KM, Kenny AM. Prevalence of sarcopenia and predictors of skeletal muscle mass in healthy, older men and women. J Gerontol A Biol Sci Med Sci 2002;57:M772-7.

51. Iglay HB, Thyfault JP, Apolzan JW, Campbell WW. Resistance training and dietary protein: effects on glucose tolerance and contents of skeletal muscle insulin signaling proteins in older persons. Am J Clin Nutr 2007;85:1005-13.

52. Janssen I, Heymsfield SB, Ross R. Low relative skeletal muscle mass (sarcopenia) in older persons is associated with functional impairment and physical disability. J Am Geriatr Soc 2002;50:889-96.

53. Janssen I, Heymsfield SB, Wang ZM, Ross R. Skeletal muscle mass and distribution in 468 men and women aged 18-88 yr. J Appl Physiol 2000;89:81-8.

54. Janssen I, Shepard DS, Katzmarzyk PT, Roubenoff R. The healthcare costs of sarcopenia in the United States. J Am Geriatr Soc 2004;52:80-5.

55. Kadi F, Charifi N, Denis C, Lexell J. Satellite cells and myonuclei in young and elderly women and men. Muscle Nerve 2004;29:120-7.

56. Kadi F, Schjerling P, Andersen LL, et al. The effects of heavy resistance training and detraining on satellite cells in human skeletal muscles. J Physiol 2004;558:1005-12.

57. Kadi F, Thornell LE. Concomitant increases in myonuclear and satellite cell content in female trapezius muscle following strength training. Histochem Cell Biol 2000;113:99103.

58. Kamel HK. Sarcopenia and aging. Nutr Rev 2003;61:157-67.

59. Kamel HK, Maas D, Duthie EH, Jr. Role of hormones in the pathogenesis and management of sarcopenia. Drugs Aging 2002;19:865-77.

60. Katsanos CS, Kobayashi H, Sheffield-Moore M, Aarsland A, Wolfe RR. Aging is associated with diminished accretion of muscle proteins after the ingestion of a small bolus of essential amino acids. Am J Clin Nutr 2005;82:1065-73.

61. Kehayias JJ, Fiatarone MA, Zhuang H, Roubenoff R. Total body potassium and body fat: relevance to aging. Am J Clin Nutr 1997;66:904-10.

62. Kirkeby S, Garbarsch C. Aging affects different human muscles in various ways. An image analysis of the histomorphometric characteristics of fiber types in human masseter and vastus lateralis muscles from young adults and the very old. Histol Histopathol 2000;15:61-71.

63. Klein CS, Rice CL, Marsh GD. Normalized force, activation, and coactivation in the arm muscles of young and old men. J Appl Physiol 2001;91:1341-9. 
64. Klitgaard H, Mantoni M, Schiaffino S, et al. Function, morphology and protein expression of ageing skeletal muscle: a cross-sectional study of elderly men with different training backgrounds. Acta Physiol Scand 1990;140:41-54.

65. Koopman R, Verdijk L, Manders RJ, et al. Co-ingestion of protein and leucine stimulates muscle protein synthesis rates to the same extent in young and elderly lean men. Am J Clin Nutr 2006;84:623-32.

66. Koopman R, Verdijk LB, Beelen M, et al. Co-ingestion of leucine with protein does not further augment post-exercise muscle protein synthesis rates in elderly men. Br J Nutr 2008;99:571-80.

67. Kosek DJ, Kim JS, Petrella JK, Cross JM, Bamman MM. Efficacy of 3 days/wk resistance training on myofiber hypertrophy and myogenic mechanisms in young vs. older adults. J Appl Physiol 2006;101:531-44.

68. Kumar V, Selby A, Rankin D, et al. Age-related differences in the dose-response relationship of muscle protein synthesis to resistance exercise in young and old men. $\mathrm{J}$ Physiol 2009;587:211-7.

69. Lamberts SW, van den Beld AW, van der Lely AJ. The endocrinology of aging. Science 1997;278:419-24.

70. Larsson L, Grimby G, Karlsson J. Muscle strength and speed of movement in relation to age and muscle morphology. J Appl Physiol 1979;46:451-6.

71. Larsson L, Sjodin B, Karlsson J. Histochemical and biochemical changes in human skeletal muscle with age in sedentary males, age 22--65 years. Acta Physiol Scand 1978;103:31-9.

72. Lexell J. Human aging, muscle mass, and fiber type composition. J Gerontol A Biol Sci Med Sci 1995;50 Spec No:11-6.

73. Lexell J, Taylor CC, Sjostrom M. What is the cause of the ageing atrophy? Total number, size and proportion of different fiber types studied in whole vastus lateralis muscle from 15- to 83-year-old men. J Neurol Sci 1988;84:275-94.

74. Lindle RS, Metter EJ, Lynch NA, et al. Age and gender comparisons of muscle strength in 654 women and men aged 20-93 yr. J Appl Physiol 1997;83:1581-7.

75. Lynch GS, Schertzer JD, Ryall JG. Therapeutic approaches for muscle wasting disorders. Pharmacol Ther 2007;113:461-87.

76. Mauro A. Satellite cell of skeletal muscle fibers. J Biophys Biochem Cytol 1961;9:4935.

77. McCarthy JJ, Esser KA. Counterpoint: Satellite cell addition is not obligatory for skeletal muscle hypertrophy. J Appl Physiol 2007;103:1100-2; discussion 1102-3.

78. Moss FP, Leblond CP. Nature of dividing nuclei in skeletal muscle of growing rats. $\mathrm{J}$ Cell Biol 1970;44:459-62.

79. Moss FP, Leblond CP. Satellite cells as the source of nuclei in muscles of growing rats. Anat Rec 1971;170:421-35.

80. Nair KS. Aging muscle. Am J Clin Nutr 2005;81:953-63.

81. O'Connor RS, Pavlath GK. Point:Counterpoint: Satellite cell addition is/is not obligatory for skeletal muscle hypertrophy. J Appl Physiol 2007;103:1099-100.

82. Ohira Y, Yoshinaga T, Ohara M, et al. Myonuclear domain and myosin phenotype in human soleus after bed rest with or without loading. J Appl Physiol 1999;87:1776-85.

83. Petrella JK, Kim JS, Tuggle SC, Hall SR, Bamman MM. Age differences in knee extension power, contractile velocity, and fatigability. J Appl Physiol 2005;98:211-20.

84. Rall LC, Rosen CJ, Dolnikowski G, et al. Protein metabolism in rheumatoid arthritis and aging. Effects of muscle strength training and tumor necrosis factor alpha. Arthritis Rheum 1996;39:1115-24.

85. Rand WM, Pellett PL, Young VR. Meta-analysis of nitrogen balance studies for estimating protein requirements in healthy adults. Am J Clin Nutr 2003;77:109-27. 
86. Rantanen T, Avlund K, Suominen H, Schroll M, Frandin K, Pertti E. Muscle strength as a predictor of onset of ADL dependence in people aged 75 years. Aging Clin Exp Res 2002;14:10-5.

87. Renault V, Thornell LE, Eriksson PO, Butler-Browne G, Mouly V. Regenerative potential of human skeletal muscle during aging. Aging Cell 2002;1:132-9.

88. Rennie MJ, Edwards RH, Halliday D, Matthews DE, Wolman SL, Millward DJ. Muscle protein synthesis measured by stable isotope techniques in man: the effects of feeding and fasting. Clin Sci (Lond) 1982;63:519-23.

89. Rosenberg IW. Summary comments. Am J Clin Nutr 1989;50:1231-1233.

90. Rosenblatt JD, Yong D, Parry DJ. Satellite cell activity is required for hypertrophy of overloaded adult rat muscle. Muscle Nerve 1994;17:608-13.

91. Roth SM, Martel GF, Ivey FM, et al. Skeletal muscle satellite cell populations in healthy young and older men and women. Anat Rec 2000;260:351-8.

92. Roth SM, Martel GF, Ivey FM, et al. Skeletal muscle satellite cell characteristics in young and older men and women after heavy resistance strength training. J Gerontol A Biol Sci Med Sci 2001;56:B240-7.

93. Roubenoff R. Sarcopenia and its implications for the elderly. Eur J Clin Nutr 2000;54 Suppl 3:S40-7.

94. Roubenoff R, Heymsfield SB, Kehayias JJ, Cannon JG, Rosenberg IH. Standardization of nomenclature of body composition in weight loss. Am J Clin Nutr 1997;66:192-6.

95. Schultz E, Lipton BH. Skeletal muscle satellite cells: changes in proliferation potential as a function of age. Mech Ageing Dev 1982;20:377-83.

96. Shefer G, Van de Mark DP, Richardson JB, Yablonka-Reuveni Z. Satellite-cell pool size does matter: Defining the myogenic potency of aging skeletal muscle. Dev Biol 2006;294:50-66.

97. Short KR, Vittone JL, Bigelow ML, et al. Changes in myosin heavy chain mRNA and protein expression in human skeletal muscle with age and endurance exercise training. $\mathrm{J}$ Appl Physiol 2005;99:95-102.

98. Singh MA, Ding W, Manfredi TJ, et al. Insulin-like growth factor I in skeletal muscle after weight-lifting exercise in frail elders. Am J Physiol 1999;277:E135-43.

99. Sinha-Hikim I, Cornford M, Gaytan H, Lee ML, Bhasin S. Effects of testosterone supplementation on skeletal muscle fiber hypertrophy and satellite cells in communitydwelling older men. J Clin Endocrinol Metab 2006;91:3024-33.

100. Sinha-Hikim I, Roth SM, Lee MI, Bhasin S. Testosterone-induced muscle hypertrophy is associated with an increase in satellite cell number in healthy, young men. Am J Physiol Endocrinol Metab 2003;285:E197-205.

101. Thornell LE, Lindstrom M, Renault V, Mouly V, Butler-Browne GS. Satellite cells and training in the elderly. Scand J Med Sci Sports 2003;13:48-55.

102. Tipton KD, Ferrando AA, Phillips SM, Doyle D, Jr., Wolfe RR. Postexercise net protein synthesis in human muscle from orally administered amino acids. Am J Physiol 1999;276:E628-34.

103. Trumbo P, Schlicker S, Yates AA, Poos M. Dietary reference intakes for energy, carbohydrate, fiber, fat, fatty acids, cholesterol, protein and amino acids. J Am Diet Assoc 2002;102:1621-30.

104. U.S. Census Bureau PD. Projections of the population by selected age groups and sex for the United States: 2010 to 2050. http://www.census.gov/population/www/projections/summarytables.html. 2008.

105. Vandervoort AA. Aging of the human neuromuscular system. Muscle Nerve 2002;25:17-25.

106. Visser M, Kritchevsky SB, Goodpaster BH, et al. Leg muscle mass and composition in relation to lower extremity performance in men and women aged 70 to 79 : the health, aging and body composition study. J Am Geriatr Soc 2002;50:897-904. 
107. Volpi E, Nazemi R, Fujita S. Muscle tissue changes with aging. Curr Opin Clin Nutr Metab Care 2004;7:405-10.

108. Volpi E, Sheffield-Moore M, Rasmussen BB, Wolfe RR. Basal muscle amino acid kinetics and protein synthesis in healthy young and older men. Jama 2001;286:1206-12.

109. Welle S, Thornton C, Statt M, McHenry B. Postprandial myofibrillar and whole body protein synthesis in young and old human subjects. Am J Physiol 1994;267:E599-604.

110. Welle S, Totterman S, Thornton C. Effect of age on muscle hypertrophy induced by resistance training. J Gerontol A Biol Sci Med Sci 1996;51:M270-5.

111. Winett RA, Carpinelli RN. Potential health-related benefits of resistance training. Prev Med 2001;33:503-13.

112. Yarasheski KE, Pak-Loduca J, Hasten DL, Obert KA, Brown MB, Sinacore DR. Resistance exercise training increases mixed muscle protein synthesis rate in frail women and men $>/=76$ yr old. Am J Physiol 1999;277:E118-25.

113. Zammit PS, Golding JP, Nagata Y, Hudon V, Partridge TA, Beauchamp JR. Muscle satellite cells adopt divergent fates: a mechanism for self-renewal? J Cell Biol 2004;166:347-57. 



\section{Chapter 2}

\section{One-repetition maximum strength test}

represents a valid means to assess leg strength in vivo in humans

Lex B. Verdijk, Luc J.C. van Loon, Kenneth Meijer, and Hans H.C.M. Savelberg

Journal of Sports Sciences 2009; 27: 59-68

This is an electronic version of an article published in the
Journal of Sports Sciences, Volume 27, Issue 1 January 2009,
pages 59-68.HYPERLINK "http://www.informaworld.com/
smpp/
title $\sim \mathrm{db}=\mathrm{all} \sim$ content=t713721847 tab=issueslist branches=
27 " V "v27" |o "Click to view volume" It "-top" The published
article from the Journal of Sports Sciences is available online
at:
http://www.informaworld.com/smpp/




\begin{abstract}
Skeletal muscle strength is often determined to evaluate the adaptive response to an exercise intervention program. Although dynamometry is considered the gold standard for the assessment of muscle strength in vivo, one-repetition maximum (1-RM) testing performed on training specific equipment is more commonly applied. We assessed the validity of specific knee extension 1-RM testing by comparison with dynamometry in a heterogeneous population $(n=55)$. All participants performed 1-RM tests on regular leg extension and leg press machines. Additionally, isometric (at 7 different knee angles) and isokinetic (at 4 different velocities) knee extension peak torques were determined. Pearson's $r$ was calculated for the relations between 1-RM data and peak torques for the entire population and for subgroups defined by age and gender. 1-RM strength correlated strongly with the dynamometer results. 1-RM leg extension correlated stronger with peak torques than did 1 -RM leg press $(0.78 \leq r \leq 0.88$ vs $0.72 \leq r \leq 0.77$, respectively; $\mathrm{P}<0.001)$. Similar correlations were observed in all subgroups. We conclude that 1-RM testing represents a valid means to assess leg muscle strength in vivo in young and elderly men and women. Considering the importance of training specificity in strength assessment, we argue that 1RM testing can be applied to assess changes in leg muscle strength following exercise intervention.
\end{abstract}




\section{Introduction}

Skeletal muscle strength is an important determinant of the functional capacity of an individual. Whereas in young adults muscle strength has been related to athletic performance, in the elderly greater strength is generally associated with better health and a higher level of independent living, both of which contribute to a higher quality of life. In the elderly, strong correlations have been reported between leg muscle strength and functional performance in activities of daily living, such as stair climbing (22), the ability to rise from a chair $(3,5)$, and balance recovery tasks $(40)$. The age-associated decline in skeletal muscle mass and strength can have detrimental effects, including increased incidences of falls and bone fractures, and the general loss of independence $(11,36,37,44)$. The importance of muscle strength for daily function necessitates the development of reliable and valid procedures to quantify muscle strength. The latter are needed to compare muscle strength on an individual and population level, to evaluate muscle strength loss following disease or disability, and to evaluate the benefits of intervention programs.

In general, two forms of strength assessment are frequently used: onerepetition maximum (1-RM) testing and dynamometry. 1-RM testing requires an isoinertial contraction; i.e., a constant weight is lifted at a voluntary speed. Dynamometry requires either an isometric or isokinetic contraction. When appropriate standardization is applied, e.g., familiarization with the exercise, positioning and stabilization of the participant, and instruction and encouragement of the participant, dynamometry has been shown to provide highly reliable test results (1). Because of the high reliability and objectivity, isometric and isokinetic peak torque measurements performed on a dynamometer (e.g. Cybex) are considered the gold standard for the in vivo assessment of skeletal muscle strength in humans $(1,24,29)$. Consequently, dynamometry is generally applied to validate other strength assessment procedures $(13,21,41)$. However, a major disadvantage of dynamometry is that the contraction patterns used generally do not resemble the patterns that are performed in exercise intervention programs (1). Evaluating the effects of training in a training specific context is considered to provide a more sensitive measure and thus represents a more accurate evaluation of strength gain $(1,2)$. Therefore, in most exercise intervention studies, strength is determined by 1 RM testing, using the equipment used in the training regimen $(17,25,31$, 43).

Similar criteria apply to dynamometry and 1-RM testing when the aim is to establish reliable test results. Prediction equations for 1-RM testing facilitate the assessment of valid 1-RM measurements within 4 consecutive attempts, thereby preventing fatigue as a potential confounder (1). Thus, when applied in a standardized manner, 1-RM testing has been proposed to represent a 
reliable method for the assessment of muscle strength in both the young and elderly $(34,35)$. In addition, several studies have compared 1-RM testing with dynamometry. Whereas training induced changes measured with these 2 procedures seem to be unrelated, the correlations between 1-RM testing and dynamometry are generally high $(2,4,32)$, implying the validity of 1RM testing for strength assessment. However, most research has investigated arm strength and only small groups of young participants have been studied $(2,4,32)$. Hence, although leg strength is probably the most important factor affecting mobility in elderly $(5,15,22)$ and numerous studies have included leg extension and leg press exercises for training of the upper legs $(17,25$, 33 ), these specific 1-RM testing procedures have yet to be validated with dynamometry. The latter might be even more important in different subpopulations. Qualitative changes in muscle mass and muscle function with aging $(8,12)$ and gender based differences in muscle characteristics (28) may differentially affect muscle strength as measured with different assessment procedures. Therefore, the validity of 1-RM testing should be assessed in different age and gender subgroups.

In the present study, we assessed whether 1-RM testing represents a good means of evaluating leg muscle strength when compared with the use of dynamometry as the accepted gold standard. Therefore, we compared the results of 1-RM testing (leg extension and leg press) with isometric and isokinetic knee extension peak torque measurements in a large heterogeneous population, as well as in more homogeneous subgroups based on age and/or gender.

\section{Methods}

\section{Participants}

A total of 55 adults volunteered to participate in this study (Table 2.1). All participants were healthy volunteers; participants with any pathology or disorder known to compromise their ability to perform maximal strength exercises were excluded. To validate 1-RM testing for large heterogeneous populations and to correlate levels of muscle strength with age, both men and women over a large age range were selected. For validation in more homogeneous populations, subgroups were defined based on either gender or age (young: age $<60$ y and old: age $\geq 60 \mathrm{y}$ ). Age cut-off points were based on the finding that an age-related decline in muscle mass and function generally becomes more significant after the age of 60 (12, 39). All trials were performed on 2 days separated by no less than 3 days, and performed at the same time of day. Participants were instructed to refrain from intense physical activity in the 2 days prior to the test days. After explaining all procedures in detail, informed consent was obtained from all participants. The study was approved by the local Medical Ethics Committee. 
Table 2.1 Participants' characteristics

\begin{tabular}{lccccc}
\hline \hline & Total & Female & Male & Elderly & Young \\
& $n=55$ & $n=26$ & $n=29$ & $n=22$ & $n=33$ \\
\hline Age (y) & $47 \pm 3$ & $45 \pm 4$ & $49 \pm 4$ & $69 \pm 1^{*}$ & $33 \pm 2$ \\
Height (m) & $1.72 \pm 0.01$ & $1.65 \pm 0.01^{\dagger}$ & $1.79 \pm 0.02$ & $1.68 \pm 0.02 *$ & $1.75 \pm 0.02$ \\
Body mass (kg) & $73.8 \pm 1.4$ & $68.5 \pm 1.9^{\dagger}$ & $78.6 \pm 1.5$ & $77.0 \pm 2.1$ & $71.7 \pm 1.7$ \\
BMI (kg/m $\left.{ }^{2}\right)$ & $25.0 \pm 0.5$ & $25.1 \pm 0.8$ & $24.8 \pm 0.7$ & $27.3 \pm 0.8^{*}$ & $23.4 \pm 0.5$ \\
Leg volume (L) & $8.6 \pm 0.2$ & $8.1 \pm 0.2^{\dagger}$ & $9.1 \pm 0.2$ & $8.1 \pm 0.2^{*}$ & $9.0 \pm 0.2$ \\
PT isom (N·m) & $155 \pm 6$ & $131 \pm 6^{\dagger}$ & $177 \pm 8$ & $135 \pm 7 *$ & $168 \pm 8$ \\
PT 2.09 (N·m) & $105 \pm 4$ & $88 \pm 3^{\dagger}$ & $119 \pm 4$ & $92 \pm 4 *$ & $114 \pm 5$ \\
PT 3.14 (N·m) & $86 \pm 3$ & $72 \pm 3^{\dagger}$ & $98 \pm 4$ & $74 \pm 3 *$ & $95 \pm 4$ \\
PT 4.19 (N·m) & $72 \pm 3$ & $59 \pm 2^{\dagger}$ & $83 \pm 4$ & $63 \pm 3 *$ & $78 \pm 4$ \\
PT 5.24 (N·m) & $63 \pm 3$ & $50 \pm 2^{\dagger}$ & $73 \pm 3$ & $54 \pm 3 *$ & $69 \pm 3$ \\
1-RM LE $(\mathrm{kg})$ & $81 \pm 3$ & $67 \pm 3^{\dagger}$ & $93 \pm 4$ & $70 \pm 4 *$ & $88 \pm 4$ \\
1-RM LP $(\mathrm{kg})$ & $167 \pm 6$ & $137 \pm 5^{\dagger}$ & $193 \pm 8$ & $148 \pm 9 *$ & $179 \pm 8$ \\
\hline \hline
\end{tabular}

Values are means \pm standard error. PT: peak torque. isom: isometric. $2.09,3.14,4.19,5.24$ : isokinetic velocities in $\mathrm{rad} / \mathrm{s}$. 1-RM: one-repetition maximum. LE: leg extension. LP: leg press. ${ }^{\dagger}$ : significantly different compared with males. *: significantly different compared with the young. No age $\mathrm{x}$ gender interactions were observed.

\section{Test procedures}

At the first visit, the 1-RM for the leg press and the leg extension were estimated using the multiple-repetitions testing procedure and regular fitness machines (Technogym, Rotterdam). After a 5-min warm-up session on a cycle ergometer and demonstration of the lifting technique, familiarization trials were performed to ensure proper execution of the exercise protocol. The maximum amount of repetitions (reps) measured for a certain load was used to estimate the 1-RM: 1-RM = load / (1.0278-0.0278*reps) (30). This estimate was used at the second visit to determine the initial load for the actual 1-RM test. Body mass (digital balance scale; accuracy $0.01 \mathrm{~kg}$ ) and height (wall mounted stadiometer; accuracy $0.1 \mathrm{~cm}$ ) were measured with participants standing barefoot and dressed lightly. Leg volume was assessed according to the method described by Jones and Pearson as an estimate of leg muscle mass $(9,23)$. Since muscle mass is one of the major factors affecting muscle strength, we also aimed to determine whether leg volume represents a valid (indirect) marker for muscle strength.

At the second visit, 1-RM leg press and 1-RM leg extension were measured following the protocol described by Kraemer and Fry (26). In short, the load was set at $90 \%$ of the estimated 1-RM (30) and was increased by $2.5-5 \%$ 
after each successful lift, until failure. Resting periods of 3 min were allowed between successive attempts. Although Mayhew et al., (30) developed their prediction equation in young adults performing a bench press exercise, 1RM for leg extension and leg press in the present study was typically reached within 3-4 attempts in all subgroups. Moreover, no significant differences were observed between predicted and measured 1-RM in any of the subgroups. After 30 min of rest, dynamometer testing took place on a Cybex-II dynamometer. Participants were in a seated position, with the hip joint at $80^{\circ}$ of flexion $\left(0^{\circ}\right.$ corresponding to the upper leg in line with the trunk). The lateral femoral epicondyl was aligned with the axis of rotation of the Cybex and the upper leg and pelvis were stabilized with Velcro straps to restrict compensatory movement. The lever arm was attached just proximal to the ankle joint. Familiarization trials at low intensity were performed before each measurement. All trials were separated by 2 min of rest to reduce fatigue. Since instantaneous muscle strength depends on muscle length, isometric contractions were randomly performed at 7 different knee joint angles $\left(20,35,50,65,80,95\right.$ and $110^{\circ}$, with $0^{\circ}$ representing a fully extended knee joint). Participants were instructed to provide maximal voluntary contractions for 2-3 s. To study the effect of different contractile velocities, isokinetic knee extension torque was randomly measured at 4 different speeds $(2.09,3.14,4.19$ and $5.24 \mathrm{rad} / \mathrm{s})$. The hip joint angle and fixation to the chair were the same as in the isometric condition. A cyclic protocol was used, in that 3 consecutive extension / flexion movements were performed for each speed. All dynamometer data were sampled at $1,000 \mathrm{~Hz}$ and were digitized with a 12-bit analog-to-digital converter. All anthropometric and dynamometer measurements were performed on the right leg and all testing procedures were performed by the same investigator. Although test-retest reliability was not explicitly determined in the present study, all necessary measures were taken to ensure reliable test results for both 1-RM and dynamometry testing by adhering to a standardization routine (1).

\section{Data analysis}

After correction for gravitational forces (18), isometric peak torque was determined as the absolute maximum of all the torque data for knee extension. The knee joint angle at which isometric peak torque was obtained averaged $79 \pm 2^{\circ}$, with no differences between age and/or gender subgroups. The latter is in agreement with optimum knee joint angles reported previously $(7,27,39)$. Isokinetic data were first filtered with a $4^{\text {th }}$ order lowpass Butterworth filter with a cut-off frequency of $5 \mathrm{~Hz}$. Then, isokinetic knee extension peak torque was determined as the maximum of the 3 consecutive attempts for each speed. Thus, a total of 7 strength indices were determined for all participants: 1-RM leg extension, 1-RM leg press, 
isometric peak torque and isokinetic peak torque at 2.09, 3.14, 4.19 and 5.24 $\mathrm{rad} / \mathrm{s}$.

\section{Statistics}

To determine between-group differences in anthropometric variables and muscle strength (all 7 strength indices), a 2-way ANOVA was performed with age and gender as factors. To compare the outcome of the 1-RM testing with the dynamometer testing, bivariate Pearson correlation coefficients $(r)$ were calculated for the primary outcome measures; 1-RM leg extension and 1-RM leg press were correlated with isometric peak torque and with all isokinetic peak torques. This was done for the group as a whole, as well as for the young and elderly, and for males and females separately. As a measure of reliability for the comparisons between the different methods of strength assessment, 95\% confidence intervals $(95 \%-\mathrm{CI})$ were computed for the correlation coefficients (20). Also, standard errors of the estimates (SEE) were calculated as an indication of the magnitude of error involved in the comparisons. Differences between the correlation coefficients calculated for leg extension and leg press were tested statistically (20). Bonferroni corrections were used for multiple testing.

The relation between age and all 7 strength indices was investigated by calculating Pearson correlation coefficients for the entire group and for the male and female subgroups separately. In addition, the correlation between leg volume (as an estimate of muscle mass/volume) and all 7 strength indices was determined. All statistical procedures were performed with SPSS 13.0. Statistical significance was set at $\mathrm{P}<0.05$.

\section{Results}

A total of 55 participants aged 19-84 y were examined in this study (Table 2.1). For leg muscle strength, significant age and gender effects were observed for the group as a whole, with no age $\mathrm{x}$ gender interactions. Males were significantly stronger than females on all 7 strength indices $(\mathrm{P}<0.001)$. Young adults were significantly stronger than the elderly, with leg extension and leg press strength and all isokinetic and isometric peak torques being higher in the young vs the elderly $(\mathrm{P}<0.01)$. These age and gender effects were evident in both the male and female and in the young and elderly subgroups, respectively $(\mathrm{P}<0.05)$.

The correlations between 1-RM and isometric/isokinetic peak torques were stronger for leg extension than for leg press (Figure 2.1 and Table 2.2), with $r$-values ranging from 0.78 to 0.88 (SEE: $0.06-0.09$ ) and from 0.72 to 0.77 (SEE: 0.08-0.09), respectively $(\mathrm{P}<0.001)$. The strongest correlation was found between 1-RM leg extension and isometric peak torque $(r=0.88$; SEE: 0.06, 95\%-CI: 0.81-0.93). The correlations between 1-RM and isometric 
peak torque and between 1-RM and isokinetic peak torque at $3.14 \mathrm{rad} / \mathrm{s}$ were markedly larger for leg extension than leg press $(\mathrm{P}<0.05)$.

Table 2.2 Correlations between different strength indices

\begin{tabular}{|c|c|c|c|c|c|c|}
\hline & & PTisom & $\begin{array}{l}\text { PT } 2.09 \\
\end{array}$ & PT 3.14 & 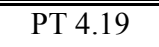 & $\begin{array}{l}\text { PT } 5.24 \\
\end{array}$ \\
\hline \multirow[t]{4}{*}{$\overline{\text { Total }}$} & 1-RM LE & $0.88^{+}$ & $0.85^{+}$ & $0.84^{*}$ & $0.78^{+}$ & $0.80^{+}$ \\
\hline & & $(0.81-0.93)^{\#}$ & $(0.75-0.91)$ & $(0.74-0.91)^{\#}$ & $(0.65-0.87)$ & $(0.68-0.88)$ \\
\hline & 1-RM LP & $0.77^{\ddagger}$ & $0.77^{\ddagger}$ & $0.74^{*}$ & 0.74 & $0.72 *$ \\
\hline & & $(0.63-0.86)$ & $(0.63-0.86)$ & $(0.59-0.84)$ & $(0.59-0.84)$ & $(0.57-0.83)$ \\
\hline \multirow[t]{4}{*}{ Female } & 1-RM LE & $0.83^{\ddagger}$ & $0.64^{\dagger}$ & $0.73^{*}$ & $0.47 *$ & $0.69^{\ddagger}$ \\
\hline & & $(0.66-0.92)$ & $(0.33-0.82)$ & $(0.47-0.87)$ & $(0.19-0.72)$ & $(0.41-0.85)$ \\
\hline & 1-RM LP & $0.75^{\ddagger}$ & $0.72^{\ddagger}$ & $0.73 *$ & $0.61^{\dagger}$ & $0.71^{\ddagger}$ \\
\hline & & $(0.51-0.88)$ & $(0.47-0.87)$ & $(0.48-0.87)$ & $(0.29-0.81)$ & $(0.45-0.86)$ \\
\hline \multirow[t]{4}{*}{ Male } & 1-RM LE & $0.83^{\ddagger}$ & $0.82^{\ddagger}$ & $0.79 *$ & $0.73^{\star}$ & $0.69^{*}$ \\
\hline & & $(0.67-0.92)^{\#}$ & $(0.64-0.91)^{\#}$ & $(0.59-0.90)$ \# & $(0.49-0.86)$ & $(0.43-0.84)$ \\
\hline & 1-RM LP & $0.64^{\ddagger}$ & $0.59^{\dagger}$ & $0.56^{\dagger}$ & $0.56^{\dagger}$ & $0.50^{\dagger}$ \\
\hline & & $(0.36-0.81)$ & $(0.29-0.79)$ & $(0.25-0.77)$ & $(0.25-0.77)$ & $(0.17-0.73)$ \\
\hline \multirow[t]{4}{*}{ Elderly } & 1-RM LE & $0.93^{\ddagger}$ & $0.75^{\ddagger}$ & $0.77^{*}$ & $0.76^{+}$ & $0.81^{*}$ \\
\hline & & $(0.83-0.97)^{\#}$ & $(0.49-0.89)$ & $(0.52-0.90)$ & $(0.49-0.89)$ & $(0.59-0.92)$ \# \\
\hline & 1-RM LP & $0.76^{\ddagger}$ & $0.60^{\dagger}$ & $0.64^{\dagger}$ & $0.58^{\dagger}$ & $0.63^{\dagger}$ \\
\hline & & $(0.49-0.89)$ & $(0.24-0.82)$ & $(0.30-0.84)$ & $(0.21-0.81)$ & $(0.28-0.83)$ \\
\hline \multirow[t]{4}{*}{ Young } & 1-RM LE & $0.84^{\ddagger}$ & $0.84^{\ddagger}$ & $0.82 *$ & $0.73^{\ddagger}$ & 0.72 \\
\hline & & $(0.69-0.92)^{\#}$ & $(0.70-0.92)$ & $(0.67-0.91)$ & $(0.52-0.86)$ & $(0.51-0.85)$ \\
\hline & 1-RM LP & $0.73^{\ddagger}$ & $0.79^{\ddagger}$ & 0.72 & $0.75^{*}$ & $0.70^{*}$ \\
\hline & & $(0.52-0.86)$ & $(0.62-0.89)$ & $(0.50-0.85)$ & $(0.55-0.87)$ & $(0.47-0.84)$ \\
\hline
\end{tabular}

Data are Pearson's $r$, with $95 \%$ confidence intervals in parentheses. Standard errors of the estimates were between 0.06 and 0.09 for the group as a whole and between 0.08 and 0.17 for the subgroups. PT: peak torque. isom: isometric. 2.09, 3.14, 4.19, 5.24: isokinetic velocities in $\mathrm{rad} / \mathrm{s}$. 1-RM: one-repetition maximum. LE: leg extension. LP: leg press. ${ }^{*}: \mathrm{P}<0.05 ;{ }^{\dagger}: \mathrm{P}<0.01$; ${ }^{\ddagger} \mathrm{P}<0.001 .{ }^{\#}$ : significantly different from 1 -RM LP $(\mathrm{P}<0.05)$.

In general, stronger relations were observed between 1-RM leg extension and peak torque values than between 1-RM leg press and peak torque values in the different age and gender subgroups, except in the female subgroup. In all subgroups separately, the strongest correlation was found between 1-RM leg extension and isometric peak torque with $r$ ranging from 0.83 (SEE: 0.11, 95\%-CI: 0.67-0.92) to 0.93 (SEE: 0.08, 95\%-CI: 0.83-0.97; $\mathrm{P}<0.001$ ). Statistically significant differences between leg extension and leg press 
$(\mathrm{P}<0.05)$ were observed for the relation between 1-RM and isometric peak torque (male, elderly and young subgroups), and for the relation between 1$\mathrm{RM}$ and isokinetic peak torque at 2.09 and $3.14 \mathrm{rad} / \mathrm{s}$ (male subgroup) and at $5.24 \mathrm{rad} / \mathrm{s}$ (elderly subgroup). For the study population as a whole and for the subgroups, the correlations between 1-RM (both leg extension and leg press) and isokinetic peak torques tended to decrease with an increase in angular velocity. Correlations between 1-RM and peak torque values were at all times moderate to strong with only 6 out of the $50 r$-values being below 0.60 and 35 of the $r$-values being 0.71 and higher (Table 2.2).
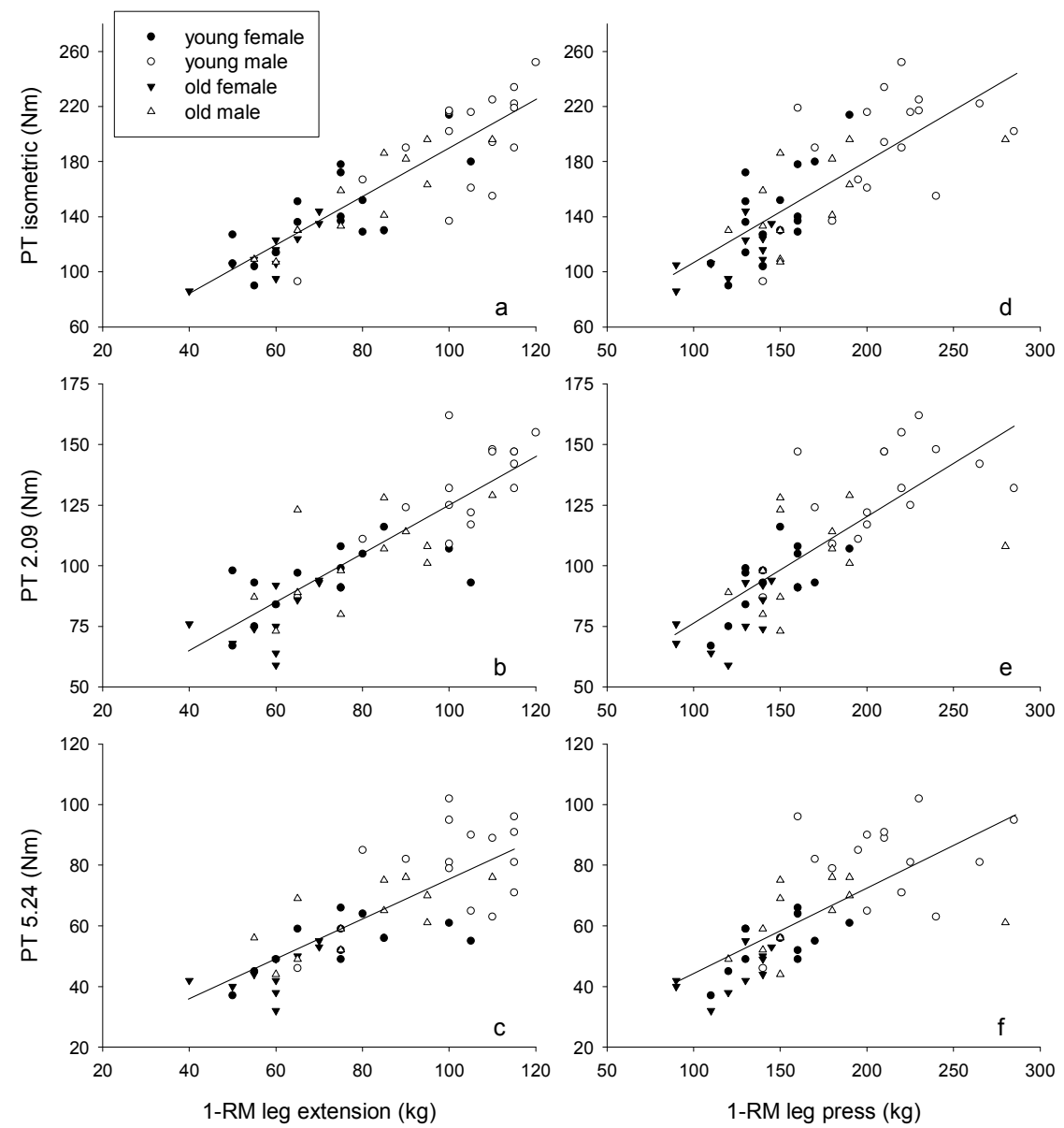

Figure 2.1 Scatterplots of the relations between one-repetition maximum (1-RM) and peak torque (PT) data. Subgroups are indicated by different symbols. a-b-c: 1-RM leg extension vs isometric, isokinetic $2.09 \mathrm{rad} / \mathrm{s}$, and isokinetic $5.24 \mathrm{rad} / \mathrm{s}$ peak torques, respectively. d-e-f: 1RM leg press vs isometric, isokinetic $2.09 \mathrm{rad} / \mathrm{s}$ and isokinetic $5.24 \mathrm{rad} / \mathrm{s}$ peak torques, respectively. Lines represent the fitted regression. 
Leg volume was significantly correlated with all strength indices, with $r$ ranging from 0.64 to $0.72(\mathrm{P}<0.001)$. The strongest relations were found between leg volume and 1-RM measures (Figure 2.2, Table 2.3). Correlations were shown to be similar in the male, young and elderly subgroups, although the absolute $r$-values tended to be lower in the elderly subgroup (range 0.46 to 0.66 ). In the female subgroup, the correlation between leg volume and strength was relatively weak and $r$ only reached significance for the correlation between leg volume and 1-RM leg extension, 1-RM leg press, isometric peak torque and isokinetic peak torque at 2.09 $\mathrm{rad} / \mathrm{s}$, with $r$-values of $0.56,0.49,0.40$ and 0.41 , respectively.

Age correlated negatively with all strength indices, with $r$ ranging from -0.30 to -0.43 (Table 2.3). In the gender subgroups, the correlations tended to be even stronger, with $r$ ranging from -0.32 to -0.61 and from -0.50 to -0.64 in the female and male subgroups, respectively $(\mathrm{P}<0.05)$.

Table 2.3 Correlations between strength, age, and leg volume

\begin{tabular}{|c|c|c|c|c|c|c|c|c|}
\hline & & 1-RM LE & 1-RM LP & PT isom & $\begin{array}{l}\text { PT } 2.09 \\
\end{array}$ & $\begin{array}{l}\text { PT } 3.14 \\
\end{array}$ & 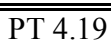 &  \\
\hline \multirow[t]{2}{*}{ Total } & Age & $-0.40^{\dagger}$ & $-0.34 *$ & $-0.36^{\dagger}$ & $-0.39^{\dagger}$ & $-0.43^{\dagger}$ & $-0.30 *$ & $-0.37^{\dagger}$ \\
\hline & $\operatorname{legV}$ & $0.72 *$ & 0.72 * & 0.67 * & $0.68^{*}$ & $0.65^{*}$ & $0.64^{*}$ & $0.67 \ddagger$ \\
\hline \multirow[t]{2}{*}{ F } & Age & $-0.48 *$ & $-0.57^{\dagger}$ & $-0.45 *$ & $-0.56^{\dagger}$ & $-0.61^{\dagger}$ & -0.32 & $-0.54 *$ \\
\hline & $\operatorname{legV}$ & $0.56^{\dagger}$ & $0.49 *$ & $0.40 *$ & $0.41^{*}$ & 0.32 & 0.14 & 0.31 \\
\hline \multirow[t]{2}{*}{ M } & Age & $-0.64^{*}$ & $-0.50^{\dagger}$ & $-0.50^{\dagger}$ & $-0.57^{\dagger}$ & $-0.56^{\dagger}$ & $-0.51^{\dagger}$ & $-0.55^{\dagger}$ \\
\hline & $\operatorname{legV}$ & $0.66^{*}$ & $0.70^{*}$ & $0.65^{\ddagger}$ & $0.65^{*}$ & $0.65^{\star}$ & $0.68^{*}$ & $0.69^{\ddagger}$ \\
\hline $\mathrm{O}$ & $\operatorname{legV}$ & $0.60^{\dagger}$ & $0.66^{\dagger}$ & $0.56^{\dagger}$ & $0.54 *$ & $0.46 *$ & $0.46 *$ & $0.56^{\dagger}$ \\
\hline Y & $\operatorname{legV}$ & 0.72 * & $0.69^{*}$ & $0.65^{*}$ & $0.67^{*}$ & $0.65^{*}$ & $0.64^{\ddagger}$ & $0.64^{*}$ \\
\hline
\end{tabular}

1-RM: one-repetition maximum. LE: leg extension. LP: leg press. PT: peak torque. isom: isometric. $2.09,3.14,4.19,5.24$ : isokinetic velocities in $\mathrm{rad} / \mathrm{s}$. F: female. M: male. O: elderly. $\mathrm{Y}$ : young. legV: leg volume *: $\mathrm{P}<0.05 ; \dagger: \mathrm{P}<0.01 ; \uparrow: \mathrm{P}<0.001$.

\section{Discussion}

The aim of the present study was to determine whether 1-RM testing is a valid means to assess muscle strength of the knee extensors. A strong correlation was observed between strength measured with 1-RM testing and knee extension peak torque as obtained using dynamometry. Furthermore, the strong correlation was shown to be independent of age and/or gender.

1-RM testing and isometric/isokinetic dynamometry are the main methods of strength assessment in scientific research $(1,4,24)$. Because of superior reliability and high internal validity, dynamometry is considered the gold standard for strength assessment. In addition, the function of individual muscles can be studied more appropriately when using dynamometry (19, 
38). However, in exercise intervention programs, resistance training equipment is used instead of dynamometers. Therefore, 1-RM testing is generally performed on the same equipment used in the training to evaluate changes in muscle strength.
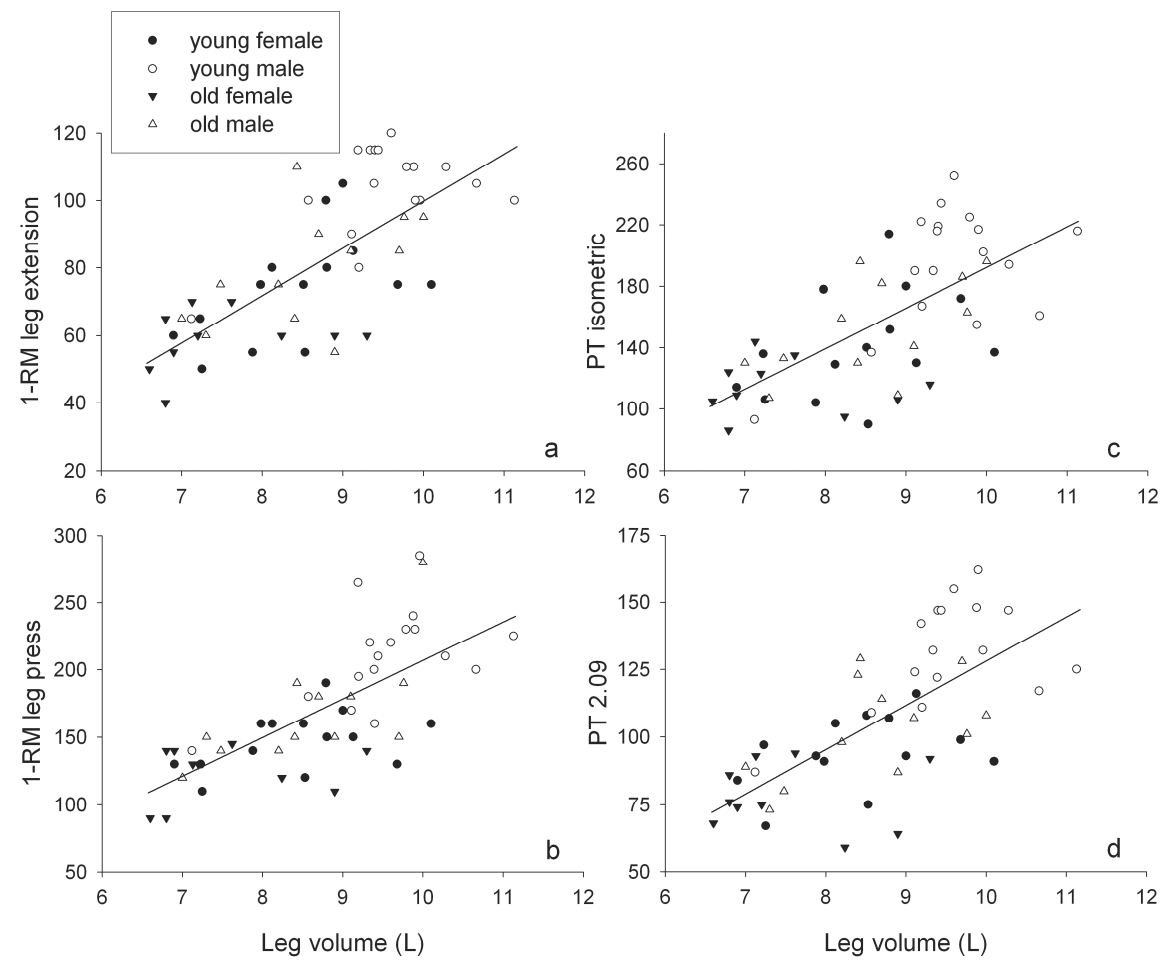

Figure 2.2 Scatter plots of the relations between leg volume and different strength indices. Subgroups are indicated by different symbols. a-b-c-d: leg volume vs one-repetition maximum (1-RM) for the leg extension, 1-RM for the leg press, isometric peak torque (PT) and isokinetic $2.09 \mathrm{rad} / \mathrm{s}$ peak torque (PT 2.09), respectively. Lines represent the fitted regression.

The 1-RM strength testing procedure represents a training specific assessment, e.g., considering activation and coordination related aspects. As such, 1-RM testing should provide the most sensitive measure of the training response (1). In accordance, greater increases have been reported in 1-RM strength when compared to isometric/isokinetic peak torques after a period of resistance training in both the young $(2,4)$ and elderly $(14,16,42)$. Resistance training programs in the elderly have often included leg press and leg extension exercises, since quadriceps muscle strength is strongly associated with mobility $(10,15,17,25)$. Strength assessment procedures used in these training programs should not only be sensitive to temporal changes, but should also allow discrimination between participants of 
different strength. Unfortunately, most validation studies comparing 1-RM testing with dynamometry have focused on arm strength in young participants $(2,4,32)$. Therefore, in the present study, we evaluated the validity of 1-RM leg extension and 1-RM leg press for measuring maximal knee extension strength with knee extension dynamometry in a heterogeneous population, consisting of participants of various ages and both sexes.

Skeletal muscle strength is affected by the speed and mode of contraction, as well as by muscle length during contraction. Each of these factors is likely to influence the relation between 1-RM testing and dynamometry. Nonetheless, in the present study we observed strong significant correlations between strength as assessed by 1-RM leg extension and dynamometry (Figure 2.1 ac; $0.78 \leq r \leq 0.88$; SEE: $0.06-0.09$ ). The latter clearly shows that there is excellent agreement between muscle strength as assessed by 1-RM leg extension and knee extension peak torques. This strong correlation is likely attributed to the similarity in joint positioning, the single-joint movement (isolating the quadriceps) and the open-chain of resistance that characterize both approaches. The differences in contraction velocity and the single-leg versus the two-legged nature of the exercises clearly do not seem to have a major effect on the relation between 1-RM leg extension and dynamometry. Our findings are in line with those of other studies reporting strong correlations between upper extremity strength as assessed with 1-RM testing and isometric/isokinetic dynamometry in young males $(2,32)$.

Although strong correlations were also observed between 1-RM leg press and knee extension peak torques, the observed correlations were generally lower than those between 1-RM leg extension and peak torques (Table 2.2). Although not always statistically significant, this difference was evident for all peak torques separately and is likely explained by the different characteristics of the leg press exercise. Leg press consists of a closed-chain exercise including hip, knee and ankle joint movement, representing whole limb extension strength rather than isolating the knee extensors, as is the case with leg extension and dynamometry. Several other studies have suggested that weaker correlations between different testing methods are the result of dissimilarities in the execution of the movement $(24,32)$.

For both leg extension and leg press, correlations tended to be stronger with isometric and low velocity isokinetic peak torques than with high velocity isokinetic peak torques. The stronger correlations are probably due to greater similarities in contraction velocity between the different methods, which has been reported previously (24). This finding might be explained by the fact that a change in maximum force with a change in contraction velocity has a differential effect in participants: this effect depends on, for example, the different training background of the participants, the activation status of the muscle (7), and fiber type differences (i.e. percentage type II fibers) between 
participants (8). Because of the high load in 1-RM testing, the contraction velocity is relatively low. Since the strongest correlations were found between 1-RM data and isometric peak torques, it could be argued that the contraction velocity during 1-RM testing is closest to the isometric condition. In addition, larger differences in the contraction velocity between the 1-RM testing and the high velocity isokinetic testing could have caused the larger variability between these testing modalities, thereby explaining the decrease in the respective correlations. In the present study, all correlations between 1-RM and dynamometer data were $>0.71$. The latter implies that 1RM testing is a valid means to evaluate maximal muscle strength.

In the present study, subgroups were defined to investigate the possible modulating effect of age and gender on the relation between strength as assessed by 1-RM and dynamometry. Although the population size of the individual groups was relatively small $(n=22)$, leading to somewhat larger SEE (see Table 2.2), we observed good correlations between the 1-RM (especially leg extension) and dynamometer data within each of the subgroups, with the only exception being the relation between 1-RM leg extension and peak torque at $4.19 \mathrm{rad} / \mathrm{s}$ in the female subgroup. Hence, we conclude that 1-RM testing can be applied in both the young and elderly, independent of gender, as a valid measure of knee extensor strength. In addition, the subtle differences we observed between both 1-RM exercises and their correlation with dynamometry suggest that leg extension more accurately isolates knee extension strength and leg press represents not merely quadriceps strength but is related to both hip and knee extension strength.

In general, the measurement of strength in a large heterogeneous population inherently increases the likelihood of finding significant correlations between the different assessment methods. To limit the range over which strength was measured, we defined specific subgroups, to improve the usefulness of correlation analyses. It should be noted that correlation analyses as applied in the present study is accompanied by further limitations, such as the inability to detect non-linear relations between the measured variables. However, since other methods of assessing validity, such as limits of agreement (6), cannot be used to compare data with different units of measurement, correlation analysis was regarded the most appropriate way of assessing 1-RM validity in the present study $(13,41)$.

Significant correlations were observed between leg volume and all 7 different strength indices, supporting the contention that leg volume can be indicative of leg muscle strength. Although the use of computed tomography and/or magnetic resonance imaging likely provides a much better estimate of leg muscle mass, we argue that non-invasive anthropometric leg volume measures may be helpful in future studies in which large cohorts are 
subjected to, for example, lifestyle intervention programs, to determine whether increases in muscle mass and/or strength have occurred.

We conclude that 1-RM testing represents a valid means to evaluate leg muscle strength in vivo in both young and elderly men and women. Although dynamometry can reveal additional information about the underlying aspects of muscle strength, it is not essential. Considering the importance of training specificity in exercise intervention studies, we suggest that training specific 1-RM strength assessment can be used to assess changes in muscle strength. 


\section{References}

1. Abernethy P, Wilson G, Logan P. Strength and power assessment. Issues, controversies and challenges. Sports Med 1995;19:401-17.

2. Abernethy PJ, Jurimae J. Cross-sectional and longitudinal uses of isoinertial, isometric, and isokinetic dynamometry. Med Sci Sports Exerc 1996;28:1180-7.

3. Alexander NB, Schultz AB, Ashton-Miller JA, Gross MM, Giordani B. Muscle strength and rising from a chair in older adults. Muscle Nerve Suppl 1997;5:S56-9.

4. Baker D, Wilson G, Carlyon B. Generality versus specificity: a comparison of dynamic and isometric measures of strength and speed-strength. Eur J Appl Physiol Occup Physiol 1994;68:350-5.

5. Bernardi M, Rosponi A, Castellano V, et al. Determinants of sit-to-stand capability in the motor impaired elderly. J Electromyogr Kinesiol 2004;14:401-10.

6. Bland JM, Altman DG. Statistical methods for assessing agreement between two methods of clinical measurement. Lancet 1986;1:307-10.

7. Bobbert MF, Harlaar J. Evaluation of moment-angle curves in isokinetic knee extension. Med Sci Sports Exerc 1993;25:251-9.

8. Bottinelli R, Reggiani C. Human skeletal muscle fibres: molecular and functional diversity. Prog Biophys Mol Biol 2000;73:195-262.

9. Buckley DC, Kudsk KA, Rose BS, Fatzinger P, Koetting CA, Schlatter M. Anthropometric and computerized tomographic measurements of lower extremity lean body mass. J Am Diet Assoc 1987;87:196-9.

10. Chrusch MJ, Chilibeck PD, Chad KE, Davison KS, Burke DG. Creatine supplementation combined with resistance training in older men. Med Sci Sports Exerc 2001;33:2111-7.

11. Daley MJ, Spinks WL. Exercise, mobility and aging. Sports Med 2000;29:1-12.

12. Doherty TJ. Invited review: Aging and sarcopenia. J Appl Physiol 2003;95:1717-27.

13. Dolny DG, Collins MG, Wilson T, Germann ML, Davis HP. Validity of lower extremity strength and power utilizing a new closed chain dynamometer. Med Sci Sports Exerc 2001;33:171-5.

14. Ferri A, Scaglioni G, Pousson M, Capodaglio P, Van Hoecke J, Narici MV. Strength and power changes of the human plantar flexors and knee extensors in response to resistance training in old age. Acta Physiol Scand 2003;177:69-78.

15. Fiatarone MA, Marks EC, Ryan ND, Meredith CN, Lipsitz LA, Evans WJ. Highintensity strength training in nonagenarians. Effects on skeletal muscle. Jama 1990;263:3029-34.

16. Frontera WR, Meredith CN, O'Reilly KP, Knuttgen HG, Evans WJ. Strength conditioning in older men: skeletal muscle hypertrophy and improved function. J Appl Physiol 1988;64:1038-44.

17. Hagerman FC, Walsh SJ, Staron RS, et al. Effects of high-intensity resistance training on untrained older men. I. Strength, cardiovascular, and metabolic responses. J Gerontol A Biol Sci Med Sci 2000;55:B336-46.

18. Herzog W. The relation between the resultant moments at a joint and the moments measured by an isokinetic dynamometer. J Biomech 1988;21:5-12.

19. Herzog W, Guimaraes AC, Anton MG, Carter-Erdman KA. Moment-length relations of rectus femoris muscles of speed skaters/cyclists and runners. Med Sci Sports Exerc 1991;23:1289-96.

20. Hinkle DE, Wiersma W, Jurs SG. Applied statistics for the behavioral sciences. 4th ed. Boston, NY: Houghton Mifflin Company, 1998.

21. Holm I, Hammer S, Larsen S, Nordsletten L, Steen H. Can a regular leg extension bench be used in testing deficits of the quadriceps muscle during rehabilitation? Scand J Med Sci Sports 1995;5:29-35. 
22. Jette AM, Jette DU. Functional and behavioral consequences of sarcopenia. Muscle Nerve Suppl 1997;5:S39-41.

23. Jones PR, Pearson J. Anthropometric determination of leg fat and muscle plus bone volumes in young male and female adults. J Physiol 1969;204:63P-66P.

24. Knapik JJ, Wright JE, Mawdsley RH, Braun JM. Isokinetic, isometric and isotonic strength relationships. Arch Phys Med Rehabil 1983;64:77-80.

25. Kostek MC, Delmonico MJ, Reichel JB, et al. Muscle strength response to strength training is influenced by insulin-like growth factor 1 genotype in older adults. J Appl Physiol 2005;98:2147-54.

26. Kraemer W, Fry A. Strength testing: development and evaluation of methodology. In: Maud P, Foster C, eds. Physiological assessment of physical fitness. Leeds: Human Kinetics, 1995:115-133.

27. Lanza IR, Towse TF, Caldwell GE, Wigmore DM, Kent-Braun JA. Effects of age on human muscle torque, velocity, and power in two muscle groups. J Appl Physiol 2003;95:2361-9.

28. Lindle RS, Metter EJ, Lynch NA, et al. Age and gender comparisons of muscle strength in 654 women and men aged 20-93 yr. J Appl Physiol 1997;83:1581-7.

29. Ly LP, Handelsman DJ. Muscle strength and ageing: methodological aspects of isokinetic dynamometry and androgen administration. Clin Exp Pharmacol Physiol 2002;29:37-47.

30. Mayhew JL, Prinster JL, Ware JS, Zimmer DL, Arabas JR, Bemben MG. Muscular endurance repetitions to predict bench press strength in men of different training levels. J Sports Med Phys Fitness 1995;35:108-13.

31. McCall GE, Byrnes WC, Dickinson A, Pattany PM, Fleck SJ. Muscle fiber hypertrophy, hyperplasia, and capillary density in college men after resistance training. J Appl Physiol 1996;81:2004-12.

32. Murphy AJ, Wilson GJ. The assessment of human dynamic muscular function: a comparison of isoinertial and isokinetic tests. J Sports Med Phys Fitness 1996;36:16977.

33. Olsen S, Aagaard P, Kadi F, et al. Creatine supplementation augments the increase in satellite cell and myonuclei number in human skeletal muscle induced by strength training. J Physiol 2006;573:525-34.

34. Phillips WT, Batterham AM, Valenzuela JE, Burkett LN. Reliability of maximal strength testing in older adults. Arch Phys Med Rehabil 2004;85:329-34.

35. Ploutz-Snyder LL, Giamis EL. Orientation and familiarization to 1RM strength testing in old and young women. J Strength Cond Res 2001;15:519-23.

36. Prince F, Corriveau H, Hébert R, Winter DA. Gait in the elderly. Gait \& Posture 1997;5:128-135.

37. Rantanen T, Avlund K, Suominen H, Schroll M, Frandin K, Pertti E. Muscle strength as a predictor of onset of ADL dependence in people aged 75 years. Aging Clin Exp Res 2002;14:10-5.

38. Savelberg HH, Meijer K. Contribution of mono- and biarticular muscles to extending knee joint moments in runners and cyclists. J Appl Physiol 2003;94:2241-8.

39. Savelberg HH, Meijer K. The effect of age and joint angle on the proportionality of extensor and flexor strength at the knee joint. J Gerontol A Biol Sci Med Sci 2004;59:1120-8.

40. Schultz AB, Ashton-Miller JA, Alexander NB. What leads to age and gender differences in balance maintenance and recovery? Muscle Nerve Suppl 1997;5:S60-4.

41. Surburg PR, Suomi R, Poppy WK. Validity and reliability of a hand-held dynamometer applied to adults with mental retardation. Arch Phys Med Rehabil 1992;73:535-9.

42. Tracy BL, Ivey FM, Hurlbut D, et al. Muscle quality. II. Effects Of strength training in 65- to 75-yr-old men and women. J Appl Physiol 1999;86:195-201. 
43. Williamson DL, Godard MP, Porter DA, Costill DL, Trappe SW. Progressive resistance training reduces myosin heavy chain coexpression in single muscle fibers from older men. J Appl Physiol 2000;88:627-33.

44. Wolfson L, Judge J, Whipple R, King M. Strength is a major factor in balance, gait, and the occurrence of falls. J Gerontol A Biol Sci Med Sci 1995;50 Spec No:64-7. 



\section{Chapter 3}

\section{Satellite cell content is specifically reduced in type II skeletal muscle fibers in the elderly}

Lex B. Verdijk, René Koopman, Gert Schaart, Kenneth Meijer, Hans H.C.M. Savelberg, and Luc J.C. van Loon

American Journal of Physiology: Endocrinology and Metabolism 2007; 292: E151-157 


\begin{abstract}
Satellite cells (SC) are essential for skeletal muscle growth and repair. Because sarcopenia is associated with type II muscle fiber atrophy, we hypothesized that SC content is specifically reduced in the type II fibers in the elderly. A total of eight elderly (E: $76 \pm 1 \mathrm{y}$ ) and eight young (Y: $20 \pm 1 \mathrm{y}$ ) healthy males were selected. Muscle biopsies were collected from the vastus lateralis in both legs. ATPase staining and a pax7-abtibody were used to determine fiber type-specific SC content (i.e. pax7-positive SC) on serial muscle cross-sections. In contrast to the type I fibers, the proportion and mean cross-sectional area of the type II fibers were substantially reduced in E vs Y. The number of SC per type I fiber was similar in E and Y. However, the number of SC per type II fiber was substantially lower in E vs Y $(0.044 \pm 0.003$ vs $0.080 \pm 0.007 ; \mathrm{P}<0.01)$. In addition, in the type II fibers, the number of SC relative to the total number of nuclei and the number of SC per fiber area were also significantly lower in E. This study is the first to show type II fiber atrophy in the elderly to be associated with a fiber typespecific decline in SC content. The latter is evident when SC content is expressed per fiber or per fiber area. The decline in SC content might be an important factor in the etiology of type II muscle fiber atrophy, which accompanies the loss of skeletal muscle with aging.
\end{abstract}




\section{Introduction}

The gradual loss of skeletal muscle mass with aging, or sarcopenia, represents a major factor determining the decline in functional capacity, mobility and general health in the elderly. Muscle mass represents a main determinant of muscle strength and has been strongly associated with performance in activities of daily living and the level of independence in the elderly $(16,36,49)$. Much work has been devoted to describing the alterations in skeletal muscle that occur with aging. The most consistent findings have been the decline in the total number of muscle fibers and the specific atrophy of the type II fibers, both contributing to the loss of skeletal muscle mass $(18,28,30)$. In accordance, type II muscle fiber atrophy and necrosis have been shown to result in a reduced (area) proportion of type II muscle fibers in skeletal muscle tissue in the elderly $(15,28,29)$.

Although the exact mechanisms that cause sarcopenia remain to be elucidated, the hypothesis that satellite cells could play an important role in this age-related loss of skeletal muscle mass has recently gained much interest. Satellite cells (SC) or "muscle stem cells" are the sole source for the generation of new myonuclei in vivo in skeletal muscle tissue $(2,34,35)$. As such, SC seem to be essential for the repair and hypertrophy of skeletal muscle tissue. Normally, SC lie quiescent between the basal lamina and the plasma membrane of muscle fibers (32). On activation and subsequent proliferation, the majority of these SC differentiate to form new myonuclei that either fuse with existing fibers or generate new fibers, while a small proportion returns to quiescence $(24,50)$.

Because SC are responsible for the maintenance of skeletal muscle mass, a decrease in the number of SC or in their ability to become activated and proliferate in response to anabolic stimuli is likely to result in impaired skeletal muscle structure and function (44). Although the latter has been speculated to occur in sarcopenia, studies investigating the effects of aging on skeletal muscle SC content in humans have been inconclusive. Whereas some studies reported both a reduced number of SC per muscle fiber and a smaller proportion of SC relative to the number of myonuclei in the elderly $(22,38)$, other studies have failed to observe such differences $(15,20,40)$. Although it has been reported that no differences exist in the number of SC between type I and II muscle fibers in young adults (23), it could be speculated that the specific type II muscle fiber atrophy with aging is associated with a fiber type-specific reduction in SC content. Such a fiber type-specific reduction in SC content could represent an important factor in the etiology of sarcopenia and might explain the apparent discrepancy in the literature regarding the effects of aging on muscle fiber SC content.

In the present study, we assessed skeletal muscle fiber type-specific characteristics and fiber type-specific satellite cell content in young and elderly men. Therefore, skeletal muscle biopsy samples were taken from the 


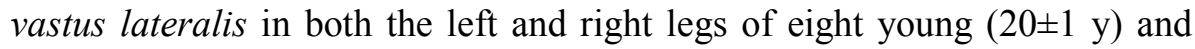
eight elderly $(76 \pm 1 \mathrm{y})$, lean males. Immunohistological staining of muscle cross-sections was performed to assess muscle fiber type-specific SC content and muscle fiber characteristics.

\section{Methods}

\section{Subjects}

Eight elderly ( $76 \pm 1 \mathrm{y})$ and eight young $(20 \pm 1 \mathrm{y})$, body weight-matched, male volunteers with no history of participating in any regular exercise program were recruited to participate in the present study. Subjects' characteristics are shown in Table 3.1. All subjects were informed on the nature and possible risks of the experimental procedures before their written informed consent was obtained. This study was approved by the Medical Ethics Committee of the Academic Hospital Maastricht.

\section{Pretesting}

The medical histories of subjects were evaluated, and an oral glucose tolerance test was performed at least 2 weeks before the start of the trials $(1$, 31). Subjects with orthopedic and/or cardiovascular abnormalities or type 2 diabetes were excluded from participation. After selection for this study, maximal strength was assessed in two one-repetition maximum (1-RM) strength tests on a leg press and leg extension machine, respectively. First, a familiarization trial was performed. Proper lifting technique was demonstrated and practiced for each of the two lower limb exercises. Thereafter, maximum strength was estimated using the multiple repetitions testing procedure (33). In an additional session, at least ten days prior to muscle biopsy collection, each subject's 1-RM was determined. After warming up, the load was set at $90-95 \%$ of the estimated maximum strength, and increased after each successful lift until failure. A 3-min resting period between subsequent attempts was allowed. A repetition was valid if the subject was able to complete the entire lift in a controlled manner without assistance.

The weight and height of subjects were measured, and leg volume was determined as described previously (21). In short, leg circumference and height were measured at seven different sites, dividing the leg into six segments. The volume of each segment was calculated by treating each segment as a truncated cone, using the anthropometric measurements for determining the height and the surface areas of each cone. All subjects were instructed to refrain from strenuous physical activity for 3 days prior to muscle biopsy collection and to maintain their normal habitual dietary 
intake. On the day before biopsy collection a standardized meal was provided, and from 9:00 pm, subjects remained fasted.

Table 3.1 Subjects' characteristics

\begin{tabular}{lcc}
\hline \hline & Young $(n=8)$ & Elderly $(n=8)$ \\
\hline Age $(\mathrm{y})$ & $20 \pm 1$ & $76 \pm 1 *$ \\
Weight $(\mathrm{kg})$ & $73.7 \pm 3.2$ & $75.5 \pm 2.1$ \\
Height $(\mathrm{m})$ & $1.81 \pm 0.03$ & $1.71 \pm 0.01 *$ \\
BMI $\left(\mathrm{kg} / \mathrm{m}^{2}\right)$ & $22.5 \pm 1.1$ & $25.7 \pm 0.7 *$ \\
Leg volume $(\mathrm{L})$ & $9.4 \pm 0.4$ & $8.2 \pm 0.3 *$ \\
HbA1c $(\%)$ & $5.0 \pm 0.2$ & $5.7 \pm 0.1 *$ \\
Basal glucose (mmol/L) & $5.3 \pm 0.1$ & $5.4 \pm 0.2$ \\
Basal insulin (mU/L) & $12.8 \pm 1.1$ & $10.2 \pm 1.5$ \\
HOMA-IR & $3.0 \pm 0.3$ & $2.5 \pm 0.4$ \\
1-RM leg extension (kg) & $108 \pm 4$ & $78 \pm 4 *$ \\
1-RM leg press (kg) & $204 \pm 7$ & $151 \pm 7 *$ \\
\hline \hline
\end{tabular}

Values are means \pm SEM. BMI: body mass index; HOMA-IR: homeostasis model assessment of insulin resistance (31); 1-RM: one-repetition maximum. *Significantly different compared with the young $(\mathrm{P}<0.05)$.

\section{Muscle biopsies}

After an overnight fast, subjects arrived at the laboratory by car or public transportation at 8:00 am. After $30 \mathrm{~min}$ of supine rest, a basal venous blood sample was collected. After local anesthesia, percutaneous needle biopsies $(50-80 \mathrm{mg})$ were taken from the vastus lateralis muscle $\sim 15 \mathrm{~cm}$ above the patella in both the left and right leg of each subject (3). Any visible nonmuscle tissue was removed from the biopsy samples, which were then frozen in liquid nitrogen-cooled isopentane, embedded in Tissue-Tek (Sakura Finetek, Zoeterwoude, The Netherlands), and stored at $-80^{\circ} \mathrm{C}$ until further analyses.

\section{Immunohistochemistry}

From all biopsies, 5- $\mu \mathrm{m}$-thick cryosections were cut at $-20^{\circ} \mathrm{C}$ and samples from the left and right leg of each subject were mounted together on uncoated glass slides. Care was taken to properly align the samples for crosssectional fiber analyses. Slides from elderly and young subjects were stained simultaneously to ensure identical staining efficiency.

An ATPase staining was performed after acid pre-incubation to determine muscle fiber type as described previously $(5,8,9)$. Instead of dehydration of 
the slides at the end of the ATPase staining procedure (5), sections were stained with anti-laminin (polyclonal rabbit anti-laminin, Sigma, Zwijndrecht, The Netherlands) and thereafter with the appropriate secondary antibody goat anti-rabbit IgG AlexaFluor488 (Molecular Probes, Invitrogen, Breda, The Netherlands). Nuclei were stained with 4',6-Diamidino-2phenylindole (DAPI; Molecular Probes), similar to the procedures described below. At a pH of 4.45, we were able to differentiate between black (type I), white (type IIa) and intermediate (type IIb/IIx) fibers (Figure 3.1). The assessment of muscle fiber typing at this $\mathrm{pH}$ was validated by staining serial muscle cross-sections of three young and three elderly subjects with myosin heavy chain (MHC)-I and MHC-IIa antibodies (A4.840 and N2.261 respectively; Developmental Studies Hybridoma Bank [DSHB], Iowa City, IA, USA). Because too few type IIb/IIx fibers were present for reliable SC counts in some of the biopsies, SC content and fiber characteristics were assessed in type I and type II muscle fibers only.

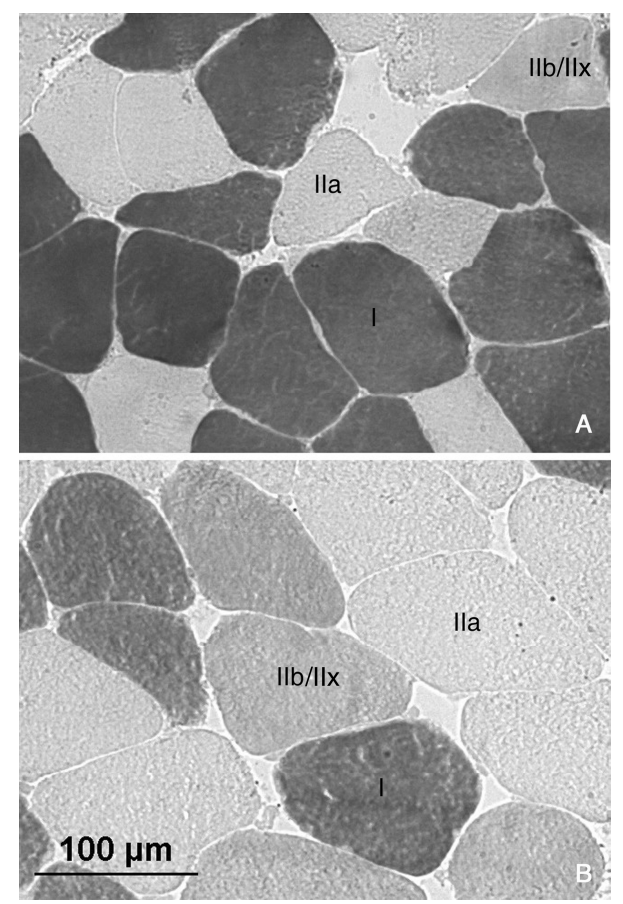

Figure 3.1 Muscle fiber type analyses performed on muscle tissue collected from elderly (A) and young (B) males by ATPase staining of muscle cross-sections; type I fibers are black, and type II fibers are white (IIa) or show intermediate staining (IIb/IIx). Type II fibers are significantly smaller in the elderly vs the young.

Immunostaining for the detection of myocellular $\mathrm{SC}$ content was performed on serial cross-sections with both pax7 (mouse anti-pax7, DSHB), which 
marks both quiescent and activated SC (43, 50), and CD56 (mouse antiCD56, BD Biosciences, San Jose, CA, USA), which has been extensively used for SC determination in human muscle tissue $(10,15,22,23)$. Because of superior staining efficiency when using pax 7 , this marker was used for the quantification of SC in the present study. After fixation for $5 \mathrm{~min}$ with acetone, slides were air-dried and incubated for $60 \mathrm{~min}$ at room temperature with primary antibodies directed against laminin (dilution 1:50) and pax7 (dilution 1:20), diluted in $0.05 \%$ Tween-PBS. Slides were then washed for 3 x $5 \mathrm{~min}$ in PBS, before incubation for $60 \mathrm{~min}$ at room temperature with the appropriate secondary antibodies, purchased from Molecular Probes. Goat anti-rabbit IgG-AlexaFluor555 (dilution 1:200) and goat anti-mouse IgG1AlexaFluor488 (dilution 1:500) were diluted together with DAPI $(0.238 \mu \mathrm{M})$ in $0.05 \%$ Tween-PBS to, respectively, stain laminin in red, $\operatorname{pax} 7$ in green and myonuclei in blue (Figure 3.2). After incubation, slides were again washed for $3 \times 5 \mathrm{~min}$ in PBS and then covered with cover glasses using Mowiol (Calbiochem, VWR, Amsterdam, The Netherlands).

Although pax7 is essential for the specification of $\mathrm{SC}$, it has been reported that pax7 expression declines when SC ontogeny proceeds into terminal differentiation $(43,50)$. As such, the use of pax 7 staining as a marker for SC content could theoretically lead to an underestimation of total SC count. Therefore, we validated the use of pax7 by simultaneously staining crosssections of 3 young and 3 elderly subjects with pax7, CD56 and DAPI. In agreement with earlier findings (37), $>96 \%$ of CD56-positive SC were also pax7-positive, with no differences between age groups. In the present study, the term 'satellite cells' (SC) refers to the number of satellite cells that stained positive for pax7.

\section{Data analyses}

All images were digitally captured, using both light microscopy (ATPase) and fluorescence microscopy (laminin, pax7 and DAPI) with a Nikon E800 combined light/fluorescence microscope (Nikon Instruments Europe B.V., Badhoevedorp, The Netherlands) coupled to a Basler A113 C progressive scan color CCD camera with a Bayer color filter. Epifluorescence signal was recorded using a Texas Red excitation filter $(540-580 \mathrm{~nm})$ for laminin, a FITC excitation filter (465-495 nm) for pax7, and a DAPI UV excitation filter $(340-380 \mathrm{~nm})$ for the nuclei. Image processing and quantitative analyses were done using Lucia 4.81 software package (Nikon). All image recordings and analyses were performed by an investigator blinded to the subject coding. 

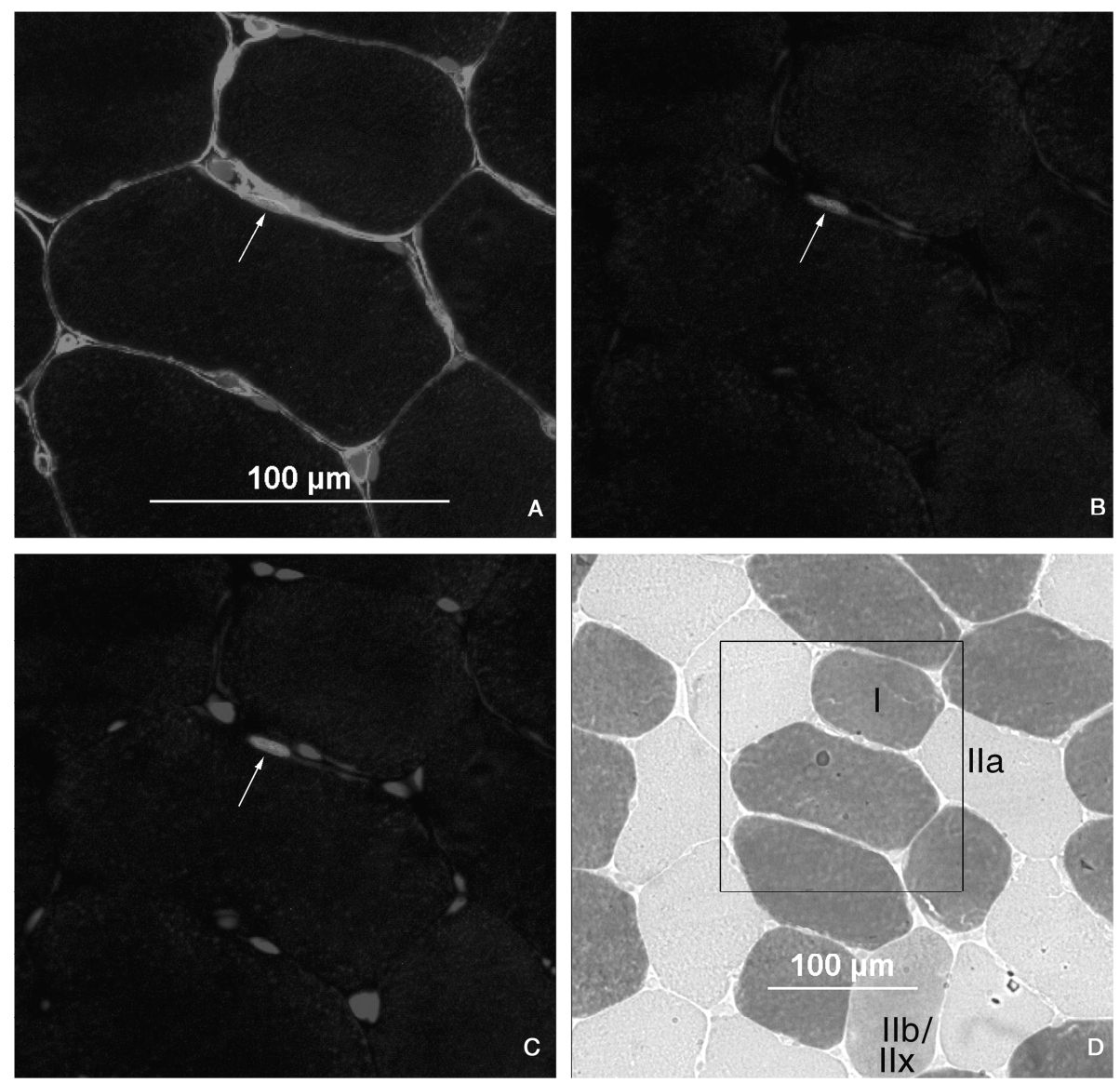

Figure 3.2 Muscle fiber type analyses for satellite cell content. A: laminin+DAPI+pax7 staining; B: only pax7 staining; and C: DAPI+pax7 staining. Arrows indicate the satellite cell. D: ATPase staining from serial muscle cross-section of image A-C; the marked area represents the same area as shown in frame A-C.

From the ATPase-stained slides, images were captured at $120 \mathrm{x}$ magnification. Laminin was used to determine cell borders, and for all fibers within each image, type I (black) and type II (white and intermediate) fibers were identified (Figure 3.1). Within each image, the number of fibers, the mean fiber cross-sectional area (CSA), the number of myonuclei per fiber and the mean fiber area per nucleus (fiber CSA/no. of myonuclei), were measured for the type I and type II fibers separately. As a measure of fiber circularity, form factors were calculated using the formula $\left(4 \pi^{*} \mathrm{CSA}\right) /$ (perimeter) ${ }^{2}$. Fiber circularity was not different between the muscle crosssections from the elderly vs the young for any fiber type.

From the pax7-stained slides, images were captured at 240x magnification to allow clear determination of SC localization. Laminin was used to visualize 
the cell borders. Fiber typing was determined by matching the serial ATPase-stained cross-sections. Satellite cells were determined in each fiber between the basal lamina and the plasma membrane and stained positive for both DNA (DAPI) and pax7 (see Figure 3.2 for example). The data were used to calculate the number of SC per muscle fiber, the proportion of SC (no. of SC/[no. of SC + no. of myonuclei]) and the number of SC per fiber area in $\mathrm{mm}^{2}$ for the type I and type II muscle fibers separately.

Because there were no differences in muscle fiber type composition and CSA of the type I and II fibers between muscle samples taken from the left vs the right leg, muscle fiber data were pooled from both biopsies in each subject, resulting in a mean number of $401 \pm 32$ and $507 \pm 69$ individual muscle fibers being analyzed in the young and elderly subjects, respectively. For SC count, $287 \pm 26$ and $291 \pm 29$ fibers were analyzed in the muscle samples collected in the young and elderly subjects, respectively.

\section{Statistics}

All values are expressed as means \pm SEM. Muscle characteristics in muscle biopsies collected from the left and right legs were analyzed using paired ttests. General differences between elderly and young subjects were evaluated by independent t-tests. In addition, fiber type-specific variables were analyzed using mixed model analyses with 'age group' (young and elderly) as between subjects factor and 'fiber type' (type I and II) as within subjects factor. In the case of significant interaction, between group differences were analyzed for the different fiber types separately, and within group differences were analyzed for the young and elderly separately. An $\alpha$ level of 0.05 was used to determine statistical significance. All analyses were performed using SPSS version 11.5 (Chicago, IL, USA).

\section{Results}

\section{Subjects}

Subjects' characteristics are provided in Table 3.1. Basal blood glucose and insulin levels, and whole-body insulin sensitivity as assessed by the homeostasis model assessment of insulin resistance (HOMA-IR) index (31) did not differ between groups. Blood HbAlc concentrations were within a normal range for both groups, but were significantly greater in the elderly. Muscle strength as assessed by 1-RM for both leg press and leg extension was significantly lower in the elderly ( $151 \pm 7$ and $78 \pm 4 \mathrm{~kg}$, respectively) vs the young ( $204 \pm 7$ and $108 \pm 4 \mathrm{~kg}$, respectively; $\mathrm{P}<0.001)$. The latter was accompanied by a lower leg volume in the elderly compared with the young. In accordance, leg volume was significantly correlated with muscle strength $(r=0.53 ; \mathrm{P}<0.05)$. 


\section{Fiber characteristics}

Fiber type composition was significantly different between groups (Table 3.2). Type II muscle fiber content was significantly lower in the elderly $(47 \pm 3 \%)$ vs the young $(57 \pm 3 \% ; \mathrm{P}<0.05)$. In addition, the percentage of total muscle area occupied by type II fibers was also significantly smaller in the elderly $(42 \pm 4 \%)$ vs the young $(59 \pm 3 \%$; P $<0.01)$. Type II, but not type I muscle fiber CSA differed significantly between groups, with mean type II muscle fiber CSA being smaller in the elderly vs the young (4451 \pm 396 vs $6126 \pm 393 \mu \mathrm{m}^{2}$, respectively, $\mathrm{P}<0.05$; Table 3.2, Figure 3.1). There was a significant interaction between age group and fiber type CSA $(\mathrm{P}<0.05)$. In the young, fiber CSA did not differ between fiber types. In contrast, in the elderly muscle fiber CSA was significantly smaller in the type II vs the type I fibers $(\mathrm{P}<0.05$; Table 3.2).

Table 3.2 Muscle fiber characteristics

\begin{tabular}{lcccccc}
\hline \hline & \multicolumn{2}{c}{ Young } & \multicolumn{3}{c}{ Elderly } \\
& $\mathrm{CSA}\left(\mu \mathrm{m}^{2}\right)$ & fiber\% & CSA\% & CSA $\left(\mu \mathrm{m}^{2}\right)$ & fiber\% & CSA\% \\
\hline Type I & $5589 \pm 281$ & $43 \pm 3$ & $41 \pm 3$ & $5471 \pm 227$ & $53 \pm 3 *$ & $58 \pm 4 *$ \\
Type II & $6126 \pm 393$ & $57 \pm 3$ & $59 \pm 3$ & $4451 \pm 396 * \dagger$ & $47 \pm 3 *$ & $42 \pm 4 *$ \\
\hline \hline
\end{tabular}

Values are means \pm SEM. CSA: fiber cross-sectional area; CSA\%: percentage muscle area occupied per fiber type. For CSA, significant interaction between group and fiber type was observed. *Significantly different compared with the young $(\mathrm{P}<0.05)$. ${ }^{\dagger}$ Significantly different compared with the type I muscle fibers (within groups; $\mathrm{P}<0.05$ ).

\section{Myonuclei}

In both the young and elderly, the number of myonuclei per fiber was significantly higher in the type I muscle fibers compared with the type II muscle fibers (Table 3.3). In accordance, the fiber area per myonucleus was smaller for the type I vs the type II muscle fibers. The number of myonuclei per muscle fiber differed significantly between groups for both the type I and II muscle fibers (Table 3.3). More myonuclei were present per type I and II muscle fiber in the elderly compared with the young (type I: $3.5 \pm 0.2$ vs $3.0 \pm 0.2$ and type II: $2.6 \pm 0.1$ vs $2.3 \pm 0.1$, respectively, $\mathrm{P}<0.01$ ). For the fiber area per myonucleus, there was significant interaction between age group and fiber type. Separate analysis showed significant differences between groups, with the elderly showing a significantly smaller fiber area per myonucleus in both the type I and II muscle fibers when compared with the young; the latter difference being more pronounced in the type II muscle fibers (Table 3.3; $\mathrm{P}<0.05$ ). 


\section{Satellite cells}

In type I muscle fibers, no differences were observed in SC content, neither as the number of SC per fiber nor as the number of SC per $\mathrm{mm}^{2}$ between the young and the elderly (Table 3.3). In addition, SC proportion in type I fibers did not differ between the young and the elderly. In contrast, in the type II muscle fibers, SC content was significantly lower in the elderly vs the young. The number of SC per type II muscle fiber was significantly reduced in the elderly when compared with the young $(0.044 \pm 0.003$ vs $0.080 \pm 0.007$, respectively; $\mathrm{P}<0.01$ ) (Figure 3.3). The latter was also evident when correcting for CSA, as the number of SC per $\mathrm{mm}^{2}$ of type II muscle fiber was also significantly reduced in the elderly compared with the young (9.7 \pm 1.0 vs $12.6 \pm 0.9$, respectively; $\mathrm{P}<0.05$ ). In accordance, $\mathrm{SC}$ proportion was significantly different between groups, with SC representing $1.5 \pm 0.2 \%$ of nuclei in the elderly type II muscle fibers compared with $2.9 \pm 0.4 \%$ in type II muscle fibers of the young $(\mathrm{P}<0.01)$. For all $\mathrm{SC}$ variables, there was a significant interaction between age group and fiber type. In the young, no significant differences were observed for any of the SC characteristics between the type I and II muscle fibers. In the elderly, the number of SC per muscle fiber, the number of SC per $\mathrm{mm}^{2}$ of muscle fiber and the proportion of SC were substantially lower in the type II vs the type I muscle fibers (Table 3.3 and Figure 3.3).

Table 3.3 Myonuclei and satellite cell characteristics

\begin{tabular}{llcc}
\hline \hline & Fiber type & Young & Elderly \\
\hline Nuclei/fiber & Type I & $3.0 \pm 0.2$ & $3.5 \pm 0.2^{*}$ \\
& Type II & $2.3 \pm 0.1^{\dagger}$ & $2.6 \pm 0 . *^{\dagger}$ \\
\cline { 2 - 4 } Fiber area/nucleus $\left(\mu \mathrm{m}^{2}\right)$ & Type I & $1849 \pm 71$ & $1562 \pm 56^{*}$ \\
& Type II & $2549 \pm 129^{\dagger}$ & $1760 \pm 10 *^{*^{\dagger}}$ \\
\hline $\mathrm{SC} /$ fiber & Type I & $0.071 \pm 0.006$ & $0.082 \pm 0.005$ \\
& Type II & $0.080 \pm 0.007$ & $0.044 \pm 0.003 *^{\dagger}$ \\
\cline { 2 - 4 } $\mathrm{SC} \%$ & Type I & $2.4 \pm 0.1$ & $2.4 \pm 0.2$ \\
& Type II & $2.9 \pm 0.4$ & $1.5 \pm 0.2 *^{\dagger}$ \\
\cline { 2 - 4 } $\mathrm{SC} / \mathrm{mm}^{2}$ & Type I & $12.7 \pm 1.1$ & $13.8 \pm 1.0$ \\
& Type II & $12.6 \pm 0.9$ & $9.7 \pm 1.0 * *^{\dagger}$ \\
\hline \hline
\end{tabular}

Values are means \pm SEM. SC: satellite cells; $\mathrm{SC} \%$ : SC proportion (no. of SC/[no. of SC + no. of myonuclei]). *Significantly different compared with the young $(\mathrm{P}<0.05)$. $†$ Significantly different compared with the type I muscle fibers (within groups; $\mathrm{P}<0.05$ ). 


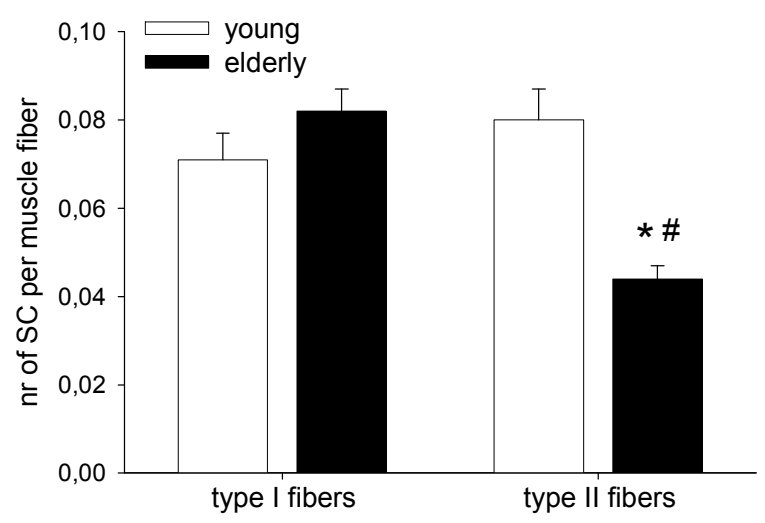

Figure 3.3 Satellite cell (SC) content in type I and II muscle fibers in the young vs the elderly. *Significantly different compared with the young $(\mathrm{P}<0.01)$; \#Significantly different compared with the type I muscle fibers $(\mathrm{P}<0.01)$.

\section{Discussion}

In the present study, we confirm that both the proportion and CSA of the type II skeletal muscle fibers are substantially reduced in skeletal muscle tissue in the elderly. As far as we know, this is the first report that shows that type II muscle fiber atrophy in the elderly is associated with a specific reduction in the number of SC in these fibers. The latter is evident when expressed as number of $\mathrm{SC}$ per muscle fiber, as proportion of $\mathrm{SC}$ relative to the total number of nuclei, or as number of SC per muscle fiber area. This muscle fiber type-specific decline in SC content might represent an important factor in the etiology of sarcopenia.

Numerous studies have demonstrated that the age-related loss of skeletal muscle mass is characterized by a reduction in the total number of muscle fibers and specific atrophy of the type II muscle fibers $(18,29,30,45)$. The decline in maximal strength with age has been attributed to this gradual loss of skeletal muscle tissue, but other intrinsic changes, e.g. fiber type shifts and reduced concentrations of contractile material could also contribute to this phenomenon $(6,12)$. Our data seem to confirm earlier reports $(26,27$, 48) showing a reduced leg volume and muscle strength in the elderly vs the young (Table 3.1). Furthermore, at the muscle level, we observed a significantly higher percentage of type I muscle fibers and the specific atrophy of the type II muscle fibers in the elderly (Table 3.2). These findings are consistent with previous reports $(15,28,45)$ and are likely responsible for the reduced muscle strength in the elderly (Table 3.1).

Even though the changes in muscle fiber type composition and morphology with aging have been described rather consistently in the literature, there is 
still considerable debate on the underlying mechanisms responsible for these changes. It has been suggested that SC content in muscle plays an important role in the age-related changes in skeletal muscle structure and function (44). However, although this topic has received much attention over the past ten years $(10,15,19,20,22,38,40,41,47)$, the exact changes in the SC pool that occur with aging still remain unresolved. Two recent studies have reported a decline in SC content with aging in the tibialis anterior (22) and in the biceps and masseter muscle (38) in humans. In contrast, other studies failed to observe such differences in either SC proportion, or in the number of SC in muscle fibers taken from the vastus lateralis muscle in young vs elderly subjects $(15,20,40)$. The apparent discrepancy between these findings might be attributed to differences in study design, e.g., selection of subjects' age, the number of fibers analyzed and the specific muscle group studied.

So far, studies investigating age-related differences in SC content in human skeletal muscle have been limited to mixed muscle fiber analyses. In contrast to the fiber type-specific differences in SC content that have been consistently shown in rodent muscle $(17,42,44)$, Kadi et al. (23) recently reported no differences in SC content between type I and II muscle fibers in young adults. However, because sarcopenia is associated with the specific atrophy of type II muscle fibers, we hypothesized that fiber type differences in SC content might exist at an older age. Therefore, in the present study, we determined type I and II muscle fiber type-specific SC content in both young and elderly men. In accordance with Kadi et al. (23), we observed 0.075 SC per muscle fiber, with no differences between the type I and II muscle fibers in the young subjects (Table 3.3). Extending their findings and consistent with the specific atrophy of type II muscle fibers with aging, we observed a $44 \pm 6 \%$ lower SC content in the type II vs type I muscle fibers in the elderly. Furthermore, SC content in the type II muscle fibers in the elderly was significantly lower when compared with type II muscle fiber SC content in the young (Table 3.3, Figure 3.3). Notably, even when correcting for fiber CSA, type II muscle fiber SC content was still significantly lower in the elderly vs the young (Table 3.3). These data support the idea that SC content is strongly associated with myofiber maintenance and imply that the age-related reduction in type II muscle fiber SC content might represent an important factor in the specific loss and atrophy of type II muscle fibers with aging.

As stated in the methods section, we used pax7 staining to assess muscle fiber type-specific SC content in skeletal muscle cross-sections. It should be noted that a slight proportion of SC may be pax7-negative in vivo, i.e. those $\mathrm{SC}$ that are progressing into terminal differentiation $(43,50)$. Therefore, we cross-validated our data by double staining with anti-CD56 in a subset of muscle samples. The vast majority of SC was both CD56- and pax7-positive, 
with no differences between the young and elderly $(94.9 \%$ vs $96.5 \%$, respectively). As such, the latter could not be responsible for the substantial differences in skeletal muscle fiber SC content between groups.

Findings from several rodent $(7,39,44)$ as well as human studies $(10,25$, 46) suggest that the abundance of SC within skeletal muscle fibers represents an important factor determining the capacity for myofiber maintenance. On the other hand, type II myofiber atrophy and a reduction in SC content might be caused by one and the same phenomenon, e.g. decreased neuronal input (13). In addition, Bonavaud et al. (4), recently reported that myotubes formed by the fusion of human SC from either fast or slow muscle fibers in vitro express both fast and slow $\mathrm{MHC}$ isoforms. This finding would argue against a direct causal link between type II fiber SC loss and atrophy, as the loss of SC could theoretically be compensated for by incorporating SC progeny from type I fibers. However, the latter has yet to be established, and one could argue that in an in vivo situation, where SC progeny generally fuses with already existing fibers, expression of fast $\mathrm{MHC}$ isoforms by SC originating from slow fibers might not occur.

Our data support the idea that SC abundance is an important factor regulating myofiber size. In addition, the reduced SC content in type II fibers in the elderly might attenuate their response to anabolic stimuli, stressing the need for potent interventions for reversing the loss of skeletal muscle mass and function with aging. Nevertheless, a direct causal link between SC loss and myofiber atrophy remains to be established. Furthermore, qualitative changes (e.g. blunted SC activation) likely play another important role in the impaired regenerative capacity of skeletal muscle tissue with aging. As such, endocrine changes as well as changes in the local SC environment with aging might also contribute to the loss of SC due to the prevention of SC self-renewal $(11,14,44)$. At this moment, we can only speculate on the potential causes and clinical relevance of qualitative and quantitative changes in skeletal muscle fiber SC content with aging, and more research is warranted.

In conclusion, this study is the first to show that SC content is specifically reduced in the type II muscle fibers in elderly men. The latter is shown to be evident when SC content is expressed as number of SC per fiber as well as number of SC per fiber area. The fiber type-specific reduction in SC content might represent an important regulatory factor in the loss of skeletal muscle mass, structure and function with aging. 


\section{References}

1. Alberti KG, Zimmet PZ. Definition, diagnosis and classification of diabetes mellitus and its complications. Part 1: diagnosis and classification of diabetes mellitus provisional report of a WHO consultation. Diabet Med 1998;15:539-53.

2. Allen DL, Roy RR, Edgerton VR. Myonuclear domains in muscle adaptation and disease. Muscle Nerve 1999;22:1350-60.

3. Bergstrom J. Percutaneous needle biopsy of skeletal muscle in physiological and clinical research. Scand J Clin Lab Invest 1975;35:609-16.

4. Bonavaud S, Agbulut O, Nizard R, D'Honneur G, Mouly V, Butler-Browne G. A discrepancy resolved: human satellite cells are not preprogrammed to fast and slow lineages. Neuromuscul Disord 2001;11:747-52.

5. Borghouts LB, Schaart G, Hesselink MK, Keizer HA. GLUT-4 expression is not consistently higher in type-1 than in type-2 fibres of rat and human vastus lateralis muscles; an immunohistochemical study. Pflugers Arch 2000;441:351-8.

6. Bottinelli R, Reggiani C. Human skeletal muscle fibres: molecular and functional diversity. Prog Biophys Mol Biol 2000;73:195-262.

7. Brack AS, Bildsoe H, Hughes SM. Evidence that satellite cell decrement contributes to preferential decline in nuclear number from large fibres during murine age-related muscle atrophy. J Cell Sci 2005;118:4813-21.

8. Brooke MH, Kaiser KK. Muscle fiber types: how many and what kind? Arch Neurol 1970;23:369-79.

9. Brooke MH, Kaiser KK. Three "myosin adenosine triphosphatase" systems: the nature of their pH lability and sulfhydryl dependence. J Histochem Cytochem 1970;18:670-2.

10. Charifi N, Kadi F, Feasson L, Denis C. Effects of endurance training on satellite cell frequency in skeletal muscle of old men. Muscle Nerve 2003;28:87-92.

11. Conboy IM, Conboy MJ, Wagers AJ, Girma ER, Weissman IL, Rando TA. Rejuvenation of aged progenitor cells by exposure to a young systemic environment. Nature 2005;433:760-4.

12. D'Antona G, Pellegrino MA, Adami R, et al. The effect of ageing and immobilization on structure and function of human skeletal muscle fibres. J Physiol 2003;552:499-511.

13. Delbono O. Neural control of aging skeletal muscle. Aging Cell 2003;2:21-9.

14. Dhawan J, Rando TA. Stem cells in postnatal myogenesis: molecular mechanisms of satellite cell quiescence, activation and replenishment. Trends Cell Biol 2005;15:66673.

15. Dreyer HC, Blanco CE, Sattler FR, Schroeder ET, Wiswell RA. Satellite cell numbers in young and older men 24 hours after eccentric exercise. Muscle Nerve 2006;33:24253.

16. Fiatarone MA, Marks EC, Ryan ND, Meredith CN, Lipsitz LA, Evans WJ. Highintensity strength training in nonagenarians. Effects on skeletal muscle. Jama 1990;263:3029-34.

17. Gibson MC, Schultz E. Age-related differences in absolute numbers of skeletal muscle satellite cells. Muscle Nerve 1983;6:574-80.

18. Grimby G. Muscle performance and structure in the elderly as studied cross-sectionally and longitudinally. J Gerontol A Biol Sci Med Sci 1995;50 Spec No:17-22.

19. Hawke TJ, Garry DJ. Myogenic satellite cells: physiology to molecular biology. J Appl Physiol 2001;91:534-51.

20. Hikida RS, Walsh S, Barylski N, Campos G, Hagerman FC, Staron RS. Is hypertrophy limited in elderly muscle fibers? A comparison of elderly and young strength-trained men. Basic Appl. Myol. 1998;8:419-427.

21. Jones PR, Pearson J. Anthropometric determination of leg fat and muscle plus bone volumes in young male and female adults. J Physiol 1969;204:63P-66P. 
22. Kadi F, Charifi N, Denis C, Lexell J. Satellite cells and myonuclei in young and elderly women and men. Muscle Nerve 2004;29:120-7.

23. Kadi F, Charifi N, Henriksson J. The number of satellite cells in slow and fast fibres from human vastus lateralis muscle. Histochem Cell Biol 2006;126:83-7.

24. Kadi F, Schjerling P, Andersen LL, et al. The effects of heavy resistance training and detraining on satellite cells in human skeletal muscles. J Physiol 2004;558:1005-12.

25. Kadi F, Thornell LE. Concomitant increases in myonuclear and satellite cell content in female trapezius muscle following strength training. Histochem Cell Biol 2000;113:99103.

26. Kim JS, Cross JM, Bamman MM. Impact of resistance loading on myostatin expression and cell cycle regulation in young and older men and women. Am J Physiol Endocrinol Metab 2005;288:E1110-9.

27. Klitgaard H, Mantoni M, Schiaffino S, et al. Function, morphology and protein expression of ageing skeletal muscle: a cross-sectional study of elderly men with different training backgrounds. Acta Physiol Scand 1990;140:41-54.

28. Larsson L, Sjodin B, Karlsson J. Histochemical and biochemical changes in human skeletal muscle with age in sedentary males, age 22--65 years. Acta Physiol Scand 1978;103:31-9.

29. Lexell J. Human aging, muscle mass, and fiber type composition. J Gerontol A Biol Sci Med Sci 1995;50 Spec No:11-6.

30. Lexell J, Taylor CC, Sjostrom M. What is the cause of the ageing atrophy? Total number, size and proportion of different fiber types studied in whole vastus lateralis muscle from 15- to 83-year-old men. J Neurol Sci 1988;84:275-94.

31. Matthews DR, Hosker JP, Rudenski AS, Naylor BA, Treacher DF, Turner RC. Homeostasis model assessment: insulin resistance and beta-cell function from fasting plasma glucose and insulin concentrations in man. Diabetologia 1985;28:412-9.

32. Mauro A. Satellite cell of skeletal muscle fibers. J Biophys Biochem Cytol 1961;9:4935.

33. Mayhew JL, Prinster JL, Ware JS, Zimmer DL, Arabas JR, Bemben MG. Muscular endurance repetitions to predict bench press strength in men of different training levels. J Sports Med Phys Fitness 1995;35:108-13.

34. Moss FP, Leblond CP. Nature of dividing nuclei in skeletal muscle of growing rats. J Cell Biol 1970;44:459-62.

35. Moss FP, Leblond CP. Satellite cells as the source of nuclei in muscles of growing rats. Anat Rec 1971;170:421-35.

36. Rantanen T, Avlund K, Suominen H, Schroll M, Frandin K, Pertti E. Muscle strength as a predictor of onset of ADL dependence in people aged 75 years. Aging Clin Exp Res 2002;14:10-5.

37. Reimann J, Brimah K, Schroder R, Wernig A, Beauchamp JR, Partridge TA. Pax7 distribution in human skeletal muscle biopsies and myogenic tissue cultures. Cell Tissue Res 2004;315:233-42.

38. Renault V, Thornell LE, Eriksson PO, Butler-Browne G, Mouly V. Regenerative potential of human skeletal muscle during aging. Aging Cell 2002;1:132-9.

39. Rosenblatt JD, Yong D, Parry DJ. Satellite cell activity is required for hypertrophy of overloaded adult rat muscle. Muscle Nerve 1994;17:608-13.

40. Roth SM, Martel GF, Ivey FM, et al. Skeletal muscle satellite cell populations in healthy young and older men and women. Anat Rec 2000;260:351-8.

41. Roth SM, Martel GF, Ivey FM, et al. Skeletal muscle satellite cell characteristics in young and older men and women after heavy resistance strength training. J Gerontol A Biol Sci Med Sci 2001;56:B240-7.

42. Schmalbruch $\mathrm{H}$, Hellhammer $\mathrm{U}$. The number of nuclei in adult rat muscles with special reference to satellite cells. Anat Rec 1977;189:169-75. 
43. Seale P, Sabourin LA, Girgis-Gabardo A, Mansouri A, Gruss P, Rudnicki MA. Pax7 is required for the specification of myogenic satellite cells. Cell 2000;102:777-86.

44. Shefer G, Van de Mark DP, Richardson JB, Yablonka-Reuveni Z. Satellite-cell pool size does matter: Defining the myogenic potency of aging skeletal muscle. Dev Biol 2006;294:50-66.

45. Singh MA, Ding W, Manfredi TJ, et al. Insulin-like growth factor I in skeletal muscle after weight-lifting exercise in frail elders. Am J Physiol 1999;277:E135-43.

46. Sinha-Hikim I, Roth SM, Lee MI, Bhasin S. Testosterone-induced muscle hypertrophy is associated with an increase in satellite cell number in healthy, young men. Am J Physiol Endocrinol Metab 2003;285:E197-205.

47. Thornell LE, Lindstrom M, Renault V, Mouly V, Butler-Browne GS. Satellite cells and training in the elderly. Scand J Med Sci Sports 2003;13:48-55.

48. Volpi E, Sheffield-Moore M, Rasmussen BB, Wolfe RR. Basal muscle amino acid kinetics and protein synthesis in healthy young and older men. Jama 2001;286:1206-12.

49. Wolfson L, Judge J, Whipple R, King M. Strength is a major factor in balance, gait, and the occurrence of falls. J Gerontol A Biol Sci Med Sci 1995;50 Spec No:64-7.

50. Zammit PS, Golding JP, Nagata Y, Hudon V, Partridge TA, Beauchamp JR. Muscle satellite cells adopt divergent fates: a mechanism for self-renewal? J Cell Biol 2004;166:347-57. 



\section{Chapter 4}

\section{Muscle fiber type characteristics are predictive of skeletal muscle mass and strength in healthy, elderly males}

Lex B. Verdijk, Tim Snijders, Milou Beelen, Hans H.C.M. Savelberg, Kenneth Meijer, Harm Kuipers, and Luc J.C. van Loon

Submitted 


\begin{abstract}
Objective: To investigate the relationship between skeletal muscle fiber type characteristics, circulating hormone concentrations, and skeletal muscle mass and strength in the elderly. Design: Cross-sectional analyses. Setting: University research centre. Participants: Forty-one healthy, communitydwelling, elderly males (>65 y). Measurements: Leg strength (1-RM) and whole-body and limb muscle mass (DXA-CT) were determined and muscle fiber type composition, cross-sectional area (CSA), myonuclear content, and satellite cell content were assessed in skeletal muscle biopsy samples. In addition, blood samples were collected to determine serum testosterone, sex hormone binding globulin, growth hormone, insulin like growth factor (IGF)-1, and IGF binding protein-3 concentrations. Results: Muscle mass (DXA-CT) correlated with muscle strength $(0.41 \leq r \leq 0.72 ; \mathrm{P}<0.01)$. Muscle fiber CSA, myonuclear content, and satellite cell content were significantly lower in type II vs type I muscle fibers. Myonuclear and satellite cell content were positively correlated with muscle fiber CSA. Furthermore, greater muscle fiber CSA (type I and II) was associated with greater thigh muscle area and muscle strength $(0.30 \leq r \leq 0.45 ; \mathrm{P}<0.05)$. Testosterone concentration was positively correlated with muscle mass and muscle fiber CSA. Conclusion: Skeletal muscle mass and strength in elderly men are associated with muscle fiber type-specific changes in CSA, myonuclear content and satellite cell content. These findings support the assumption that a decline in satellite cell content plays a key role in the age-related decline in muscle mass and strength.
\end{abstract}




\section{Introduction}

Aging is associated with a gradual but progressive loss of skeletal muscle mass and function, termed sarcopenia. The prevalence of sarcopenia is $\sim 25 \%$ beyond the age of $60 \mathrm{y}$, increasing up to $\sim 50 \%$ in subjects aged $80 \mathrm{y}$ and over $(5,23,24)$. In accordance, a $4-11 \%$ decline in muscle volume and cross-sectional area (CSA) has been reported per decade from an age of 20 to $85 \mathrm{y}(12,25,33,34,41)$. Concomitant with the loss of muscle mass, muscle strength declines after the $3^{\text {rd }}$ decade, with a more rapid decline after the $5^{\text {th }}$ decade $(30,34)$. The latter leads to a decline in functional capacity and the subsequent loss of mobility and independence. Therefore, it is imperative to identify key factors relevant to the etiology of sarcopenia.

The etiology of the age-related loss of muscle mass is generally studied in a cross-sectional manner within a large population of individuals with ages ranging from 20-80 y. However, there is little data available on the prevalence of such age-related changes in muscle mass and strength within an elderly population. Some studies have reported that both muscle mass and strength continue to decline after the age of $65 \mathrm{y}(29,43)$. The latter seems consistent with the greater prevalence of sarcopenia in elderly aged $80+$ vs elderly aged $60+(5,23,24)$ and agrees well with longitudinal changes reported previously $(14,17)$. However, there is a large variability in muscle mass and strength within the elderly population that is not necessarily related to age per se (6). Therefore, studying the potential determinants of muscle mass within the elderly population (i.e. independent of age) could provide better insight into the etiological factors of sarcopenia.

Interestingly, leg skeletal muscle mass seems to be the main determinant for leg muscle strength, independent of age $(15,49)$. By comparing elderly vs young subjects, the age-related loss of leg muscle mass has been attributed to a decline in the number of muscle fibers and, more specifically, to type II muscle fiber atrophy $(28,31,33)$. We recently extended on these findings by showing a type II muscle fiber specific decline in satellite cell content in elderly vs young muscle (45). It has been suggested that such an age-related decline in muscle fiber satellite cell content plays a key role in inducing muscle fiber atrophy in the elderly $(20,40)$. The latter would imply that satellite cell content, muscle fiber size, and muscle mass are closely linked, independent of age. Therefore, we hypothesize that within the elderly population, muscle fiber type characteristics are predictive of whole-body and/or limb skeletal muscle mass and strength.

There have been ample suggestions that age-related changes in hormonal profile can strongly modulate skeletal muscle mass and strength in the elderly (27). In accordance, significant correlations have been reported between whole-body lean mass and serum testosterone and IGF-1 concentrations in elderly males $(6,23,50)$. It remains to be assessed whether such serum hormone concentrations are predictive of skeletal muscle mass, 
muscle fiber characteristics, and/or muscle strength in a healthy, elderly population.

In the present study, we investigate determinants of muscle mass and strength within the elderly population. We hypothesize that muscle fiber type characteristics and hormonal profile are predictive of muscle mass and strength within a population of healthy, elderly males, independent of age. Therefore, we assess skeletal muscle characteristics at the whole-body, limb, and muscle fiber level, and determine circulating hormone concentrations in healthy, elderly males.

\section{Methods}

\section{Subjects}

A total of 41 healthy, elderly males (65-86 y) were included in the present study. All subjects participated in different studies that are part of a greater project investigating the clinical benefits of exercise and/or nutritional intervention in the elderly. Medical history of all subjects was evaluated and an oral glucose tolerance test (OGTT) and resting ECG were performed. Subjects with (silent) cardiac or peripheral vascular disease, orthopedic limitations and/or type 2 diabetes (1) were excluded. All subjects were living independently and had no history of participating in any structured exercise training program for at least 5 years. All subjects were informed on the nature and possible risks of the experimental procedures, before their written informed consent was obtained. The study was approved by the Medical Ethics Committee of the Academic Hospital, Maastricht.

\section{Study design}

After inclusion in this study, subjects underwent a series of measurements (outlined below) to determine muscle characteristics at the whole-body, limb, and myocellular level. In addition, fasting blood samples were taken to assess blood glucose homeostasis and hormonal profile.

\section{Dietary intake and physical activity standardization}

Standardized meals (51 kJ/kg body mass; 57 Energy\% (En\%) carbohydrate, $13 \mathrm{En} \%$ protein, and $30 \mathrm{En} \%$ fat) were consumed by all subjects the evening prior to each test day (i.e. muscle biopsy and blood sampling, and DXA-CT scanning). Subjects refrained from strenuous physical activity for 3 days prior to testing. On all test days, subjects arrived at the laboratory by car or public transportation at 8 am and in an overnight fasted state. 


\section{Strength assessment}

Maximum strength was assessed by one-repetition maximum (1-RM) strength tests on leg press and leg extension machines (Technogym, Rotterdam, The Netherlands). During a familiarization trial, proper lifting technique was demonstrated and practiced. Maximum strength was estimated using the multiple repetitions testing procedure (36). In an additional session, at least one week prior to muscle biopsy collection, each subject's 1-RM was determined as described previously (46).

\section{Thigh muscle CSA}

Anatomical cross-sectional area (CSA) of the thigh muscles was assessed by CT scanning (IDT 8000, Philips Medical Systems, The Netherlands), as described previously (44). Scans were performed at mid-thigh level, and images were loaded onto a pc using AGFA IMPAX imaging software, version 5.2 (AGFA Healthcare, Belgium). Muscle area of the right leg was selected between -29 and +150 Hounsfield units (37), after which the quadriceps muscle was selected by manual tracing. Total thigh and quadriceps muscle area were calculated using Lucia 4.81 software (Nikon Instruments Europe, Badhoevedorp, The Netherlands). All analyses were performed by 2 investigators blinded to subject coding; intra-class correlation coefficients for inter- and intra-investigator reliability were 0.997 and 0.998 , respectively.

\section{Body composition}

Directly after CT-scanning, body composition and bone mineral content were measured with dual-energy X-ray absorptiometry (DXA, Lunar Prodigy Advance, GE Healthcare, Madison, WI). The system's software package (enCORE 2005, version 9.15.00) was used to determine wholebody and regional lean and fat mass. DXA scans were performed in a fasted state, after subjects had voided. CV for repetitive scans $(n=4,2$ weeks apart) were $0.4 \%, 1.0 \%$, and $1.1 \%$ for whole-body lean mass, fat mass, and leg lean mass, respectively. Appendicular skeletal muscle mass (ASM) was calculated as the sum of lean mass in the arms and legs (5). In addition, body mass was measured to the nearest $0.1 \mathrm{~kg}$ using an electronic balance scale and height was measured to the nearest $0.1 \mathrm{~cm}$ using a wall mounted stadiometer. To control for the potential confounding effect of body size, all body composition measures were adjusted for knee height (11). Knee height was chosen instead of normal height, because the latter is confounded by age-related disorders affecting the spine, e.g. osteoporosis (39). 


\section{Oral glucose tolerance test}

During screening, a standard oral glucose tolerance test (OGTT) was performed. A fasting blood sample was drawn after which $75 \mathrm{~g}$ glucose (dissolved in $250 \mathrm{~mL}$ water) was ingested. Thereafter, blood was sampled every 30 min until $t=120$ min. Plasma glucose and insulin concentrations were determined and whole-body insulin sensitivity was determined using the oral glucose insulin sensitivity (OGIS)-index (35).

\section{Blood samples}

Fasting blood samples were collected in both EDTA containing tubes and serum tubes. After centrifugation, aliquots of plasma and serum were frozen in liquid nitrogen and stored at $-80^{\circ} \mathrm{C}$. Plasma glucose concentrations were analyzed with a COBAS FARA analyzer (Uni Kit III, Roche, Basel, Switzerland). Insulin concentration was analyzed by RIA (Insulin RIA Kit, Linco Research Inc., St. Charles, MO). Blood HbAlc content ( $3 \mathrm{~mL}$ blood sample, EDTA) was analyzed by high-performance liquid chromatography (Bio-Rad Variant II, Munich, Germany).

Total serum testosterone and sex hormone binding globulin (SHBG) concentrations were measured using reagents from Roche Diagnostics (Mannheim, Germany), and assays were run on a Modular Analytics E170 analyzer (Hitachi Data Systems, Santa Clara, CA). The intra-assay CV's are $2.7-1.8 \%$ and $1.1-1.7 \%$ for low-high concentrations of testosterone and SHBG, respectively. Bio-available testosterone was determined as nonSHBG bound testosterone as described and validated previously (47). IGF-1 was analyzed on a Liaison system (DiaSorin, Brussels, Belgium) with reagentia from DiaSorin. Intra-assay CV's are $2.4-4.4 \%$ for high and low concentrations, respectively. IGF binding protein (BP)-3 was analyzed using a commercially available test kit (Biosource Europe, Nivelles, Belgium) on a Tecan/GENios analyzer (Tecan Group Ltd., Männedorf, Switzerland), with intra-assay CV's of 4-8\%. For human growth hormone (hGH) analysis, reagents came from Beckman Coulter (Fullerton, CA) and assays were run on an Access analyzer (Beckman Coulter). Intra-assay CV's for different concentrations were between $1.5-3.5 \%$.

\section{Muscle biopsy sampling}

Muscle biopsy samples were collected from the right leg, in the morning following an overnight fast. After local anesthesia, percutaneous needle biopsies $(50-80 \mathrm{mg}$ ) were taken from the vastus lateralis muscle, $\sim 15 \mathrm{~cm}$ above the patella (7). Any visible non-muscle tissue was removed immediately, and biopsy samples were embedded in Tissue-Tek (Sakura Finetek, Zoeterwoude, The Netherlands), frozen in liquid nitrogen-cooled isopentane, and stored at $-80^{\circ} \mathrm{C}$. 


\section{Immunohistochemistry}

From all biopsies, $5 \mu \mathrm{m}$ thick cryosections were cut at $-20^{\circ} \mathrm{C}$. Samples from 2 subjects were mounted together on uncoated glass slides. Care was taken to properly align the samples for cross-sectional fiber analyses. Serial crosssections were stained for muscle fiber typing and myocellular satellite cell (SC) content. Details of the analytical procedures have been described previously (44). In short, muscle fiber typing (type I vs II) was determined based on MHC-staining, and a CD56 antibody was used to determine SC content. Laminin was used to visualize the basement membrane and nuclei were stained with DAPI. After staining, all images were digitally captured, using fluorescence microscopy (Nikon Instruments Europe). Image processing and quantitative analyses were done using Lucia 4.81 software package. All image recordings and analyses were performed by an investigator blinded to subject coding. Within each image, the number of fibers, the mean fiber cross-sectional area (CSA), the number of myonuclei per fiber, and the myonuclear domain (i.e. fiber CSA/number of myonuclei) were measured for the type I and type II muscle fibers separately. For the SC slides, fiber typing was determined by matching the serial fiber typing slides. Satellite cells were determined at the periphery of each fiber and stained positive for both DNA (DAPI) and CD56. The number of SC per muscle fiber and the percentage of SC [number of SC/(number of SC + number of myonuclei)*100] were determined for the type I and II muscle fibers separately. A mean total of $338 \pm 24$ muscle fibers, i.e. $178 \pm 14$ type I and $160 \pm 14$ type II muscle fibers, were analyzed for each subject.

\section{Statistics}

All data are presented as means \pm SE. After confirming normality of the data (Kolmogorov-Smirnov test), muscle biopsy data were analyzed for differences between type I and II muscle fibers with paired samples t-tests. Bivariate Pearson's correlation coefficients were calculated to determine the relation between age and all other variables (measured from DXA, CT, muscle biopsy and blood sample analyses). The relation between the various muscle characteristics and between muscle characteristics and hormonal profiles was also determined by calculating bivariate Pearson's correlation coefficients. In addition, partial correlations (adjusting for the effect of age) were calculated, eliminating age as a contributing factor to the correlation. Likewise, the correlation between age and muscle strength was adjusted for the effect of quadriceps muscle area. Differences between the various correlation coefficients were tested for statistical significance (21). All analyses were performed using SPSS version 15.0 (Chicago, IL). An $\alpha$-level of 0.05 was used to determine statistical significance. 


\section{Results}

Subjects' characteristics are provided in Table 4.1. Mean age of the participants was $72 \pm 2$ y (range 65-86 y). All subjects were living independently and had no history of participating in any regular exercise program over the past 5 years. No mobility problems were reported and drug treatment was restricted to mild anti-hypertensive medication. Basal blood glucose concentrations $(5.7 \pm 0.1 \mathrm{mmol} / \mathrm{L})$, blood HbAlc contents $(5.9 \pm 0.1 \%)$, and oral glucose tolerance were within a normal range for healthy, elderly males.

Table 4.1 Subjects' characteristics

\begin{tabular}{lc}
\hline \hline Age $(\mathrm{y})$ & $72 \pm 2$ \\
Body mass $(\mathrm{kg})$ & $80.3 \pm 1.8$ \\
Height $(\mathrm{m})$ & $1.73 \pm 0.01$ \\
BMI $\left(\mathrm{kg} / \mathrm{m}^{2}\right)$ & $27.0 \pm 0.5$ \\
Fasting glucose (mmol/L) & $5.7 \pm 0.1$ \\
HbAlc (\%) & $5.9 \pm 0.1$ \\
OGIS & $366 \pm 10$ \\
Body fat (\%) & $25.4 \pm 1.0$ \\
Lean mass $(\mathrm{kg})$ & $56.1 \pm 0.8$ \\
\hline \hline
\end{tabular}

Data represent means \pm SEM. OGIS: oral glucose insulin sensitivity index (35).

\section{Age-related changes}

For both the leg press and leg extension exercises, muscle strength was negatively correlated with age $(r=-0.41$ and $r=-0.45$, respectively; $\mathrm{P}<0.01)$. Within this elderly population, age did not correlate with whole-body lean mass. However, there was a significant negative correlation between age and regional measures of muscle mass (Table 4.2). The strongest correlation was observed between age and total thigh and quadriceps muscle CSA; $r=-0.55$, and $r=-0.51$, respectively $(\mathrm{P}<0.001)$. Notably, when adjusted for the effect of quadriceps muscle area, the correlation between age and muscle strength disappeared $(r=-0.10$ and $r=-0.14$ for leg press and leg extension, respectively; $\mathrm{P}>0.40$ ).

At the myocellular level, significant differences were observed between type I and II muscle fibers (Table 4.3). Type II muscle fiber cross-sectional area (CSA) was smaller when compared with type I muscle fibers. In addition, both myonuclear and satellite cell content were lower in the type II vs type I muscle fibers. Whereas the percentage type I and II muscle fiber was similar, the percentage type II muscle fiber area was smaller when compared with 
the type I muscle fibers. In contrast to type I muscle fiber CSA, type II muscle fiber CSA correlated significantly with age $(r=-0.26 ; \mathrm{P}<0.05)$.

Table 4.2 Lean body compartments and their correlations with age

\begin{tabular}{lccc}
\hline \hline & mean & $r$ & P-value \\
\hline WB lean mass (kg) & $56.1 \pm 0.8$ & $-0.24 \pm 0.16$ & 0.071 \\
Leg lean mass (kg) & $17.8 \pm 0.3$ & $-0.31 \pm 0.15$ & 0.026 \\
Arm lean mass (kg) & $6.5 \pm 0.1$ & $-0.32 \pm 0.15$ & 0.025 \\
ASM (kg) & $24.3 \pm 0.4$ & $-0.34 \pm 0.15$ & 0.016 \\
Quadriceps CSA $\left(\mathrm{cm}^{2}\right)$ & $73.0 \pm 1.8$ & $-0.51 \pm 0.14$ & $<0.001$ \\
Thigh muscle CSA $\left(\mathrm{cm}^{2}\right)$ & $159.2 \pm 3.0$ & $-0.55 \pm 0.13$ & $<0.001$ \\
\hline \hline
\end{tabular}

Data represent means \pm SEM and Pearson's correlation coefficients $(r) \pm$ SEE. WB: whole body. ASM: appendicular skeletal muscle mass (sum of lean mass in arms and legs). CSA: cross-sectional area.

Table 4.3 Muscle fiber type characteristics

\begin{tabular}{lcc}
\hline \hline & Type I & Type II \\
\hline Fiber \% & $52 \pm 2$ & $48 \pm 2$ \\
$\mathrm{CSA}\left(\mu \mathrm{m}^{2}\right)$ & $6460 \pm 260$ & $5276 \pm 219 *$ \\
$\mathrm{CSA} \%$ & $57 \pm 2$ & $43 \pm 2 *$ \\
Nuclei/fiber & $3.3 \pm 0.1$ & $2.7 \pm 0.1 *$ \\
$\mathrm{CSA} /$ nucleus $\left(\mu \mathrm{m}^{2}\right)$ & $2036 \pm 75$ & $1970 \pm 79$ \\
$\mathrm{SC} /$ fiber & $0.087 \pm 0.004$ & $0.050 \pm 0.003 *$ \\
$\mathrm{SC} \%$ & $2.7 \pm 0.1$ & $1.8 \pm 0.1 *$ \\
\hline \hline
\end{tabular}

Data represent means \pm SEM; CSA: muscle fiber cross-sectional area; CSA\%: \% of total area occupied per fiber type; SC: satellite cell; SC\%: percentage of SC = number of SC /(number of SC + number of myonuclei) x 100\%. *: significantly different compared with type I muscle fibers.

\section{Whole-body, regional, and myocellular characteristics}

All measures of lean mass (i.e. whole-body lean mass, ASM, leg lean mass) and thigh and quadriceps muscle CSA showed positive correlations with each other and with leg extension and leg press strength $(0.41 \leq r \leq 0.72$; $\mathrm{P}<0.01)$. However, correlations between quadriceps CSA and leg extension strength $(r=0.72)$ and between thigh muscle CSA and leg press strength $(r=0.72)$ were most pronounced $(\mathrm{P}<0.001)$. Partial correlation coefficients were calculated to eliminate the potential contributing effects of age. 
Correlation coefficients between muscle mass and strength did not change when adjusted for age.

For both the type I and type II muscle fibers, positive correlations were observed between muscle fiber CSA, myonuclear content, and satellite cell content. Greater muscle fiber CSA was associated with more myonuclei per fiber ( $r=0.56$ for type I and II fibers; $\mathrm{P}<0.001)$, a greater myonuclear domain ( $r=0.41$ for type I fibers, and $r=0.50$ for type II fibers; $\mathrm{P}<0.01$ ), and more satellite cells per muscle fiber ( $r=0.55$ for type I fibers, and $r=0.50$ for type II fibers; $\mathrm{P}<0.05)$. The number of myonuclei per muscle fiber correlated positively with the number of satellite cells per muscle fiber $(r=0.40$ for both type I and II muscle fibers; $\mathrm{P}<0.01$ ).

Both type I and II muscle fiber CSA showed a positive correlation with leg extension strength (Figure 4.1), and with quadriceps CSA, but not with leg press strength. All $r$-values were between 0.30 and 0.45 and correlations tended to be stronger for type II vs type I muscle fibers $(\mathrm{P}<0.10)$. Adjusting for age did not modulate any of the correlations.



Figure 4.1 Scatter plot for the correlation of type I (filled circles) and type II (open circles) muscle fiber cross-sectional area (CSA) with one-repetition maximum (1-RM) leg extension strength. Lines represent the fitted regression. Pearson's correlation coefficient tended to be stronger $(\mathrm{P}=0.06)$ for type II (dashed line, $r=0.45 ; \mathrm{P}<0.01$ ) vs type I muscle fibers (solid line, $r=0.33 ; \mathrm{P}<0.05)$.

\section{Hormonal profiles and muscle characteristics}

Higher total testosterone concentrations correlated with higher serum SHBG and hGH concentrations. Bio-available testosterone concentrations correlated positively with hGH and IGF-1. In addition, positive correlations were observed between SHBG and hGH, and between IGF-1 and IGF-BP3 concentrations (all $r$-values between 0.27 and $0.52 ; \mathrm{P}<0.05$ ). 
Higher levels of bio-available testosterone were associated with greater $\operatorname{ASM}(r=0.26 ; \mathrm{P}<0.05)$, and greater muscle mass measured by CT $(r=0.27$; $\mathrm{P}<0.05$ ). In addition, type I and type II muscle fiber CSA were greater with higher concentrations of bio-available testosterone expressed as a percentage of total testosterone. However, the latter correlation was only significant for the type II muscle fibers $(r=0.30 ; \mathrm{P}<0.05)$ and did not reach statistical significance for the type I fibers $(r=0.23 ; \mathrm{P}<0.07)$. Furthermore, higher bioavailable testosterone levels were associated with a larger percentage of fiber area occupied by type II muscle fibers $(r=0.31 ; \mathrm{P}<0.05)$. Fat mass was negatively correlated with total testosterone, bio-available testosterone, and SHBG concentrations ( $r=-0.52,-0.25$, and -0.35 , respectively; $\mathrm{P}<0.05$ ).

\section{Discussion}

The present study shows that muscle fiber type characteristics and bioavailable testosterone concentrations are predictive of whole-body and/or limb skeletal muscle mass and strength in healthy, elderly males. Our findings provide further support to the idea that a decline in satellite cell content plays a key role in the loss of muscle mass and strength in the elderly.

Skeletal muscle mass correlated strongly with muscle strength in this healthy, elderly population, with the strongest correlation observed for muscle CSA measured by CT scans. These findings are consistent with previous studies $(6,14,15)$ and confirm that the loss of muscle mass is a major determinant of muscle weakness and functional impairment in the elderly $(13,49)$. The relation between muscle mass and strength has generally been assessed at the whole-body level and/or for specific muscle groups. Furthermore, we (45) as well as others $(4,20,40)$ have suggested a link between the age-related loss of muscle mass and the age-related decline in muscle fiber size, myonuclear content, and/or satellite cell content. Although differences in skeletal muscle characteristics between young and elderly subjects are well-established, it remains to be determined whether the proposed age-related changes in muscle fiber characteristics are predictive for the actual amount of muscle mass and strength at a more advanced age. Therefore, we compared skeletal muscle fiber type characteristics with whole-body and limb muscle mass and strength within a large group of healthy, elderly males.

Type II muscle fiber CSA was shown to be reduced when compared with type I muscle fiber CSA (Table 4.2). In addition, both myonuclear and satellite cell content were reduced in the type II vs type I muscle fibers. These data are in line with previous studies from our laboratory $(44,45)$ and others $(31,33,48)$. Interestingly, both type I and type II muscle fiber satellite cell and myonuclear content were positively correlated with muscle fiber CSA. The relation between myofiber size and myonuclear content has been 
attributed to the myonuclear domain theory $(3,10)$, which suggests that the ratio between cytoplasmic volume and the number of myonuclei remains relatively constant. Thus, large muscle fibers contain more myonuclei than small muscle fibers $(2,26)$. Moreover, a decline in myonuclear content will eventually result in muscle fiber atrophy $(2,9)$. It has been proposed that a decline in satellite cell content with aging results in a decreased capacity for myofiber maintenance (40) and a decline in the number of myonuclei (9). The observation that a reduced satellite cell content is associated with smaller muscle fiber CSA supports the idea that skeletal muscle satellite cells play a key role in the maintenance of muscle fiber size. The latter is further strengthened by the observation that the lower type II muscle fiber satellite cell content was associated with a reduced type II muscle fiber size when compared with the type I muscle fibers (Table 4.2).

Apart from its relation with myonuclear and satellite cell content, muscle fiber size (CSA) correlated well with muscle mass and strength measured at the whole-body and/or limb level. Previous studies, with subjects selected over a wide age range (18-80 y), report similar correlations between strength and type I and II (30) or merely type II muscle fiber size (22). We extend on these findings by showing that independently of age, reduced type I and II muscle fiber size is associated with a lower quadriceps CSA and reduced leg strength within an elderly, male population. Notably, the correlation between muscle fiber size and muscle strength tended to be stronger for the type II vs type I muscle fibers (Figure 4.1). The latter is likely attributed to the observation that type II muscle fibers are stronger than type I muscle fibers, even after adjusting for muscle fiber size (16). As such, specific type II muscle fiber atrophy as observed with aging seems to cause muscle weakness from a quantitative (loss of muscle fiber area), as well as a qualitative perspective (relative increase of type I muscle fiber area). Besides type II muscle fiber atrophy, other (qualitative) changes likely contribute to the variability in muscle mass and strength within the elderly population. Increased intramuscular lipid and/or connective tissue content (19, 32), decreased neural function (12), and decreased level of physical activity (6, 12) have been associated with a reduced muscle mass and strength. However, these aspects were not specifically addressed in the present study. Nonetheless, the present findings show that muscle fiber size represents a key factor in determining skeletal muscle mass and strength in the elderly. Furthermore, satellite cell content is closely related to myonuclear content and predictive of muscle fiber size. We speculate that the muscle fiber typespecific decline in satellite cell content observed with aging represents a key factor in the gradual loss of muscle mass and strength with aging.

Animal studies have shown that muscle fiber hypertrophy in response to exercise training is preceded by an increase in muscle fiber satellite cell content (3). In accordance, we recently reported that type II muscle fiber 
hypertrophy following prolonged resistance type exercise training is associated with an increase in type II muscle fiber satellite cell content in healthy, elderly males (44). Furthermore, it has recently been suggested that muscle fiber hypertrophy following exercise is dependent on the size of the satellite cell pool prior to intervention (38). These findings confirm the significance of satellite cells in facilitating skeletal muscle fiber hypertrophy. As such, satellite cell content seems to represent an important diagnostic target when evaluating exercise, nutritional and/or pharmaceutical intervention strategies to improve skeletal muscle mass and strength in the elderly.

Age-related changes in sex hormones and the growth hormone/IGF-1 axis have been suggested to be associated with the loss of muscle mass with aging $(6,23,50)$. However, to what extent relations exist between hormonal profile and muscle fiber type characteristics within the elderly population remains to be determined. We observed a positive correlation between bioavailable testosterone levels and muscle mass (CT, DXA) and muscle fiber size. Furthermore, serum testosterone concentrations were negatively correlated with fat mass. These findings seem to be in line with previous work showing an increase in satellite cell content, myonuclear content and muscle fiber size (42) and a decrease in fat mass (8) after prolonged testosterone supplementation in elderly men. Previous studies have also reported positive correlations between $\mathrm{GH} / \mathrm{IGF}-1$ and muscle mass $(6,50)$. In the present study though, none of the hormones of the GH/IGF-1 axis showed significant correlations with measures of muscle mass and/or muscle fiber size in elderly men. However, the present findings seem to be in line with previous reports showing that GH supplementation generally fails to increase muscle mass and strength in healthy, elderly males (18). It remains to be determined whether other strategies to increase systemic and/or local GH/IGF-1 can prevent and/or reverse the progressive loss of muscle mass and function in the elderly (18).

Obviously, the present cross-sectional analysis does not allow us to define any direct causal relationships. Longitudinal studies are difficult to assess and methodological problems regarding follow-up duration, sample size, and high drop-out rates generally hamper the study outcome. We determined correlations between muscle mass, strength, and muscle fiber characteristics within a large group of healthy, elderly men. The latter allows us to assess whether age-related changes in muscle fiber characteristics are associated with the large variance in muscle mass and strength within the elderly population. This is the first study to show a correlation between satellite cell content, muscle fiber size, and skeletal muscle mass and strength in elderly men. Combined with the findings from recent intervention studies $(38,42$, 44) and in vivo animal experiments $(3,9,40)$, these data imply that satellite cells play a key role in the age-related loss of muscle mass and function. 
In conclusion, muscle fiber size, myonuclear and satellite cell content and bio-available testosterone concentrations are predictive of skeletal muscle mass and strength in healthy, elderly males. Our findings provide further support to the idea that a decline in type II muscle fiber satellite cell content plays a key role in the loss of muscle mass and strength in the elderly.

\section{Acknowledgments}

We thank all volunteers for their enthusiastic participation in this study. This study was partly supported by a grant from The Anna Foundation, Leiden, The Netherlands. 


\section{References}

1. Diagnosis and classification of diabetes mellitus. Diabetes Care 2006;29 Suppl 1:S43-8.

2. Allen DL, Linderman JK, Roy RR, Grindeland RE, Mukku V, Edgerton VR. Growth hormone/IGF-I and/or resistive exercise maintains myonuclear number in hindlimb unweighted muscles. J Appl Physiol 1997;83:1857-61.

3. Allen DL, Roy RR, Edgerton VR. Myonuclear domains in muscle adaptation and disease. Muscle Nerve 1999;22:1350-60.

4. Alway SE, Siu PM. Nuclear apoptosis contributes to sarcopenia. Exerc Sport Sci Rev 2008;36:51-7.

5. Baumgartner RN, Koehler KM, Gallagher D, et al. Epidemiology of sarcopenia among the elderly in New Mexico. Am J Epidemiol 1998;147:755-63.

6. Baumgartner RN, Waters DL, Gallagher D, Morley JE, Garry PJ. Predictors of skeletal muscle mass in elderly men and women. Mech Ageing Dev 1999;107:123-36.

7. Bergstrom J. Percutaneous needle biopsy of skeletal muscle in physiological and clinical research. Scand J Clin Lab Invest 1975;35:609-16.

8. Bhasin S, Woodhouse L, Casaburi R, et al. Older men are as responsive as young men to the anabolic effects of graded doses of testosterone on the skeletal muscle. J Clin Endocrinol Metab 2005;90:678-88.

9. Brack AS, Bildsoe H, Hughes SM. Evidence that satellite cell decrement contributes to preferential decline in nuclear number from large fibres during murine age-related muscle atrophy. J Cell Sci 2005;118:4813-21.

10. Cheek DB. The control of cell mass and replication. The DNA unit--a personal 20-year study. Early Hum Dev 1985;12:211-39.

11. Chumlea WC, Roche AF, Steinbaugh ML. Estimating stature from knee height for persons 60 to 90 years of age. J Am Geriatr Soc 1985;33:116-20.

12. Doherty TJ. Invited review: Aging and sarcopenia. J Appl Physiol 2003;95:1717-27.

13. Fiatarone MA, Marks EC, Ryan ND, Meredith CN, Lipsitz LA, Evans WJ. Highintensity strength training in nonagenarians. Effects on skeletal muscle. Jama 1990;263:3029-34.

14. Frontera WR, Hughes VA, Fielding RA, Fiatarone MA, Evans WJ, Roubenoff R. Aging of skeletal muscle: a 12-yr longitudinal study. J Appl Physiol 2000;88:1321-6.

15. Frontera WR, Hughes VA, Lutz KJ, Evans WJ. A cross-sectional study of muscle strength and mass in 45- to 78-yr-old men and women. J Appl Physiol 1991;71:644-50.

16. Frontera WR, Suh D, Krivickas LS, Hughes VA, Goldstein R, Roubenoff R. Skeletal muscle fiber quality in older men and women. Am J Physiol Cell Physiol 2000;279:C611-8.

17. Gallagher D, Ruts E, Visser M, et al. Weight stability masks sarcopenia in elderly men and women. Am J Physiol Endocrinol Metab 2000;279:E366-75.

18. Giovannini S, Marzetti E, Borst SE, Leeuwenburgh C. Modulation of GH/IGF-1 axis: Potential strategies to counteract sarcopenia in older adults. Mech Ageing Dev 2008;129:593-601.

19. Goodpaster BH, Carlson CL, Visser M, et al. Attenuation of skeletal muscle and strength in the elderly: The Health ABC Study. J Appl Physiol 2001;90:2157-65.

20. Hawke TJ, Garry DJ. Myogenic satellite cells: physiology to molecular biology. J Appl Physiol 2001;91:534-51.

21. Hinkle DE, Wiersma W, Jurs SG. Applied statistics for the behavioral sciences. 4th ed. Boston, NY: Houghton Mifflin Company, 1998.

22. Hortobagyi T, Zheng D, Weidner M, Lambert NJ, Westbrook S, Houmard JA. The influence of aging on muscle strength and muscle fiber characteristics with special reference to eccentric strength. J Gerontol A Biol Sci Med Sci 1995;50:B399-406. 
23. Iannuzzi-Sucich M, Prestwood KM, Kenny AM. Prevalence of sarcopenia and predictors of skeletal muscle mass in healthy, older men and women. J Gerontol A Biol Sci Med Sci 2002;57:M772-7.

24. Janssen I, Heymsfield SB, Ross R. Low relative skeletal muscle mass (sarcopenia) in older persons is associated with functional impairment and physical disability. J Am Geriatr Soc 2002;50:889-96.

25. Janssen I, Heymsfield SB, Wang ZM, Ross R. Skeletal muscle mass and distribution in 468 men and women aged 18-88 yr. J Appl Physiol 2000;89:81-8.

26. Kadi F, Eriksson A, Holmner S, Butler-Browne GS, Thornell LE. Cellular adaptation of the trapezius muscle in strength-trained athletes. Histochem Cell Biol 1999;111:189-95.

27. Kamel HK, Maas D, Duthie EH, Jr. Role of hormones in the pathogenesis and management of sarcopenia. Drugs Aging 2002;19:865-77.

28. Klitgaard H, Mantoni M, Schiaffino S, et al. Function, morphology and protein expression of ageing skeletal muscle: a cross-sectional study of elderly men with different training backgrounds. Acta Physiol Scand 1990;140:41-54.

29. Kyle UG, Genton L, Hans D, et al. Total body mass, fat mass, fat-free mass, and skeletal muscle in older people: cross-sectional differences in 60 -year-old persons. J Am Geriatr Soc 2001;49:1633-40.

30. Larsson L, Grimby G, Karlsson J. Muscle strength and speed of movement in relation to age and muscle morphology. J Appl Physiol 1979;46:451-6.

31. Larsson L, Sjodin B, Karlsson J. Histochemical and biochemical changes in human skeletal muscle with age in sedentary males, age 22--65 years. Acta Physiol Scand 1978;103:31-9.

32. Lexell J. Human aging, muscle mass, and fiber type composition. J Gerontol A Biol Sci Med Sci 1995;50 Spec No:11-6.

33. Lexell J, Taylor CC, Sjostrom M. What is the cause of the ageing atrophy? Total number, size and proportion of different fiber types studied in whole vastus lateralis muscle from 15- to 83-year-old men. J Neurol Sci 1988;84:275-94.

34. Lindle RS, Metter EJ, Lynch NA, et al. Age and gender comparisons of muscle strength in 654 women and men aged 20-93 yr. J Appl Physiol 1997;83:1581-7.

35. Mari A, Pacini G, Murphy E, Ludvik B, Nolan JJ. A model-based method for assessing insulin sensitivity from the oral glucose tolerance test. Diabetes Care 2001;24:539-48.

36. Mayhew JL, Prinster JL, Ware JS, Zimmer DL, Arabas JR, Bemben MG. Muscular endurance repetitions to predict bench press strength in men of different training levels. J Sports Med Phys Fitness 1995;35:108-13.

37. Mitsiopoulos N, Baumgartner RN, Heymsfield SB, Lyons W, Gallagher D, Ross R. Cadaver validation of skeletal muscle measurement by magnetic resonance imaging and computerized tomography. J Appl Physiol 1998;85:115-22.

38. Petrella JK, Kim JS, Mayhew DL, Cross JM, Bamman MM. Potent myofiber hypertrophy during resistance training in humans is associated with satellite cellmediated myonuclear addition: a cluster analysis. J Appl Physiol 2008;104:1736-42.

39. Roubenoff R, Wilson PW. Advantage of knee height over height as an index of stature in expression of body composition in adults. Am J Clin Nutr 1993;57:609-13.

40. Shefer G, Van de Mark DP, Richardson JB, Yablonka-Reuveni Z. Satellite-cell pool size does matter: Defining the myogenic potency of aging skeletal muscle. Dev Biol 2006;294:50-66.

41. Short KR, Vittone JL, Bigelow ML, et al. Changes in myosin heavy chain mRNA and protein expression in human skeletal muscle with age and endurance exercise training. $\mathrm{J}$ Appl Physiol 2005;99:95-102.

42. Sinha-Hikim I, Cornford M, Gaytan H, Lee ML, Bhasin S. Effects of testosterone supplementation on skeletal muscle fiber hypertrophy and satellite cells in communitydwelling older men. J Clin Endocrinol Metab 2006;91:3024-33. 
43. van den Beld AW, de Jong FH, Grobbee DE, Pols HA, Lamberts SW. Measures of bioavailable serum testosterone and estradiol and their relationships with muscle strength, bone density, and body composition in elderly men. J Clin Endocrinol Metab 2000;85:3276-82.

44. Verdijk LB, Gleeson BG, Jonkers RA, et al. Skeletal muscle hypertrophy following resistance training is accompanied by a fiber type-specific increase in satellite cell content in elderly men. J Gerontol A Biol Sci Med Sci 2009;64:332-9.

45. Verdijk LB, Koopman R, Schaart G, Meijer K, Savelberg HH, van Loon LJ. Satellite cell content is specifically reduced in type II skeletal muscle fibers in the elderly. Am J Physiol Endocrinol Metab 2007;292:E151-7.

46. Verdijk LB, van Loon L, Meijer K, Savelberg HH. One-repetition maximum strength test represents a valid means to assess leg strength in vivo in humans. J Sports Sci 2009;27:59-68.

47. Vermeulen A, Verdonck L, Kaufman JM. A critical evaluation of simple methods for the estimation of free testosterone in serum. J Clin Endocrinol Metab 1999;84:3666-72.

48. Verney J, Kadi F, Charifi N, et al. Effects of combined lower body endurance and upper body resistance training on the satellite cell pool in elderly subjects. Muscle Nerve 2008;38:1147-54.

49. Visser M, Kritchevsky SB, Goodpaster BH, et al. Leg muscle mass and composition in relation to lower extremity performance in men and women aged 70 to 79 : the health, aging and body composition study. J Am Geriatr Soc 2002;50:897-904.

50. Waters DL, Yau CL, Montoya GD, Baumgartner RN. Serum Sex Hormones, IGF-1, and IGFBP3 Exert a Sexually Dimorphic Effect on Lean Body Mass in Aging. J Gerontol A Biol Sci Med Sci 2003;58:648-52. 



\section{Chapter 5}

\section{Skeletal muscle hypertrophy following}

resistance training is accompanied by a fiber type-specific increase in satellite cell content in elderly men

Lex B. Verdijk, Benjamin G. Gleeson, Richard A.M. Jonkers, Kenneth Meijer, Hans H.C.M. Savelberg, Paul Dendale, and Luc J.C. van Loon

The Journals of Gerontology Series A: Biological Sciences and Medical Sciences 2009; 64: 332-339

This is an electronic version of an article published in the Journals of Gerontology, Series A: Biological Sciences and Medical Sciences, 64A(3), 2009, pages 332-339. The published article is available online at: http://biomedgerontology.oxfordjournals.org/cgi/content/full/ gln050?ijkey $=84 V 0 k N R a w X w Z y 6 S \&$ keytype $=$ ref 


\begin{abstract}
We determined muscle fiber type-specific hypertrophy and changes in satellite cell (SC) content following a 12-wk resistance training program in 13 healthy, elderly men $(72 \pm 2 y)$. Leg strength and body composition (DXA and CT) were assessed, and muscle biopsy samples were collected. Leg strength increased $25-30 \%$ after training $(\mathrm{P}<0.001)$. Leg lean mass and quadriceps cross-sectional area increased 6-9\% $(\mathrm{P}<0.001)$. At baseline, mean fiber area and SC content were smaller in the type II vs type I muscle fibers $(\mathrm{P}<0.01)$. Following training, type II muscle fiber area increased from $5438 \pm 319$ to $6982 \pm 503 \mu \mathrm{m}^{2}(\mathrm{P}<0.01)$. Type II muscle fiber SC content increased from $0.048 \pm 0.003$ to $0.084 \pm 0.008 \mathrm{SC} /$ fiber $(\mathrm{P}<0.001)$. No changes were observed in the type I muscle fibers. In the elderly, skeletal muscle tissue is still capable of inducing satellite cell proliferation and differentiation, resulting in type II muscle fiber hypertrophy.
\end{abstract}




\section{Introduction}

Sarcopenia is defined as the gradual decline in skeletal muscle mass and strength with aging. On a myocellular level, sarcopenia is characterized by a reduction in the number of both type I and II muscle fibers (26) and specific type II muscle fiber atrophy $(9,24,26,44)$. In skeletal muscle tissue, satellite cells (SC) are essential for myofiber repair, maintenance and growth $(16,30,33,34)$. As such, an age-related decline in SC number and/or function could play an important role in the etiology of sarcopenia. Previous studies have either shown a similar $(9,18,39,43)$ or lower $(20,38) \mathrm{SC}$ content in the elderly when compared with young adults. Recently, we reported that type II muscle fiber atrophy in the elderly is associated with a specific decline in type II muscle fiber SC content (44). The latter likely explains the discrepant findings in previous studies that only assessed SC content in mixed muscle tissue.

Resistance type exercise training has been shown to represent an effective interventional strategy to augment muscle mass, strength, and function in the elderly $(4,13,15,23,29,42)$. Previous studies in the elderly have shown that the muscle adaptive response to resistance training is characterized by type II muscle fiber hypertrophy $(4,23,29,42)$. For muscle fiber hypertrophy to occur beyond a certain threshold, the addition of new myonuclei is essential. The latter is facilitated by the proliferation of SC and the differentiation of their progeny into new myonuclei that fuse with existing muscle fibers $(2,33,34)$. Though the exact signaling pathways leading to muscle hypertrophy following resistance type exercise remain to be elucidated, it seems evident that an increase in the number of SC is needed to allow the muscle adaptive response to occur. In accordance, some studies $(27,40)$ have reported an upregulation of the number of SC in mixed muscle tissue following exercise training in the elderly. However, others have failed to confirm these findings $(18,36)$. The apparent discrepancy in the literature is likely attributed to the lack of fiber type-specific data on this topic. We hypothesized that resistance type exercise training in the elderly increases SC content in a fiber type-specific manner, thereby allowing type II muscle fiber hypertrophy.

The present study aims to assess the impact of a 3 month resistance type exercise training program on muscle strength, body composition and muscle fiber type-specific characteristics in healthy, elderly men. Skeletal muscle biopsies were collected before and after completion of the exercise intervention program to determine the impact of resistance type exercise training on muscle fiber type-specific hypertrophy, myonuclei and satellite cell content in the elderly. 


\section{Methods}

\section{Subjects}

A total of 14 healthy elderly men (65-85 y) volunteered to participate in a 12 wk resistance type exercise intervention program (3 sessions/wk). One subject dropped out during the study because of an acute back problem that occurred during gardening. Medical history of all subjects was evaluated and an oral glucose tolerance test (OGTT) and resting ECG were performed before selection. Exclusion criteria were defined that would preclude successful participation in the exercise program, and included (silent) cardiac or peripheral vascular disease, orthopedic limitations and/or type 2 diabetes (1). The latter was used as an exclusion criterion as insulin resistance and/or type 2 diabetes can strongly impact the process of muscle mass loss with aging (35). All subjects were living independently and had not participated in any structured exercise training program over the past 5 years.

All subjects were informed on the nature and possible risks of the experimental procedures, before their written informed consent was obtained. All procedures were performed according to the Declaration of Helsinki and the study was approved by the Medical Ethics Committee of the Academic Hospital, Maastricht. This study is part of a greater project investigating the clinical benefits of exercise intervention in the elderly.

\section{Study design}

After screening, all eligible subjects were enrolled in a $12 \mathrm{wk}$ resistance type exercise intervention program. Before, during and after the exercise intervention, anthropometric measurements (height, body mass, leg volume (19)), strength assessments, CT- and DXA-scans were performed and muscle biopsies, blood samples, and dietary intake records were collected.

\section{Dietary intake and physical activity standardization}

Standardized meals ( 4.0 MJ: 57 Energy\% carbohydrate, 30 En\% fat, and 13 En\% protein) were provided to all subjects prior to each test day and subjects were instructed to refrain from strenuous physical activity for 3 days prior to testing. Dietary intake was recorded for 2 days prior to muscle biopsy and blood sample collection. These records were used to standardize food intake prior to muscle biopsy and blood sampling 4 days after cessation of the exercise intervention program. On all test days, subjects arrived at the laboratory by car or public transportation, following an overnight fast. The latter was confirmed by dietary intake records and further verified by the assessment of basal blood glucose and insulin concentrations and blood lipid profile. To assess potential changes in daily food intake that might had 
occurred during the intervention period, subjects recorded 3-day weighted dietary records (Thursday-Saturday), prior to the onset of the intervention program and in week 11 of the exercise intervention. Food intake records were analyzed with Eetmeter software 2005, version 1.4.0 (Voedingscentrum, The Hague, The Netherlands).

\section{Strength assessment}

Maximum strength was assessed by means of one-repetition maximum (1RM) strength tests on regular leg press and leg extension machines (Technogym, Rotterdam, The Netherlands). During a familiarization trial, proper lifting technique was demonstrated and practiced and maximum strength was estimated using the multiple repetitions testing procedure (31). In an additional session, at least one week before muscle biopsy collection, each subject's 1RM was determined as described previously (44). 1RM tests were repeated following 4 and 8 wks of intervention and after cessation of the intervention program, 2 days after the last exercise session.

\section{Exercise intervention program}

Supervised resistance type exercise training was performed 3 times a week for a period of 12 wks. Training consisted of 5 min of warming-up on a cycle ergometer, followed by 4 sets on both the leg press and leg extension machines, and a 5 min cooling-down period on the cycle ergometer. During the first 4 wks of training, the workload was increased from $60 \%$ of $1 \mathrm{RM}$ (10-15 repetitions in each set) to $75 \%$ of 1 RM (8-10 repetitions). Starting at week 5, 4 sets of 8 repetitions were performed at $75-80 \%$ of 1RM on each machine. Resting periods of 1.5 and $3 \mathrm{~min}$ were allowed between sets and exercises, respectively. Workload intensity was adjusted based on the 1RM tests (week 4 and 8). In addition, workload was increased if more than 8 repetitions could be performed in 3 out of 4 sets. Exercise sessions were always performed in the morning, at the same time of day. Subjects used breakfast $1.5 \mathrm{~h}$ before each exercise session, and lunch $2 \mathrm{~h}$ after each session. On average, subjects attended $35 \pm 1$ of the 36 scheduled exercise sessions.

\section{CT-scans}

Anatomical cross-sectional area (CSA) of the quadriceps muscle was measured with a CT scanner (IDT 8000, Philips Medical Systems, The Netherlands) prior to and after cessation of the exercise intervention program (3 days after strength assessment and prior to muscle biopsy collection). With subjects lying supine, legs extended and their feet secured, a $3 \mathrm{~mm}$ thick axial image (scanning characteristics: $120 \mathrm{kV}, 300 \mathrm{~mA}$, rotation time of $0.75 \mathrm{~s}$, field of view of $500 \mathrm{~mm}$ ) was taken midway between the anterior 
superior iliac spine and the bottom of the patella. The exact scanning position was measured and marked, to be replicated after cessation of the intervention program. Using the described approach we determined the coefficient of variation for repeated scans to be $0.6 \%$. Images were loaded onto a PC using AGFA IMPAX imaging software, version 5.2 (AGFA Healthcare, Belgium). Muscle area of the right leg was selected between -29 and +150 Hounsfield units (32), after which the quadriceps muscle was selected by manual tracing. Quadriceps CSA was calculated using Lucia 4.81 software (Nikon Instruments Europe, Badhoevedorp, The Netherlands). All analyses were performed by 2 investigators blinded to subject coding; intraclass correlation coefficients for inter- and intra-investigator reliability were 0.997 and 0.998 , respectively.

\section{DXA-scans}

Directly after CT-scanning, body composition and bone mineral content were measured with dual-energy X-ray absorptiometry (DXA, Lunar Prodigy Advance, GE Healthcare, Madison, WI). Whole-body and regional lean mass, fat mass and bone mineral content were determined using the system's software package enCORE 2005 (version 9.15.00).

\section{Blood samples}

To determine glucose homeostasis and exclude insulin resistant and/or diabetic subjects, fasting blood samples were collected prior to the intervention, and 4 days after the strength assessment performed after completion of the exercise program. Blood samples were collected in EDTA containing tubes and centrifuged at $1000 \mathrm{~g}$ and $4^{\circ} \mathrm{C}$ for $10 \mathrm{~min}$. Aliquots of plasma were frozen in liquid nitrogen and stored at $-80^{\circ} \mathrm{C}$. Plasma samples were analyzed for glucose (COBAS FARA, Uni Kit III, Roche, Basel, Switzerland) and insulin concentrations (Insulin RIA Kit, LINCO Research INC., St. Charles, MO). Blood HbA1c content ( $3 \mathrm{~mL}$ blood sample, EDTA) was analyzed by high-performance liquid chromatography (Bio-Rad Variant II, Munich, Germany). Plasma glucose and insulin concentrations from the OGTT were used to estimate whole-body insulin sensitivity using the oral glucose insulin sensitivity (OGIS)-index (28).

\section{Muscle biopsies}

3 days prior to the onset of exercise training and 4 days after the postintervention strength assessment, muscle biopsy samples were taken from the right leg of each subject, in the morning after an overnight fast. After local anesthesia, percutaneous needle biopsies $(50-80 \mathrm{mg})$ were taken from the vastus lateralis muscle, $\sim 15 \mathrm{~cm}$ above the patella (3). The post training biopsy was performed $\sim 1 \mathrm{~cm}$ proximal to the pre training biopsy, at the same 
depth. Any visible non-muscle tissue was removed from the biopsy samples, which were then embedded in Tissue-Tek (Sakura Finetek, Zoeterwoude, The Netherlands), immediately frozen in liquid nitrogen-cooled isopentane, and stored at $-80^{\circ} \mathrm{C}$ until further analyses.

\section{Immunohistochemistry}

From all biopsies, $5 \mu \mathrm{m}$ thick cryosections were cut at $-20^{\circ} \mathrm{C}$. Pre- and postintervention samples from one subject were mounted together on uncoated glass slides. Care was taken to properly align the samples for cross-sectional fiber analyses. Serial cross-sections were stained for muscle fiber typing (FT) and myocellular satellite cell (SC) content as described previously (22, 44). First antibodies used are directed against MHC-I (A4.951, Developmental Studies Hybridoma Bank [DSHB], Iowa City, IA; dilution 1:20), laminin (polyclonal rabbit anti-laminin; Sigma, Zwijndrecht, The Netherlands; dilution 1:50) and CD56 (BD biosciences, San Jose, CA; dilution 1:40). The latter antibody has been extensively used for SC determination in human muscle tissue $(5,9,20,21,27,36)$. Appropriate secondary antibodies were applied: goat anti-mouse IgG1 AlexaFluor488, goat anti-rabbit IgG AlexaFluor555 (Molecular Probes, Invitrogen, Breda, The Netherlands; dilution 1:500 and 1:200, respectively) and Avidin-D (Vector Laboratories Inc., Burlingame, CA; dilution 1:333), respectively. Nuclei were stained with 4-,6-diamidino-2-phenylindole (DAPI; Molecular Probes; $0.238 \mu \mathrm{M}$ ). Staining procedures were as follows. After fixation (5 min acetone), slides were air-dried and incubated for $60 \mathrm{~min}$ at room temperature with primary antibodies directed against laminin and either MHC-I or CD56, diluted in $0.05 \%$ Tween-PBS. Slides were then washed (3*5 min PBS). Slides for FT were then incubated for $30 \mathrm{~min}$ at room temperature with the appropriate secondary antibodies, diluted together with DAPI in $0.05 \%$ Tween-PBS. For optimizing the staining result, slides for SC were first incubated for $30 \mathrm{~min}$ with biotinylated horse anti-mouse IgG (Vector; dilution 1:150), diluted in PBS. After another washing step with PBS, SC slides were then incubated for $10 \mathrm{~min}$ with the secondary antibodies, diluted together with DAPI in $0.05 \%$ Tween-PBS. After a final washing step, all slides were mounted with cover glasses using Mowiol (Calbiochem, Amsterdam, The Netherlands). Staining procedures resulted in laminin stained in red, nuclei in blue, and either MHC-I or CD56 in green (Figure 5.1).

All images were digitally captured, using fluorescence microscopy with a Nikon E800 fluorescence microscope (Nikon Instruments Europe) coupled to a Basler A113 C progressive scan color CCD camera with a Bayer color filter. Epifluorescence signal was recorded using a Texas Red excitation filter (540-580 nm) for laminin, a DAPI UV excitation filter (340-380 nm) for the nuclei, and a FITC excitation filter (465-495 nm) for either MHC-I 
or CD56. Image processing and quantitative analyses were done using Lucia 4.81 software package, as described previously (44). All image recordings and analyses were performed by an investigator blinded to subject coding.

From the FT slides, images were captured at a 120x magnification. Laminin was used to determine the basement membrane, and all fibers within each image were identified as type I or type II fiber (Figure 5.1). Within each image, the number of fibers, the mean fiber cross-sectional area (CSA), the number of myonuclei per fiber, and the mean fiber area per myonucleus (fiber CSA/no. myonuclei) were measured for the type I and type II muscle fibers separately. To obtain the true number of myonuclei (i.e. not SC nuclei), the number of nuclei was corrected for the number of SC counted on the SC slides. Fiber circularity was calculated as $(4 \pi \cdot \mathrm{CSA}) /(\text { perimeter })^{2}$; all fibers with circularity below 0.60 were excluded from analysis (23). No differences in fiber circularity were observed over time or between fiber types, validating the comparison of pre and post training data on muscle fiber CSA.
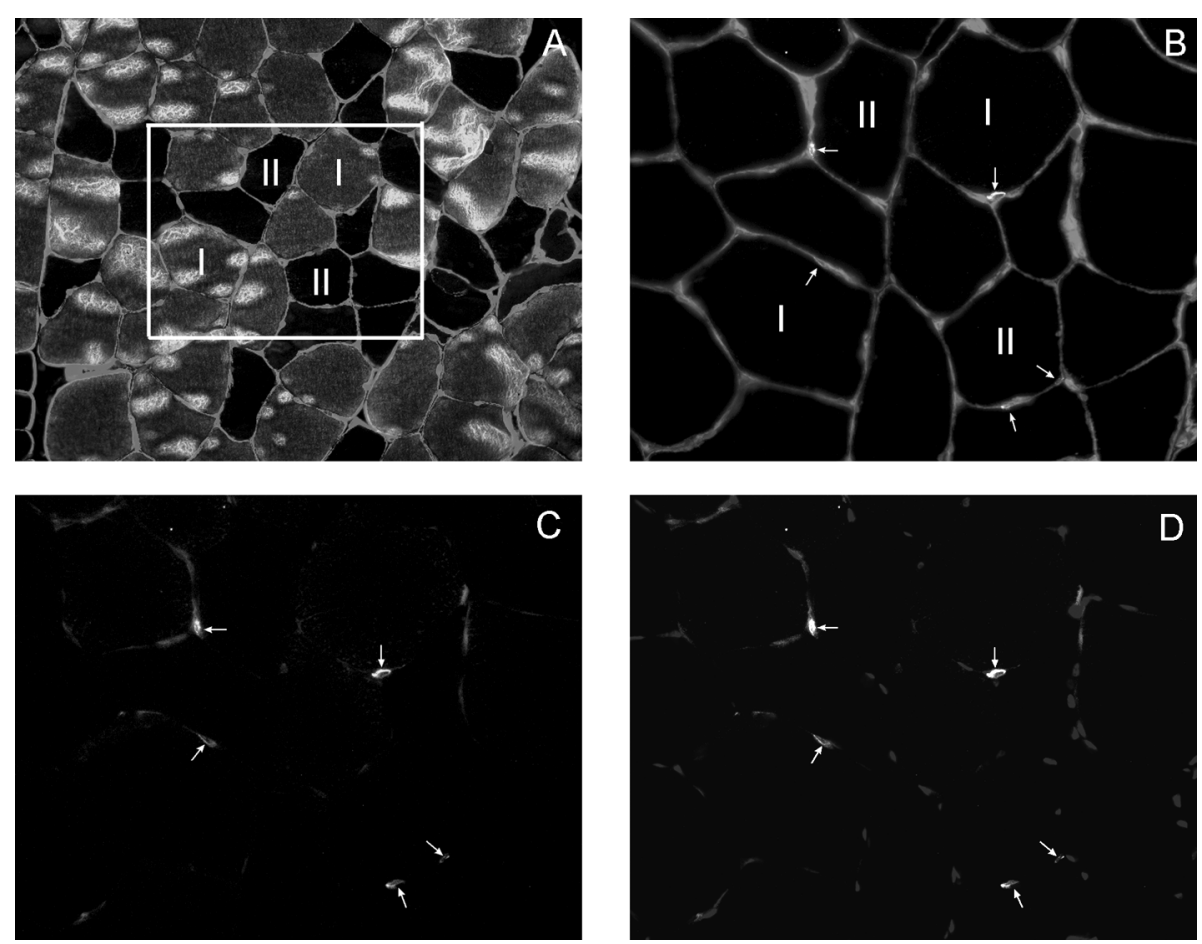

Figure 5.1 Muscle fiber type-specific analysis for satellite cell content. A: MHCI+laminin+DAPI staining from serial cross-section of image B-D; the marked area represents the same area as shown in frame B-D; B: CD56+laminin+DAPI staining; C: CD56 staining; D: CD56+DAPI staining. Arrows indicate the satellite cells. Numbers indicate muscle fiber type I and II. 
From the SC slides, images were captured at a 240x magnification to allow clear determination of SC localization. Laminin was used to visualize cell borders. Fiber typing was determined by matching the serial FT slides. SC were determined at the periphery of each fiber and stained positive for both DNA (DAPI) and CD56 (Figure 5.1). The number of SC per muscle fiber, the percentage of SC [no. SC/(no. SC + no. myonuclei)*100], and the number of SC per fiber area (in $\mathrm{mm}^{2}$ ) were calculated for the type I and type II muscle fibers separately. A mean total of $328 \pm 31$ and $254 \pm 37$ muscle fibers were analyzed in each subjects' pre- and post-intervention biopsy sample, respectively.

\section{Statistics}

All data are expressed as means \pm SEM. Differences between pre- and postintervention values were analyzed with Student's paired t-tests. In addition, 2-way repeated measures ANOVA with time (pre vs post) and fiber type (type I vs type II) as within subjects factors was used to determine training induced changes in muscle fiber type-specific variables. In case of significant interaction, Student's paired t-tests were performed for time effects within type I or type II muscle fiber characteristics, and/or effects of muscle fiber type within the pre- or post-intervention values. All analyses were performed using SPSS version 13.0 (Chicago, IL). An $\alpha$-level of 0.05 was used to determine statistical significance.

\section{Results}

\section{Subjects}

Subjects' characteristics at baseline and after intervention are provided in Table 5.1. Subjects' age averaged $72 \pm 2$ y. Total body mass, height and BMI did not change over the intervention period. Fasting blood glucose and insulin concentrations and $\mathrm{HbAlc}$ contents were within normal range for healthy individuals and did not change over time.

\section{Muscle strength}

Strength (1RM) increased significantly from pre- to post-intervention for both the leg extension and leg press exercises, from $88 \pm 4$ to $111 \pm 5 \mathrm{~kg}$ and $170 \pm 8$ to $210 \pm 10 \mathrm{~kg}$, respectively $(\mathrm{P}<0.001)$. Repeated measures analysis revealed that the increase in $1 \mathrm{RM}$ strength was statistically significant for each 4-wk interval during the intervention period for both exercises (data not shown). 
Table 5.1 Subjects' characteristics

\begin{tabular}{lcc}
\hline \hline & Before & After \\
\hline Body mass (kg) & $80.2 \pm 3.4$ & $80.1 \pm 3.4$ \\
Height $(\mathrm{m})$ & $1.71 \pm 0.01$ & $1.71 \pm 0.01$ \\
BMI $\left(\mathrm{kg} / \mathrm{m}^{2}\right)$ & $27.4 \pm 1.1$ & $27.4 \pm 1.1$ \\
Leg volume (L) & $8.2 \pm 0.5$ & $8.3 \pm 0.5 *$ \\
Glucose $(\mathrm{mmol} / \mathrm{L})$ & $5.6 \pm 0.2$ & $5.5 \pm 0.1$ \\
HbA1c $(\%)$ & $5.8 \pm 0.1$ & $5.7 \pm 0.1$ \\
OGIS $\left(\mathrm{mL} / \mathrm{min} / \mathrm{m}^{2}\right)$ & $368 \pm 22$ & $382 \pm 19$ \\
1RM LE $(\mathrm{kg})$ & $88 \pm 4$ & $111 \pm 5 *$ \\
1RM LP $(\mathrm{kg})$ & $170 \pm 8$ & $210 \pm 10 *$ \\
\hline \hline
\end{tabular}

Data are means \pm SEM; BMI: body mass index; OGIS: oral glucose insulin sensitivity-index (28); 1RM: one-repetition maximum; LE: leg extension; LP: leg press; *: significantly different compared with before the intervention $(\mathrm{P}<0.05)$.

\section{Body composition and muscle mass}

Whole-body lean mass tended to increase throughout the intervention period (from $57.4 \pm 1.6$ to $58.0 \pm 1.7 \mathrm{~kg} ; \mathrm{P}=0.062$ ). Total fat mass decreased significantly $(\mathrm{P}<0.01)$, resulting in a significant decline in whole-body fat percentage $(\mathrm{P}<0.01$; Table 5.2). Leg lean mass increased from $18.3 \pm 0.5$ to $19.3 \pm 0.5 \mathrm{~kg}(\mathrm{P}<0.001)$. In accordance, fat percentage in the legs had also decreased following the exercise intervention $(\mathrm{P}<0.05$; Table 5.2). No changes were observed in whole-body and regional bone mineral content (data not shown).

CT-scans of the upper leg, performed prior to and after the exercise program, revealed a substantial $8.8 \pm 1.4 \%$ increase in quadriceps anatomical CSA following the intervention program, from $75.9 \pm 3.7$ to $82.4 \pm 3.9 \mathrm{~cm}^{2}$ $(\mathrm{P}<0.001)$.

\section{Dietary records}

Analysis of the 3-day dietary records before and after $11 \mathrm{wks}$ of intervention did not show any changes in total daily energy intake ( $9.2 \pm 0.6$ vs $9.1 \pm 0.4$ $\mathrm{MJ} / \mathrm{d}$, respectively). Likewise, macronutrient composition of the diet did not change during the intervention period, and averaged $50 \pm 2,33 \pm 2$ and $17 \pm 1$ Energy $\%$ before intervention and $52 \pm 2,32 \pm 2$ and $16 \pm 1$ Energy\% after 11 wks of intervention, for carbohydrate, fat and protein, respectively. Daily protein intake averaged $1.1 \pm 0.1 \mathrm{~g}$ per kg body mass per day, both before and after 11 wks of intervention. 
Table 5.2 Body composition and muscle mass

\begin{tabular}{lcc}
\hline \hline & Before & After \\
\hline Lean mass $(\mathrm{kg})$ & $57.4 \pm 1.6$ & $58.0 \pm 1.7$ \\
Fat mass $(\mathrm{kg})$ & $19.6 \pm 2.4$ & $19.0 \pm 2.4 *$ \\
Body fat $(\%)$ & $23.6 \pm 2.2$ & $22.9 \pm 2.2 *$ \\
Leg lean mass $(\mathrm{kg})$ & $18.3 \pm 0.5$ & $19.3 \pm 0.5 *$ \\
Leg fat $(\%)$ & $18.9 \pm 2.3$ & $18.3 \pm 2.3 *$ \\
$\mathrm{CSA}\left(\mathrm{cm}^{2}\right)$ & $75.9 \pm 3.7$ & $82.4 \pm 3.9 *$ \\
\hline \hline
\end{tabular}

Data are means \pm SEM; CSA: cross-sectional area of the right quadriceps muscle; *: significantly different compared with before the intervention $(\mathrm{P}<0.05)$.

\section{Muscle fiber type composition and fiber area}

At baseline, the proportion of type I and type II muscle fibers was $47 \pm 4$ and $53 \pm 4 \%$, and the proportion of muscle area occupied by type I and II fibers was $52 \pm 4$ and $48 \pm 4 \%$, respectively. Muscle fiber type percentage, expressed either as fiber number or area occupied by type I and type II muscle fibers, did not show any changes following 3 months of exercise intervention (Table 5.3).

For muscle fiber CSA, a significant 'time $\mathrm{x}$ fiber type' interaction was observed. At baseline, type II muscle fiber CSA was smaller than type I muscle fiber CSA (Table 5.3, $\mathrm{P}<0.01$ ). However, the difference in fiber type CSA was no longer apparent after the intervention period, with a mean type I and II muscle fiber CSA of $6881 \pm 493$ and $6982 \pm 503 \mu \mathrm{m}^{2}$, respectively (Table 5.3). In contrast to the type I fibers, type II muscle fiber CSA significantly increased following exercise intervention from $5438 \pm 319$ to $6982 \pm 503 \mu \mathrm{m}^{2}(\mathrm{P}<0.01)$.

Table 5.3 Muscle fiber type composition

\begin{tabular}{lcccccc}
\hline \hline & \multicolumn{3}{c}{ Before intervention } & \multicolumn{3}{c}{ After intervention } \\
& fiber\% & $\mathrm{CSA}\left(\mu \mathrm{m}^{2}\right)$ & $\mathrm{CSA} \%$ & fiber\% & $\mathrm{CSA}\left(\mu \mathrm{m}^{2}\right)$ & $\mathrm{CSA} \%$ \\
\hline Type I & $47 \pm 4$ & $6635 \pm 354$ & $52 \pm 4$ & $47 \pm 3$ & $6881 \pm 493$ & $46 \pm 3$ \\
Type II & $53 \pm 4$ & $5438 \pm 319^{\dagger}$ & $48 \pm 4$ & $53 \pm 3$ & $6982 \pm 503 *$ & $54 \pm 3$ \\
\hline \hline
\end{tabular}

Data area means \pm SEM; CSA: fiber cross-sectional area; CSA\%: percentage area occupied by muscle fiber type; *: significantly different compared with before the intervention $(\mathrm{P}<0.01)$; ${ }^{\dagger}$ : significantly different compared with the type I muscle fibers $(\mathrm{P}<0.01)$.

\section{Myonuclear and satellite cell content}

At baseline, the number of myonuclei per muscle fiber was higher in the type I vs type II muscle fibers ( $3.6 \pm 0.2$ vs $2.8 \pm 0.2$, respectively; $\mathrm{P}<0.01)$. A 
significant 'time $\mathrm{x}$ fiber type' interaction revealed that after the exercise intervention, differences in myonuclear content were no longer apparent between the type I and II muscle fibers ( $3.4 \pm 0.3$ vs $3.3 \pm 0.8$, respectively). In contrast to the type I fibers, the number of myonuclei per type II muscle fiber tended to increase from $2.8 \pm 0.2$ to $3.3 \pm 0.3$ during the intervention program $(\mathrm{P}=0.091)$. Mean fiber area per myonucleus was similar for the type I and II muscle fibers at baseline, and did not change over time (Table 5.4).

Table 5.4 Myonuclear and satellite cell content

\begin{tabular}{llcc}
\hline \hline & & Before & After \\
\hline No. nuclei per fiber & Type I & $3.6 \pm 0.2$ & $3.4 \pm 0.3$ \\
& Type II & $2.8 \pm 0.2^{\dagger}$ & $3.3 \pm 0.3$ \\
\cline { 2 - 4 } Fiber area per nucleus $\left(\mu \mathrm{m}^{2}\right)$ & Type I & $1918 \pm 133$ & $2096 \pm 118$ \\
& Type II & $2029 \pm 159$ & $2149 \pm 148$ \\
\hline No. SC per fiber & Type I & $0.089 \pm 0.006$ & $0.096 \pm 0.011$ \\
& Type II & $0.048 \pm 0.003^{\dagger}$ & $0.084 \pm 0.008^{*}$ \\
\cline { 2 - 4 } SC \% & Type I & $2.6 \pm 0.3$ & $2.7 \pm 0.3$ \\
& Type II & $1.8 \pm 0.1^{\dagger}$ & $2.6 \pm 0.3 *$ \\
No. SC per mm & Type I & $13.9 \pm 1.2$ & $12.9 \pm 1.2$ \\
& Type II & $9.2 \pm 0.8^{\dagger}$ & $11.9 \pm 0.9 *$ \\
\hline \hline
\end{tabular}

Data are means \pm SEM; $S C$ : satellite cells; $\mathrm{SC} \%$ : number of $\mathrm{SC}$ as a percentage of the total number of nuclei (i.e. no. of myonuclei + no. of SC); Type I-II: type I and II muscle fibers *: significantly different compared with before the intervention $(\mathrm{P}<0.01)$; ${ }^{\dagger}$ : significantly different compared with the type I muscle fibers $(\mathrm{P}<0.01)$.

For all SC variables, significant 'time $\mathrm{x}$ fiber type' interactions were observed. The number of SC per muscle fiber at baseline was lower for the type II fibers compared with the type I fibers $(0.048 \pm 0.003$ vs $0.089 \pm 0.006$, respectively; $\mathrm{P}<0.001)$. For the percentage of $\mathrm{SC}$ and the number of $\mathrm{SC}$ per $\mathrm{mm}^{2}$, analysis also revealed a significantly lower SC content in the type II vs type I fibers at baseline (Table 5.4). In contrast to the type I muscle fibers, significant increases were observed in the type II muscle fiber SC content after 3 months of exercise intervention (Figure 5.2, Table 5.4). The number of SC per type II muscle fiber increased substantially from $0.048 \pm 0.003$ to $0.084 \pm 0.008(\mathrm{P}<0.001)$, the percentage of $\mathrm{SC}$ increased from $1.8 \pm 0.1$ to $2.6 \pm 0.3(\mathrm{P}<0.01)$, and the number of SC per $\mathrm{mm}^{2}$ of type II fiber area increased from $9.2 \pm 0.8$ to $11.9 \pm 0.9(\mathrm{P}<0.01)$. In accordance, after the intervention program, no differences in SC content were observed between the type I and II muscle fibers for any of the SC variables (Figure 5.2, Table 5.4). 


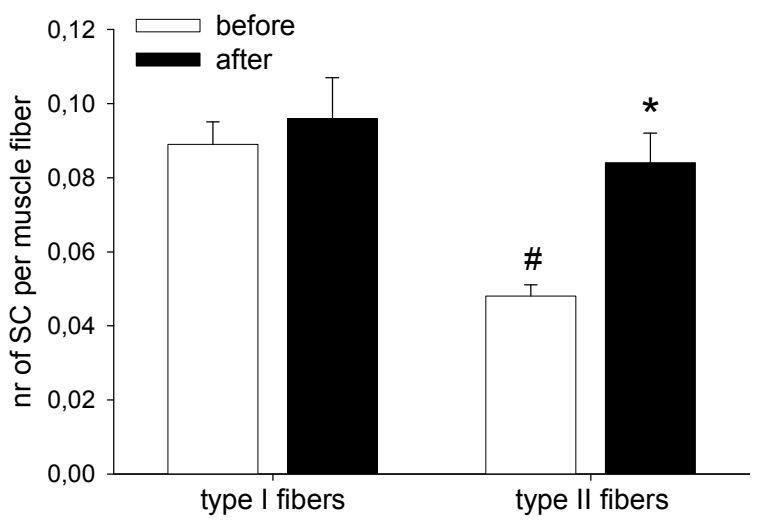

Figure 5.2 Mean number of satellite cells (SC) in the type I and type II muscle fibers before and after the exercise intervention program. \#: significantly different compared with the type I muscle fibers $(\mathrm{P}<0.01)$; *: significantly different compared with before the intervention $(\mathrm{P}<0.01)$.

\section{Discussion}

The present study shows that 3 months of resistance type exercise training augments muscle mass, reduces fat mass, and increases muscle strength in healthy, elderly men. The observed skeletal muscle hypertrophy is shown to be specific for the type II muscle fibers and accompanied by a specific increase in type II muscle fiber SC content.

Aging is associated with the loss of muscle mass, strength and functional capacity $(12,14,25)$. It has been well established that resistance type exercise training represents a feasible and effective interventional strategy to counteract sarcopenia in various elderly populations $(4,11-13,15,17,23$, $27,29,40,42)$. The resistance exercise program implemented in the present study was shown to be feasible, and resulted in a high compliance and adherence rate, with $35 \pm 1$ out of 36 sessions being performed by the subjects. In accordance, we observed $25-30 \%$ improvements in 1RM strength for the LE and LP exercises. This increase in muscle strength is similar to previously published studies $(23,29,40)$. Skeletal muscle strength has been positively correlated with muscle mass and muscle CSA $(12,14)$. In accordance, we observed a concomitant increase in leg lean mass $(6 \pm 1 \%)$


efficacy of the $12 \mathrm{wk}$ exercise program to increase muscle mass and strength in healthy, elderly men.

Previous studies by other groups $(9,24,26)$ as well as from our laboratory (44) have shown that the loss of muscle mass with aging is largely attributed to the specific atrophy of type II muscle fibers. In the present study, we confirm a substantially smaller type II muscle fiber area when compared to 
type I muscle fibers at baseline in the elderly males (Table 5.3). Furthermore, we observed a significantly lower myonuclear and SC content in the type II vs type I muscle fibers prior to intervention (Figure 5.2, Table 5.4). The latter is consistent with our recent findings showing a lower SC content in type II muscle fibers in muscle tissue from elderly versus young men (44). In the present study, no young control group was included, and type II muscle fiber characteristics at baseline could only be compared to type I muscle fibers, which were relatively large in the present study. However, the latter was probably due to the lower fiber circularity as compared with our previous study $(0.71$ vs 0.74 , (44)). In addition, interindividual variability was large in the present study, with fiber size ranging from 3700 to $9000 \mu \mathrm{m}^{2}$. Despite these findings, specific type II muscle fiber atrophy was still apparent when the present data were compared to the young control group in our previous study (44). Moreover, we (44) and others (21) have previously shown that SC content is similar between type I and type II muscle fibers in young adults. Therefore, we argue that the lower fiber size and SC content of the type II vs type I muscle fibers at baseline in the present study are consistent with and indicative of the specific reduction of type II muscle fiber size and SC content with aging. Similar fiber typespecific changes in SC content have also been observed in animal studies (41). These data might suggest a causal relationship between a decline in myonuclear and/or SC content and muscle fiber type-specific atrophy. The lower number of SC might be insufficient to support myofiber maintenance and, as such, contribute to the gradual loss of muscle mass with aging (41). Reduced neuromuscular activity (due to a more sedentary lifestyle and/or functional disability) and/or impaired neuronal input might represent important factors contributing to the age-related decline in myonuclear and SC number and activity, and the associated reduction in muscle fiber size (2, 7). More research is warranted to elucidate the potential role of the decline in type II muscle fiber SC content in the etiology of sarcopenia.

To further investigate the proposed functional relationship between the reduced SC content in the type II versus type I muscle fibers and the accompanying smaller type II muscle fiber size in elderly males, it is of substantial clinical relevance to assess whether strategies that induce muscle fiber hypertrophy are associated with an increase in muscle fiber SC content. This would provide important novel information, offering new targets for the evaluation of effective nutritional, pharmaceutical and/or exercise interventions to combat sarcopenia in the elderly. Resistance type exercise training has been established as an effective therapeutic strategy to induce muscle hypertrophy in the elderly, and has been associated with a more pronounced hypertrophy of the type II muscle fibers $(4,23,29,42)$. The latter is supported by the present findings, as we observed a $28 \pm 6 \%$ increase in type II muscle fiber cross-sectional area following 12 wks of training 
(Table 5.3). Notably, differences in fiber size between type I and II muscle fibers as observed prior to intervention were no longer apparent after completing the exercise intervention program (Table 5.3).

There has been much discrepancy in the literature on the proposed impact of resistance type exercise training on myonuclear and/or SC content in muscle tissue in the elderly $(18,27,36,40)$. The apparent discrepancy is likely attributed to the lack of fiber type-specific data on muscle fiber hypertrophy/atrophy and the associated changes in myonuclear and/or SC content. In the present study, the specific hypertrophy of type II muscle fibers after training was accompanied by a substantial $76 \pm 15 \%$ increase in type II muscle fiber SC content (Figure 5.2, Table 5.4). In addition, the number of myonuclei per type II muscle fiber tended to increase from $2.8 \pm 0.2$ to $3.3 \pm 0.3(\mathrm{P}=0.091)$, while the fiber area per myonucleus was maintained throughout the intervention period $(\mathrm{P}=0.531$; Table 5.4). These findings are in line with the rationale that myofiber hypertrophy is facilitated by increased translational activity of pre-existing myonuclei and/or the incorporation of newly formed myonuclei $(10,37,43)$. Consequently, our findings suggest that the maximum amount of cytoplasm that can be controlled by one myonucleus, referred to as the 'myonuclear domain' ceiling $(6,36)$, was reached during the intervention program. Therefore, SC proliferation and the subsequent incorporation of their differentiated progeny (i.e. newly formed myonuclei) was essential to allow further type II muscle fiber hypertrophy. In that respect, it was surprising that we only observed a tendency towards an increase in type II muscle fiber myonuclear content ( $\mathrm{P}=0.091)$. However, as described by Petrella et al. in their recent paper (37), the myofiber response to an exercise program can be highly variable. By using cluster analysis, the authors reported that subjects with extreme myofiber hypertrophy also showed the largest increases in SC content and both myonuclear number and domain size (37). In accordance, interindividual variability plays an important role in the apparent discrepancy between significant myofiber hypertrophy and non-significant changes in myonuclear content and/or domain as observed in the present and previous studies $(18,36)$. Supposedly, some subjects might have relied more heavily on expansion of the myonuclear domain, whereas most subjects were able to incorporate new myonuclei. In the present study, we observed a nonsignificant $25 \pm 12 \%$ increase in the number of myonuclei per type II muscle fiber. The latter tends to be in line with the $26 \%$ increase observed by Petrella et al. (37). Since only pre- and post-intervention biopsy samples were collected, we can only speculate on the proposed time line between an increase in SC number, the incorporation of new myonuclei, and subsequent muscle fiber hypertrophy. However, in vitro data and rodent studies indicate that an increase in SC number and subsequent incorporation of new myonuclei precedes muscle hypertrophy (reviewed in (2)). 
Considering the large inter-individual variability in the hypertrophy response and the relations between the changes in myofiber size, SC content and myonuclear content, it is interesting to speculate which factors might be responsible for the apparent differential responses. Previous research implicated that the myogenic regulatory factors (myogenin, MyoD, myf-5, MRF4), and various growth agents such as IGF-I, MGF, and HGF play a role in the (load mediated) hypertrophy and in SC activation and/or proliferation and differentiation (reviewed in $(8,16)$ ). However, most data are derived from in vitro and acute in vivo studies and, as such, little is known on the potential role these agents might play in the response to prolonged exercise training. However, as we restricted ourselves to the assessment of the impact of exercise training on muscle fiber characteristics, we can only speculate on this matter.

This is the first study to show that the relatively lower type II muscle fiber size and SC content in the elderly can be specifically enhanced following 3 months of resistance type exercise training. Though the exact signaling pathways leading to SC induced muscle fiber hypertrophy, as well as the reasons for inter-individual response variability in these pathways remain to be elucidated, these findings might open up novel opportunities for evaluating the efficacy of nutritional, pharmaceutical, and/or exercise based interventional strategies to counteract the loss of muscle mass, strength and function with aging.

We conclude that prolonged resistance type exercise training effectively increases muscle mass and strength in healthy, elderly men. The relative type II muscle fiber atrophy and the associated lower satellite cell content in type II versus type I muscle fibers in the elderly can be reversed by prolonged resistance type exercise training. The latter indicates that muscle tissue in the elderly is still capable of inducing satellite cell proliferation, differentiation and fusion of new myonuclei into existing muscle fibers, resulting in type II muscle fiber hypertrophy.

\section{Acknowledgements}

We thank Milou Beelen -dept. of Human Movement Sciences, Maastricht University- for performing muscle biopsies, Luk Corluy -dept. of Rheumatology, Virga Jesse Hospital Hasselt- for performing DXA scans, and Geert Souverijns and Dominic Moermans -dept. of Radiology, Virga Jesse Hospital Hasselt- for performing CT scans. This study was supported by a grant from The Anna Foundation, Leiden, The Netherlands. 


\section{References}

1. Diagnosis and classification of diabetes mellitus. Diabetes Care 2006;29 Suppl 1:S43-8.

2. Allen DL, Roy RR, Edgerton VR. Myonuclear domains in muscle adaptation and disease. Muscle Nerve 1999;22:1350-60.

3. Bergstrom J. Percutaneous needle biopsy of skeletal muscle in physiological and clinical research. Scand J Clin Lab Invest 1975;35:609-16.

4. Charette SL, McEvoy L, Pyka G, et al. Muscle hypertrophy response to resistance training in older women. J Appl Physiol 1991;70:1912-6.

5. Charifi N, Kadi F, Feasson L, Denis C. Effects of endurance training on satellite cell frequency in skeletal muscle of old men. Muscle Nerve 2003;28:87-92.

6. Cheek DB. The control of cell mass and replication. The DNA unit--a personal 20-year study. Early Hum Dev 1985;12:211-39.

7. Delbono O. Neural control of aging skeletal muscle. Aging Cell 2003;2:21-9.

8. Dhawan J, Rando TA. Stem cells in postnatal myogenesis: molecular mechanisms of satellite cell quiescence, activation and replenishment. Trends Cell Biol 2005;15:66673.

9. Dreyer HC, Blanco CE, Sattler FR, Schroeder ET, Wiswell RA. Satellite cell numbers in young and older men 24 hours after eccentric exercise. Muscle Nerve 2006;33:24253.

10. Edgerton VR, Roy RR. Regulation of skeletal muscle fiber size, shape and function. J Biomech 1991;24 Suppl 1:123-33.

11. Esmarck B, Andersen JL, Olsen S, Richter EA, Mizuno M, Kjaer M. Timing of postexercise protein intake is important for muscle hypertrophy with resistance training in elderly humans. J Physiol 2001;535:301-11.

12. Fiatarone MA, Marks EC, Ryan ND, Meredith CN, Lipsitz LA, Evans WJ. Highintensity strength training in nonagenarians. Effects on skeletal muscle. Jama 1990;263:3029-34.

13. Fiatarone MA, O'Neill EF, Ryan ND, et al. Exercise training and nutritional supplementation for physical frailty in very elderly people. $\mathrm{N}$ Engl $\mathrm{J}$ Med 1994;330:1769-75.

14. Frontera WR, Hughes VA, Fielding RA, Fiatarone MA, Evans WJ, Roubenoff R. Aging of skeletal muscle: a 12-yr longitudinal study. J Appl Physiol 2000;88:1321-6.

15. Frontera WR, Meredith CN, O'Reilly KP, Knuttgen HG, Evans WJ. Strength conditioning in older men: skeletal muscle hypertrophy and improved function. J Appl Physiol 1988;64:1038-44.

16. Hawke TJ, Garry DJ. Myogenic satellite cells: physiology to molecular biology. J Appl Physiol 2001;91:534-51.

17. Hikida RS, Staron RS, Hagerman FC, et al. Effects of high-intensity resistance training on untrained older men. II. Muscle fiber characteristics and nucleo-cytoplasmic relationships. J Gerontol A Biol Sci Med Sci 2000;55:B347-54.

18. Hikida RS, Walsh S, Barylski N, Campos G, Hagerman FC, Staron RS. Is hypertrophy limited in elderly muscle fibers? A comparison of elderly and young strength-trained men. Basic Appl. Myol. 1998;8:419-427.

19. Jones PR, Pearson J. Anthropometric determination of leg fat and muscle plus bone volumes in young male and female adults. J Physiol 1969;204:63P-66P.

20. Kadi F, Charifi N, Denis C, Lexell J. Satellite cells and myonuclei in young and elderly women and men. Muscle Nerve 2004;29:120-7.

21. Kadi F, Charifi N, Henriksson J. The number of satellite cells in slow and fast fibres from human vastus lateralis muscle. Histochem Cell Biol 2006;126:83-7.

22. Koopman R, Zorenc AH, Gransier RJ, Cameron-Smith D, van Loon LJ. Increase in S6K1 phosphorylation in human skeletal muscle following resistance exercise occurs mainly in type II muscle fibers. Am J Physiol Endocrinol Metab 2006;290:E1245-52. 
23. Kosek DJ, Kim JS, Petrella JK, Cross JM, Bamman MM. Efficacy of 3 days/wk resistance training on myofiber hypertrophy and myogenic mechanisms in young vs. older adults. J Appl Physiol 2006;101:531-44.

24. Larsson L, Sjodin B, Karlsson J. Histochemical and biochemical changes in human skeletal muscle with age in sedentary males, age 22--65 years. Acta Physiol Scand 1978;103:31-9.

25. Lexell J. Human aging, muscle mass, and fiber type composition. J Gerontol A Biol Sci Med Sci 1995;50 Spec No:11-6.

26. Lexell J, Taylor CC, Sjostrom M. What is the cause of the ageing atrophy? Total number, size and proportion of different fiber types studied in whole vastus lateralis muscle from 15- to 83-year-old men. J Neurol Sci 1988;84:275-94.

27. Mackey AL, Esmarck B, Kadi F, et al. Enhanced satellite cell proliferation with resistance training in elderly men and women. Scand J Med Sci Sports 2007;17:34-42.

28. Mari A, Pacini G, Murphy E, Ludvik B, Nolan JJ. A model-based method for assessing insulin sensitivity from the oral glucose tolerance test. Diabetes Care 2001;24:539-48.

29. Martel GF, Roth SM, Ivey FM, et al. Age and sex affect human muscle fibre adaptations to heavy-resistance strength training. Exp Physiol 2006;91:457-64.

30. Mauro A. Satellite cell of skeletal muscle fibers. J Biophys Biochem Cytol 1961;9:4935.

31. Mayhew JL, Prinster JL, Ware JS, Zimmer DL, Arabas JR, Bemben MG. Muscular endurance repetitions to predict bench press strength in men of different training levels. J Sports Med Phys Fitness 1995;35:108-13.

32. Mitsiopoulos N, Baumgartner RN, Heymsfield SB, Lyons W, Gallagher D, Ross R. Cadaver validation of skeletal muscle measurement by magnetic resonance imaging and computerized tomography. J Appl Physiol 1998;85:115-22.

33. Moss FP, Leblond CP. Nature of dividing nuclei in skeletal muscle of growing rats. $\mathrm{J}$ Cell Biol 1970;44:459-62.

34. Moss FP, Leblond CP. Satellite cells as the source of nuclei in muscles of growing rats. Anat Rec 1971;170:421-35.

35. Park SW, Goodpaster BH, Strotmeyer ES, et al. Decreased muscle strength and quality in older adults with type 2 diabetes: the health, aging, and body composition study. Diabetes 2006;55:1813-8.

36. Petrella JK, Kim JS, Cross JM, Kosek DJ, Bamman MM. Efficacy of myonuclear addition may explain differential myofiber growth among resistance-trained young and older men and women. Am J Physiol Endocrinol Metab 2006;291:E937-46.

37. Petrella JK, Kim JS, Mayhew DL, Cross JM, Bamman MM. Potent myofiber hypertrophy during resistance training in humans is associated with satellite cellmediated myonuclear addition: a cluster analysis. J Appl Physiol 2008;104:1736-42.

38. Renault V, Thornell LE, Eriksson PO, Butler-Browne G, Mouly V. Regenerative potential of human skeletal muscle during aging. Aging Cell 2002;1:132-9.

39. Roth SM, Martel GF, Ivey FM, et al. Skeletal muscle satellite cell populations in healthy young and older men and women. Anat Rec 2000;260:351-8.

40. Roth SM, Martel GF, Ivey FM, et al. Skeletal muscle satellite cell characteristics in young and older men and women after heavy resistance strength training. J Gerontol A Biol Sci Med Sci 2001;56:B240-7.

41. Shefer G, Van de Mark DP, Richardson JB, Yablonka-Reuveni Z. Satellite-cell pool size does matter: Defining the myogenic potency of aging skeletal muscle. Dev Biol 2006;294:50-66.

42. Singh MA, Ding W, Manfredi TJ, et al. Insulin-like growth factor I in skeletal muscle after weight-lifting exercise in frail elders. Am J Physiol 1999;277:E135-43.

43. Sinha-Hikim I, Cornford M, Gaytan H, Lee ML, Bhasin S. Effects of testosterone supplementation on skeletal muscle fiber hypertrophy and satellite cells in communitydwelling older men. J Clin Endocrinol Metab 2006;91:3024-33. 
44. Verdijk LB, Koopman R, Schaart G, Meijer K, Savelberg HH, van Loon LJ. Satellite cell content is specifically reduced in type II skeletal muscle fibers in the elderly. Am J Physiol Endocrinol Metab 2007;292:E151-7. 



\section{Chapter 6}

\section{Protein supplementation before and after exercise does not further augment skeletal muscle hypertrophy after resistance training in elderly men}

Lex B. Verdijk, Richard A.M. Jonkers, Benjamin G. Gleeson, Milou Beelen, Kenneth Meijer, Hans H.C.M. Savelberg, Will K.W.H. Wodzig, Paul Dendale, and Luc J.C. van Loon

American Journal of Clinical Nutrition 2009; 89: 608-616

This is an electronic version of an article published in The American Journal of Clinical Nutrition, Vol 89, No 2, 2009, pages 608-616. The published article is available online at: http://www.ajcn.org/ 


\begin{abstract}
Background: There is considerable discrepancy in the literature on the proposed benefits of protein supplementation on the skeletal muscle adaptive response to resistance type exercise training in the elderly. Objective: To assess the benefits of timed protein supplementation on the increase in muscle mass and strength during prolonged resistance type exercise training (RT) in healthy, elderly males who habitually consume adequate dietary protein. Design: 26 healthy, elderly males ( $72 \pm 2$ y) were randomly assigned to a progressive 12 week RT-program with (PRO) or without (PLA) protein provided prior to and immediately after each exercise session ( 3 sessions/wk, $20 \mathrm{~g}$ protein/session). One-repetition maximum (1RM) tests were performed regularly to ensure a progressive workload during the intervention. Muscle hypertrophy was assessed on a whole-body (DXA), limb (CT), and muscle fiber (biopsy) level. Results: 1RM strength increased $\sim 25-35 \%$ in both groups $(\mathrm{P}<0.001)$. DXA and CT scans showed similar increases in leg muscle mass $(6 \pm 1 \%$ in both groups; $\mathrm{P}<0.001)$, and in quadriceps area $(9 \pm 1 \%$ in both groups, from $75.9 \pm 3.7$ and $73.8 \pm 3.2$, to $82.4 \pm 3.9$ and $80.0 \pm 3.0 \mathrm{~cm}^{2}$ in the PLA and PRO group, respectively; $\mathrm{P}<0.001)$. Muscle fiber hypertrophy was greater in type II (PLA: $28 \pm 6 \%$, PRO: $29 \pm 4 \%$ ) vs type I fibers (PLA: $5 \pm 4 \%$, PRO: $13 \pm 6 \%$, with no differences between groups. Conclusion: Timed protein supplementation immediately prior to and after exercise does not further augment the increase in skeletal muscle mass and strength following prolonged resistance type exercise training in healthy, elderly males who habitually consume adequate dietary protein.
\end{abstract}




\section{Introduction}

The age-related loss of skeletal muscle mass and strength, sarcopenia, is associated with a progressive decline in functional performance $(11,27,30$, 48). Resistance type exercise training has been shown to represent an effective strategy to augment skeletal muscle mass and strength and improve functional capacity in the elderly $(9,12,14,17,26,33,44)$. Physical activity stimulates muscle protein synthesis and accelerates protein breakdown (16, $42,43,50,51)$. However, in the absence of food intake net muscle protein balance will remain negative (38). Post-exercise carbohydrate ingestion attenuates the exercise induced increase in protein breakdown $(35,41)$. However, amino acid and/or protein administration, with $(23,24,40)$ or without carbohydrate $(4,45)$, is required to inhibit protein breakdown and stimulate muscle protein synthesis, resulting in a positive muscle protein balance. The timing of protein ingestion seems to represent an important factor in stimulating post-exercise muscle protein accretion $(2,28,46)$. Levenhagen et al. (28) reported an improved post-exercise net protein balance following consumption of protein and carbohydrate immediately after cessation of exercise as opposed to a more delayed supplementation regimen. Furthermore, recent studies suggest that protein co-ingestion prior to and/or during exercise can further augment post-exercise muscle protein accretion $(2,46)$.

Though the acute studies underline the relevance of protein ingestion prior to and immediately after exercise, there is considerable discussion on the proposed benefits of protein supplementation on the adaptive response to more prolonged exercise training in the elderly. From a series of wellcontrolled nutritional intervention studies (6, 8, 20), Campbell et al. concluded that resistance training induced improvements in muscle mass and strength are not enhanced when older people who consume adequate dietary protein (in excess of $0.8 \mathrm{~g} / \mathrm{kg} / \mathrm{d}$ ) further increase their protein intake (7). The latter is in line with previous studies that failed to observe benefits of nutritional co-intervention during long-term exercise intervention in the elderly $(13,15)$. The absence of any apparent benefits of protein supplementation on the adaptive response to long-term resistance exercise training might be attributed to a less than optimal timing of the applied feeding regimen. Esmarck et al. (10) reported that the timing of the administration of a protein containing supplement following resistance exercise is essential for skeletal muscle hypertrophy to occur during exercise training in the elderly. In their study, the control group receiving nutritional supplementation $2 \mathrm{~h}$ after cessation of exercise, as opposed to immediately after, did not show any improvements in muscle hypertrophy following 12 weeks of training (10). However, the latter seems to be in contrast with previous studies that generally show muscle hypertrophy following resistance exercise training without dietary co-intervention $(9,12,14,17,26$, 
$33,44)$. Nonetheless, recent studies in other populations $(18,19)$ showed that timed protein supplementation after resistance exercise might induce slight benefits over resistance training alone, although the additional effects were less marked than suggested by Esmarck et al. (10).

We hypothesized that protein supplementation immediately prior to and after resistance exercise would augment the gain in muscle mass and strength during prolonged resistance type exercise training in elderly people. Therefore, we assessed the impact of timed protein supplementation on the increase in muscle mass and strength during 3 months of resistance type exercise training in healthy, elderly males who habitually consume adequate dietary protein.

\section{Subjects and methods}

\section{Subjects}

A total of 28 healthy, elderly men ( $72 \pm 2$ y) volunteered to participate in a 12 week resistance type exercise intervention program, with or without additional protein supplementation prior to and immediately after each exercise session (3 sessions/wk). Two subjects dropped out during the study, one because of an acute back problem that occurred during gardening and the other because of fear of regaining an old back injury. Medical history of all subjects was evaluated and an oral glucose tolerance test (OGTT) and resting ECG were performed before selection. Exclusion criteria were defined that would preclude successful participation in the exercise program, and included (silent) cardiac or peripheral vascular disease and orthopedic limitations. Furthermore, as insulin resistance and/or type 2 diabetes have been associated with a more progressive loss of muscle mass and strength with aging (37), type 2 diabetes patients were excluded from participation (1). All subjects were living independently and had no history of participating in any structured exercise training program in the past 5 years. All subjects were informed on the nature and possible risks of the experimental procedures, before their written informed consent was obtained. This study was approved by the Medical Ethics Committee of the Academic Hospital, Maastricht. This study is part of a greater project investigating the clinical benefits of exercise and/or nutritional intervention in the elderly.

\section{Study design}

After inclusion in this study, subjects were randomly allocated to either the protein (PRO) or the placebo (PLA) supplemented group. Before, during, and after exercise intervention, anthropometric measurements (height, body mass, leg volume (21)), strength assessment (one-repetition maximum), CT 
and DXA scans were performed and muscle biopsies, blood samples, $24 \mathrm{~h}$ urine, and dietary intake records were collected.

\section{Dietary intake and physical activity standardization}

Standardized meals ( $\sim 51 \mathrm{~kJ} / \mathrm{kg}$ body mass; 57 Energy\% carbohydrate, 13 $\mathrm{En} \%$ protein, and $30 \mathrm{En} \%$ fat) were provided to all subjects prior to each test day (i.e. prior to muscle biopsy and/or blood sampling) and subjects were instructed to refrain from strenuous physical activity for 3 days prior to testing. Dietary intake was recorded for 2 days prior to blood sample collection to standardize food intake prior to blood collection after cessation of the intervention program, thereby minimizing the impact of differences in food intake on blood glucose homeostasis. On all test days, subjects arrived at the laboratory by car or public transportation, following an overnight fast. Prior to the onset of the intervention program and in week 11 of the exercise intervention, subjects recorded 3-day weighted dietary records (ThursdaySaturday) to assess potential changes in daily food intake that might had occurred during the intervention period. Food intake records were scrutinized by a dietician and analyzed with Eetmeter software 2005, version 1.4.0 (Voedingscentrum, The Hague, The Netherlands). Dietary intake was calculated for the entire day, as well as for breakfast and lunch separately. The energy derived from the protein supplements was not included in the analysis.

\section{Strength assessment}

Maximum strength was assessed by one-repetition maximum (1RM) strength tests on leg press and leg extension machines (Technogym, Rotterdam, The Netherlands). During a familiarization trial, proper lifting technique was demonstrated and practiced and maximum strength was estimated using the multiple repetitions testing procedure (34). In an additional session, at least one week prior to muscle biopsy collection, each subject's 1RM was determined as described previously (48). 1RM testing is preferred to evaluate changes in muscle strength during resistance type exercise training (49). Therefore, 1RM tests were repeated after 4 and 8 weeks of intervention and 2 days after the last training session of the intervention program. None of the subjects experienced any joint pain and/or muscle soreness due to the 1RM testing procedures.

\section{Exercise intervention program}

Supervised resistance type exercise training was performed 3 times a week for a 12-week period. All sessions were performed in the morning, at the same time of day. Training consisted of a 5 min warm-up on a cycle ergometer, followed by 4 sets on both the leg press and leg extension 
machines, followed by a 5 min cooling-down period on the cycle ergometer. During the first 4 weeks of training, the workload was increased from $60 \%$ of $1 \mathrm{RM}$ (10-15 repetitions in each set) to $75 \%$ of $1 \mathrm{RM}$ (8-10 repetitions). Starting at week 5,4 sets of 8 repetitions were performed at $75-80 \%$ of $1 \mathrm{RM}$ on each machine. Resting periods of 1.5 and 3 min were allowed between sets and exercises, respectively. Workload intensity was adjusted based on the 1RM tests (week 4 and 8). In addition, workload was increased when more than 8 repetitions could be performed in 3 out of 4 sets. On average, subjects attended $35 \pm 1$ of the 36 scheduled exercise sessions in both groups.

\section{Protein supplementation}

During the 5 min warm-up and cooling-down procedure, subjects received $250 \mathrm{~mL}$ of a beverage containing either water only (placebo group, PLA) or protein (protein group, PRO). The protein beverages contained $10 \mathrm{~g}$ protein (casein hydrolysate, DSM, Delft, The Netherlands); as such, the PRO group received $20 \mathrm{~g}$ protein per exercise session. All beverages were flavoured to mask the contents of the drinks (cream vanilla: $5 \mathrm{~g} / \mathrm{L}$, citric acid: $1.8 \mathrm{~g} / \mathrm{L}$, and sodium saccharinate: $0.28 \mathrm{~g} / \mathrm{L}$ ). All subjects ate breakfast at least $1.5 \mathrm{~h}$ before starting the exercise sessions, and lunch was eaten no less than $2 \mathrm{~h}$ after cessation of each session. On training days, no food or drinks were allowed other than the experimental beverages between breakfast and lunch. Subjects were allowed to drink water prior to, during and after each exercise session.

\section{CT-scans}

Anatomical cross-sectional area (CSA) of the quadriceps muscle was assessed by CT scanning (IDT 8000, Philips Medical Systems, The Netherlands) prior to and after cessation of the exercise intervention program (3 days after strength assessment and prior to muscle biopsy collection). With subjects lying supine, legs extended and their feet secured, a $3 \mathrm{~mm}$ thick axial image was taken midway between the anterior superior iliac spine and the distal end of the patella. Scanning characteristics were $120 \mathrm{kV}, 300$ $\mathrm{mA}$, with a rotation time of $0.75 \mathrm{~s}$ and a field of view of $500 \mathrm{~mm}$. The exact scanning position was measured and marked, to be replicated after cessation of the intervention program. Using the described approach, we determined the $\mathrm{CV}$ for repeated scans to be less than $0.6 \%$. Images were loaded onto a pc using AGFA IMPAX imaging software, version 5.2 (AGFA Healthcare, Belgium). Muscle CSA of the right leg was selected between -29 and +150 Hounsfield units (36), after which the quadriceps muscle was selected by manual tracing. Quadriceps CSA was calculated using Lucia 4.81 software (Nikon, Badhoevedorp, The Netherlands). All analyses were performed by 2 investigators blinded to subject coding; intraclass correlation coefficients for inter- and intra-investigator reliability were 0.997 and 0.998 , respectively. 


\section{DXA-scans}

Directly after CT-scanning, body composition and bone mineral content were measured with dual-energy X-ray absorptiometry (DXA, Lunar Prodigy Advance, GE Healthcare, Madison, WI). The system's software package (enCORE 2005, version 9.15.00) was used to determine wholebody and regional lean mass, fat mass and bone mineral content. DXA scans were performed in a fasted state, after subjects had voided. CV for repetitive scans ( $n=4,2$ weeks apart) were $0.4 \%, 1.0 \%$, and $1.1 \%$ for whole-body lean mass, fat mass, and leg lean mass, respectively.

\section{Blood samples}

To determine glucose homeostasis and exclude insulin resistant and/or type 2 diabetic subjects, fasting blood samples were collected prior to and after 4 , 8 , and 11 weeks of intervention, and 4 days after the strength assessment performed after cessation of the exercise program. In addition, a standard OGTT was performed 2 weeks prior to and 1 week after cessation of the intervention. Blood samples were collected in both EDTA containing tubes and serum tubes and centrifuged at $1000 \mathrm{~g}$ and $4^{\circ} \mathrm{C}$ for $10 \mathrm{~min}$ (plasma) or $18^{\circ} \mathrm{C}$ for $15 \mathrm{~min}$ (serum). Aliquots of plasma and serum were frozen in liquid nitrogen and stored at $-80^{\circ} \mathrm{C}$. Samples were analyzed for plasma glucose and insulin, to assess potential changes in whole-body insulin sensitivity using the oral glucose insulin sensitivity (OGIS)-index (31). Plasma glucose concentrations were analyzed with a COBAS FARA analyzer (Uni Kit III, Roche, Basel, Switzerland). Insulin was analyzed by RIA (Insulin RIA Kit, LINCO Research INC., St. Charles, MO). Blood HbA1c content ( $3 \mathrm{~mL}$ blood sample, EDTA) was analyzed by highperformance liquid chromatography (Bio-Rad Variant II, Munich, Germany). As a measure of renal function, serum creatinine was measured using the Jaffe rate method on a Synchron LX20 analyzer (Beckmann Coulter Inc., Fullerton, CA).

\section{4 h urine collection}

To determine urinary nitrogen and creatinine excretion, and 3methylhistidine concentration, $24 \mathrm{~h}$ urine was collected over the last day of the 3-day dietary intake assessment. Urine was collected from the second voiding on day 3 until the first voiding on the day after, in containers with 10 $\mathrm{mL} 4 \mathrm{M} \mathrm{H}_{2} \mathrm{SO}_{4}$. After determining total urine production, aliquots of urine were frozen in liquid nitrogen and stored at $-80^{\circ} \mathrm{C}$. Nitrogen content was analyzed on an elemental analyzer (model CHN-O-RAPID, Heraeus Co., Germany). Total nitrogen excretion was calculated from total urinary nitrogen excretion and an estimated $0.031 \mathrm{~g} / \mathrm{kg}$ body mass for miscellaneous nitrogen loss (32). Nitrogen balance was calculated as the difference 
between nitrogen intake (protein intake $(\mathrm{g}) / 6.25)$ and total nitrogen excretion, and was used to determine nitrogen balance prior to and after 11 weeks of intervention. Urinary creatinine excretion was measured as described above. As a measure of renal function, creatinine clearance was calculated from urinary excretion and its serum concentration and corrected for body surface area, yielding the amount of blood (in $\mathrm{mL}$ ) that is cleared from creatinine per min per $1.73 \mathrm{~m}^{2}$ of total body surface area (29). As an indirect marker for myofibrillar protein degradation, 3-methylhistidine was determined by high performance liquid chromatography and fluorescence detection (Shimadzu Deutschland GmbH, Duisburg, Germany). Urinary 3methylhistidine concentration was expressed relative to creatinine concentration.

\section{Muscle biopsy sampling}

Three days prior to the onset of exercise training and 4 days after the postintervention strength assessment, muscle biopsy samples were taken from the right leg of each subject, in the morning following an overnight fast. After local anesthesia, percutaneous needle biopsies (50-80 mg) were taken from the vastus lateralis muscle, $\sim 15 \mathrm{~cm}$ above the patella (3). Any visible non-muscle tissue was removed immediately, and biopsy samples were embedded in Tissue-Tek (Sakura Finetek, Zoeterwoude, The Netherlands), frozen in liquid nitrogen-cooled isopentane, and stored at $-80^{\circ} \mathrm{C}$ until further analyses.

\section{Immunohistochemistry}

From all biopsies, $5 \mu \mathrm{m}$ thick cryosections were cut at $-20^{\circ} \mathrm{C}$. Pre- and postintervention samples from 2 subjects (from both the PRO and PLA group) were mounted together on uncoated glass slides. Slides were stained for muscle fiber typing as described before $(25,48)$. First antibodies used are directed against MHC-I (A4.951, Developmental Studies Hybridoma Bank [DSHB], Iowa City, IA; dilution 1:20), and laminin (polyclonal rabbit antilaminin; Sigma, Zwijndrecht, The Netherlands; dilution 1:50). Appropriate secondary antibodies were applied: goat anti-mouse IgG1 AlexaFluor488, and goat anti-rabbit IgG AlexaFluor555 (Molecular Probes, Invitrogen, Breda, The Netherlands; dilution 1:500 and 1:200, respectively). Staining procedures were as follows. After fixation ( $5 \mathrm{~min}$ acetone), slides were airdried and incubated for $60 \mathrm{~min}$ at room temperature with primary antibodies directed against laminin and MHC-I, diluted in $0.05 \%$ Tween-PBS. Slides were then washed ( $3 * 5 \mathrm{~min}$ PBS), and incubated for $30 \mathrm{~min}$ at room temperature with the appropriate secondary antibodies, diluted in $0.05 \%$ Tween-PBS. After a final washing step, all slides were mounted with cover glasses using Mowiol (Calbiochem, Amsterdam, The Netherlands). 
All images were digitally captured, using fluorescence microscopy with a Nikon E800 fluorescence microscope (Nikon Instruments Europe, Badhoevedorp, The Netherlands) coupled to a Basler A113 C progressive scan color CCD camera with a Bayer color filter. Epifluorescence signal was recorded using a Texas Red excitation filter $(540-580 \mathrm{~nm})$ for laminin, and a FITC excitation filter (465-495 nm) for MHC-I. Image processing and quantitative analyses were done using Lucia 4.81 software package (Nikon). All image recordings and analyses were performed by an investigator blinded to subject coding. Images were captured at a 120x magnification. Laminin was used to determine cell borders, and for all fibers within each image, type I and type II muscle fibers were identified. Within each image, the number of fibers, the mean fiber cross-sectional area (CSA), and the percentage of area occupied per fiber type were measured for the type I and type II muscle fibers separately. As a measure of fiber circularity, form factors were calculated using the formula $(4 \pi \cdot \mathrm{CSA}) /(\text { perimeter })^{2}$. No differences in fiber circularity were observed over time and between groups. A mean number of $335 \pm 30$ and $265 \pm 22$ individual muscle fibers were analyzed in the pre- and post-intervention biopsy samples, respectively.

\section{Statistics}

All data are expressed as means \pm SEM. Baseline characteristics between groups were compared by means of an independent t-test. Since all data were normally distributed, training induced changes were analyzed with mixed model repeated measures ANOVA with time (before vs after exercise training) as within-subjects factor and group (protein vs placebo) as between-subjects factor. Fiber type-specific variables were analyzed by adding a second within-subjects factor (type I vs type II muscle fibers). In case of significant interaction, paired t-tests were performed for time effects within groups or within type I or II fibers, and independent t-tests for group differences in the pre- and post-intervention values. Bonferroni corrections were applied when appropriate. In addition to the repeated measures analysis, relative changes over time were calculated and analyzed by independent t-tests to detect potential differences between groups. Since the results from both analyses were identical, we report both absolute and relative changes but only present $\mathrm{P}$-values for the repeated measures analyses. The relation between the average habitual daily protein intake and the degree of hypertrophy was determined by correlation analyses. All analyses were performed using SPSS version 15.0 (Chicago, IL). An $\alpha$-level of 0.05 was used to determine statistical significance. 


\section{Results}

\section{Subjects}

Subjects' characteristics prior to and after intervention are provided in Table 6.1. In total, 26 subjects completed the intervention program, 13 in each group. No differences were observed in baseline variables between groups. Subjects' age was $72 \pm 2$ y for both groups. Total body mass, height and BMI did not change over the intervention period in either group. Fasting blood glucose concentration and $\mathrm{HbAlc}$ values were within normal range for healthy, elderly individuals and did not change over time, although HbAlc tended to decline in both groups $(\mathrm{P}=0.057$; Table 6.1$)$. Whole-body insulin sensitivity as determined by OGIS (31) did not change over time in either group.

Table 6.1 Subjects' characteristics

\begin{tabular}{lcccc}
\hline \hline & \multicolumn{2}{c}{ Placebo group $(n=13)$} & \multicolumn{2}{c}{ Protein group $(n=13)$} \\
& Before & After & Before & After \\
\hline Body mass (kg) & $80.2 \pm 3.4$ & $80.1 \pm 3.4$ & $79.2 \pm 2.8$ & $78.9 \pm 2.9$ \\
Height (m) & $1.71 \pm 0.01$ & $1.71 \pm 0.01$ & $1.73 \pm 0.02$ & $1.73 \pm 0.02$ \\
BMI (kg/m $\left.{ }^{2}\right)$ & $27.4 \pm 1.1$ & $27.4 \pm 1.1$ & $26.5 \pm 1.0$ & $26.4 \pm 1.0$ \\
Leg volume (L) & $8.2 \pm 0.5$ & $8.3 \pm 0.5 *$ & $8.0 \pm 0.3$ & $8.2 \pm 0.3 *$ \\
Glucose (mmol/ L) & $5.6 \pm 0.2$ & $5.5 \pm 0.1$ & $5.9 \pm 0.2$ & $5.8 \pm 0.1$ \\
HbA1c (\%) & $5.8 \pm 0.1$ & $5.7 \pm 0.1$ & $5.9 \pm 0.1$ & $5.8 \pm 0.1$ \\
OGIS (mL/kg/min) & $368 \pm 22$ & $382 \pm 19$ & $365 \pm 12$ & $368 \pm 16$ \\
\hline \hline
\end{tabular}

Data represent means \pm SEM; OGIS: oral glucose insulin sensitivity-index (31). Data were analyzed using repeated measures ANOVA with time and group as factors. No significant differences were observed between groups before intervention. No 'time $\mathrm{x}$ group' interaction was observed for any of the variables $(\mathrm{P} \geq 0.40)$. No main effect of group was observed for any of the variables. *Indicates a significant time effect compared with before intervention $(\mathrm{P}<0.05)$.

\section{Skeletal muscle hypertrophy}

Prior to exercise intervention, no differences were observed between the placebo (PLA) and protein (PRO) supplemented group for quadriceps anatomical CSA $\left(75.9 \pm 3.7\right.$ vs $73.8 \pm 3.2 \mathrm{~cm}^{2}$, respectively). Over time, quadriceps CSA increased $9 \pm 1 \%$ in both groups to $82.4 \pm 3.9$ and $80.0 \pm 3.0$ $\mathrm{cm}^{2}$ in the PLA and PRO group, respectively $(\mathrm{P}<0.001)$, with no differences between groups (Figure 6.1). 




Figure 6.1 Mean (+SEM) quadriceps cross-sectional area (CSA) before and after 3 months resistance exercise training in elderly men with (protein, $n=13$ ) or without (placebo, $n=13$ ) protein supplementation during each exercise session. Data were analyzed using repeated measures ANOVA with time and group as factors. No 'time $\mathrm{x}$ group' interaction $(\mathrm{P}=0.79)$ or main group effect $(\mathrm{P}=0.65)$ was observed. *Indicates a significant time effect compared with before intervention $(\mathrm{P}<0.001)$.

At baseline, muscle fiber cross-sectional area (CSA) was smaller in type II vs type I fibers in both groups (Figure 6.2; $\mathrm{P}<0.001$ ), with no differences between groups. For muscle fiber CSA, a significant 'time $\mathrm{x}$ fiber type' interaction was observed $(\mathrm{P}<0.001)$. After intervention, muscle fiber CSA had increased in both type I and II muscle fibers in PLA ( $5 \pm 4$ and $28 \pm 6 \%$, respectively) and PRO (13 \pm 6 and $29 \pm 4 \%$, respectively). The increase in fiber CSA was greater in the type II vs type I fibers, with no differences between groups. As a consequence, differences in muscle fiber type CSA were no longer apparent after exercise intervention (Figure 6.2).

\section{Muscle strength}

At baseline, no differences in muscle strength (1RM) were observed between the PLA and PRO group (leg extension: $88 \pm 4$ vs $84 \pm 3 \mathrm{~kg}$, and leg press: $170 \pm 8$ vs $173 \pm 8 \mathrm{~kg}$, respectively). After intervention, $1 \mathrm{RM}$ for leg extension had increased by $27 \pm 3$ and $38 \pm 4 \%$ to $111 \pm 5$ and $115 \pm 5 \mathrm{~kg}$ in the PLA and PRO group, respectively $(\mathrm{P}<0.001)$. Likewise, $1 \mathrm{RM}$ for leg press increased by $24 \pm 3$ and $24 \pm 2 \%$ to $210 \pm 10$ and $215 \pm 11 \mathrm{~kg}$ in the PLA and PRO group, respectively $(\mathrm{P}<0.001)$. No differences were observed between groups. Repeated measures analysis revealed that the increase in 1RM strength was statistically significant for each 4-week interval during the intervention period for both exercises, with no differences between groups (data not shown). 


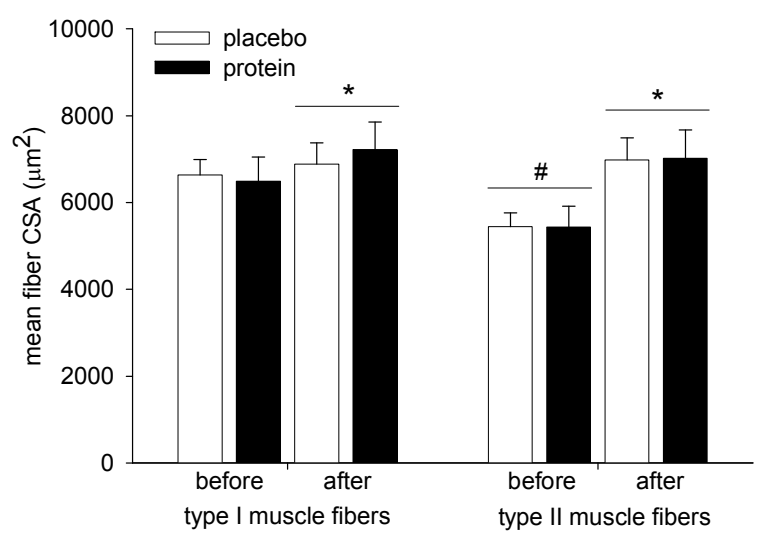

Figure 6.2 Mean (+SEM) muscle fiber cross-sectional area (CSA) for type I and II muscle fibers before and after 3 months resistance exercise training in elderly men with (protein, $n=13$ ) or without (placebo, $n=13$ ) protein supplementation during each exercise session. Data were analyzed using repeated measures ANOVA with time, group, and fiber type as factors. No 'time $x$ fiber type $x$ group' $(\mathrm{P}=0.17)$, ‘time $x$ group' $(\mathrm{P}=0.54)$, or 'fiber type $x$ group' $(\mathrm{P}=0.82)$ interactions were observed. A significant 'time $\mathrm{x}$ fiber type' interaction $(\mathrm{P}<0.001)$ revealed a difference in type I vs II muscle fiber size before intervention; in addition, the increase in muscle fiber CSA over time was greater in type II vs type I muscle fibers. \#Indicates a significant fiber type effect compared with type I fibers at baseline ('fiber type $\mathrm{x}$ group' interaction: $\mathrm{P}=0.69$; main group effect: $\mathrm{P}=0.90$; main fiber type effect: $\mathrm{P}<0.001$ ). *Indicates a significant time effect compared with before intervention (type I fibers: 'time $\mathrm{x}$ group' interaction: $\mathrm{P}=0.31$; main group effect: $\mathrm{P}=0.90$; main time effect $\mathrm{P}<0.05$. Type II fibers: 'time $\mathrm{x}$ group' interaction: $\mathrm{P}=0.93$; main group effect: $\mathrm{P}=0.98$; main time effect $\mathrm{P}<0.001)$.

\section{Body composition}

No differences were observed between groups at baseline for any of the DXA measurements. Leg lean mass increased $6 \pm 1 \%$ in both groups, from $18.3 \pm 0.5$ and $18.0 \pm 0.6 \mathrm{~kg}$ to $19.3 \pm 0.5$ and $19.0 \pm 0.6 \mathrm{~kg}$ in the PLA and PRO group, respectively (Figure 6.3; $\mathrm{P}<0.001$ ). Whole-body lean mass increased throughout the intervention period, from $57.4 \pm 1.6$ and $56.1 \pm 1.4 \mathrm{~kg}$ to $58.0 \pm 1.7$ and $56.8 \pm 1.4 \mathrm{~kg}$ in the PLA and PRO group, respectively $(\mathrm{P}<0.01)$. Total fat mass decreased significantly $(\mathrm{P}<0.01)$, resulting in a significant decline in whole-body fat percentage (PLA: from 23.6 \pm 2.2 to $22.9 \pm 2.2 \%$; and PRO: from $24.9 \pm 1.4$ to $23.7 \pm 1.4 \% ; \mathrm{P}<0.001)$. In accordance, leg fat percentage was lower following exercise intervention $(\mathrm{P}<0.001)$. No differences were observed between groups. No changes were observed in bone mineral content (data not shown).

\section{Muscle fiber type composition}

At baseline, no group differences were observed in the percentage of type I and II muscle fibers (fiber\%) and/or the percentage of muscle area occupied 
by type I and II fibers (area\%). Type I and II muscle fiber\% had not changed following 3 months of exercise intervention (Table 6.2). In contrast, type II muscle fiber area $\%$ tended to increase from $48 \pm 4$ and $40 \pm 4 \%$ to $54 \pm 3$ and $47 \pm 3 \%$ in the PLA and PRO group, respectively ( $\mathrm{P}=0.057)$. No group differences were observed.

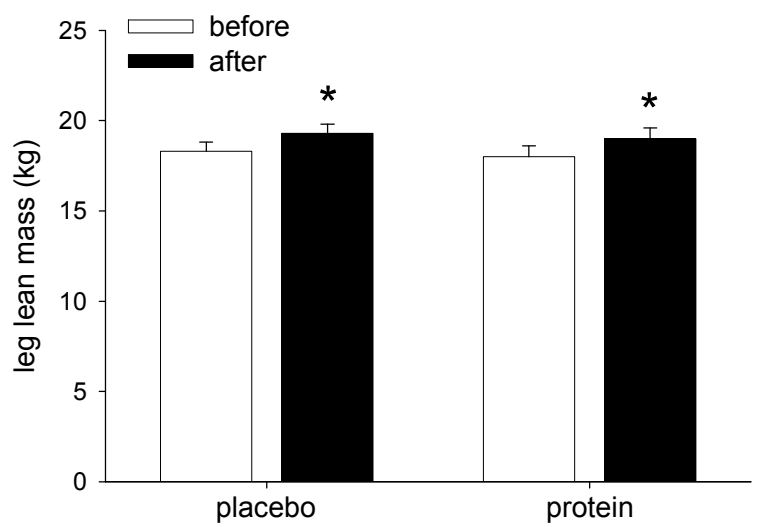

Figure 6.3 Mean (+SEM) leg lean mass before and after 3 months resistance exercise training in elderly men with (protein, $n=13$ ) or without (placebo, $n=13$ ) protein supplementation during each exercise session. Data were analyzed using repeated measures ANOVA with time and group as factors. No 'time $x$ group' interaction $(\mathrm{P}=0.79)$ or main group effect $(\mathrm{P}=0.65)$ was observed. *Indicates a significant time effect compared with before intervention $(\mathrm{P}<0.001)$.

Table 6.2 Muscle fiber type composition

\begin{tabular}{llllll}
\hline \hline & & \multicolumn{2}{c}{ Placebo group $(n=13)$} & \multicolumn{2}{c}{ Protein group $(n=13)$} \\
& & Before & After & Before & After \\
\hline Fiber \% & Type I & $47 \pm 4$ & $47 \pm 3$ & $56 \pm 4$ & $52 \pm 4$ \\
& Type II & $53 \pm 4$ & $53 \pm 3$ & $44 \pm 4$ & $48 \pm 4$ \\
\cline { 2 - 6 } CSA\% & Type I & $52 \pm 4$ & $46 \pm 3$ & $60 \pm 4$ & $53 \pm 3$ \\
& Type II & $48 \pm 4$ & $54 \pm 3$ & $40 \pm 4$ & $47 \pm 3$ \\
\hline \hline
\end{tabular}

Data represent means \pm SEM; CSA\%: percentage area occupied by fiber type. Data were analyzed using repeated measures ANOVA with time and group as factors. No significant differences were observed between groups before intervention. No 'time $\mathrm{x}$ group' interaction was observed ( $\mathrm{P}=0.48$ for fiber $\%, \mathrm{P}=0.70$ for $\mathrm{CSA} \%$ ). No significant main effects of group and/or time were observed. 


\section{Dietary intake records}

Analysis of the 3-day dietary intake records collected prior to and after 11 weeks of intervention did not show any differences in total daily energy intake between groups and/or over time $(9.2 \pm 0.6$ and $9.3 \pm 0.4 \mathrm{MJ} / \mathrm{d}$ to $9.1 \pm 0.4$ and $9.4 \pm 0.6 \mathrm{MJ} / \mathrm{d}$ in the PLA and PRO group, respectively). Macronutrient composition of the diet did not change during the intervention period and did not differ between groups (Table 6.3). Daily protein intake averaged $1.1 \pm 0.1 \mathrm{~g} / \mathrm{kg} / \mathrm{d}$ in both groups, and had not changed during the intervention period.

Total energy intake and macronutrient composition of both breakfast and lunch did not differ between groups prior to intervention, and did not change over time in either group (data not shown). Protein intake at breakfast and lunch did not differ between groups and did not change over time (Table 6.3).

Correlation analyses revealed that the daily dietary protein intake was positively correlated to the degree of muscle hypertrophy. Pearson correlation coefficients between total dietary protein intake $(\mathrm{g} / \mathrm{kg} / \mathrm{d})$ and the increase in lean mass and leg lean mass were 0.34 and 0.33 , respectively. These correlations were unchanged when adjusting for the effect of protein supplementation.

Table 6.3 Energy intake and macronutrient composition of the diet

\begin{tabular}{lcccc}
\hline \hline & \multicolumn{2}{c}{ Placebo group $(n=13)$} & \multicolumn{2}{c}{ Protein group $(n=13)$} \\
& Before & After & Before & After \\
\hline Total En (MJ/d) & $9.2 \pm 0.6$ & $9.1 \pm 0.4$ & $9.3 \pm 0.4$ & $9.4 \pm 0.6$ \\
CHO (En\%) & $50 \pm 2$ & $52 \pm 2$ & $52 \pm 2$ & $53 \pm 2$ \\
FAT (En\%) & $33 \pm 2$ & $32 \pm 2$ & $31 \pm 1$ & $31 \pm 1$ \\
PRO (En\%) & $17 \pm 1$ & $16 \pm 1$ & $16 \pm 1$ & $16 \pm 1$ \\
PRO (g/kg/d) & $1.1 \pm 0.1$ & $1.1 \pm 0.1$ & $1.1 \pm 0.1$ & $1.1 \pm 0.1$ \\
PRO-bf (g/kg/d) & $0.21 \pm 0.05$ & $0.23 \pm 0.05$ & $0.22 \pm 0.02$ & $0.23 \pm 0.03$ \\
PRO-lu (g/kg/d) & $0.30 \pm 0.02$ & $0.32 \pm 0.03$ & $0.28 \pm 0.03$ & $0.27 \pm 0.03$ \\
\hline \hline
\end{tabular}

Data represent means \pm SEM. En: energy intake per day; En\%: energy percentage for daily intake of carbohydrate (CHO), fat (FAT), and protein (PRO); bf: breakfast; lu: lunch. Data were analyzed using repeated measures ANOVA with time and group as factors. No significant differences were observed between groups before intervention. No 'time $\mathrm{x}$ group' interaction was observed for any of the variables $(\mathrm{P} \geq 0.30)$. No significant main effects of group and/or time were observed for any of the variables. 


\section{Blood and 24 h urine collection}

Serum creatinine concentrations were within a normal range prior to intervention and did not change over time in either group (from $1.16 \pm 0.04$ and $1.10 \pm 0.06 \mathrm{mg} / \mathrm{dL}$ to $1.19 \pm 0.03$ and $1.11 \pm 0.06 \mathrm{mg} / \mathrm{dL}$ in the PLA and PRO group, respectively). No differences were observed between groups. Creatinine clearance was similar between groups prior to intervention (PLA: 59.1 \pm 6.3 and PRO: $61.0 \pm 4.7 \mathrm{~mL} / \mathrm{min}$ per $1.73 \mathrm{~m}^{2}$ ) and did not change over time in either group. $24 \mathrm{~h}$ nitrogen balance as measured prior to intervention revealed that both groups were in nitrogen balance $(0.25 \pm 0.40$ and $0.22 \pm 0.92$ $\mathrm{g} / \mathrm{d}$ in the PLA and PRO group, respectively). No significant changes were observed over time, with subjects still being in nitrogen balance after 11 weeks of intervention $(-0.03 \pm 0.99$ and $-0.14 \pm 0.87 \mathrm{~g} / \mathrm{d}$ in the PLA and PRO group, respectively). No differences were observed in 3-methylhistidine excretion between groups before intervention $(14.3 \pm 2.0$ and $11.7 \pm 2.1$ $\mathrm{mmol} / \mathrm{mol}$ creatinine in the PLA and PRO group, respectively). No significant changes were observed over time and/or between groups (mean changes were $5 \pm 9$ and $3 \pm 9 \%$ in the PLA and PRO group, respectively).

\section{Discussion}

The present study shows that timed protein supplementation prior to and immediately after each exercise session does not further augment the increase in skeletal muscle mass and strength following 3 months of resistance type exercise training in healthy, elderly men who habitually consume adequate dietary protein.

Resistance type exercise training has been shown to represent an effective interventional strategy to counteract sarcopenia $(9,12,14,17,26,33,44)$. In the present study, we observed a $0.6 \pm 0.3 \mathrm{~kg}$ (PLA) and $0.7 \pm 0.2 \mathrm{~kg}$ (PRO) gain in whole-body lean mass and a concomitant decline in whole-body fat mass. The observed improvements are similar to previous findings reported after 12-16 weeks resistance exercise training in the elderly $(20,26)$. Improvements were predominantly located in the lower extremities, with a $6 \pm 1 \%$ increase in total leg lean mass and a $9 \pm 1 \%$ increase in quadriceps CSA in both groups. The increase in quadriceps CSA was very similar to the $\sim 9 \%$ increase in muscle area observed after exercise training in subjects aged 60-72 y (14) as well as in subjects at an age above 85 y (12). Skeletal muscle mass and muscle CSA are positively correlated with strength (12). In accordance, we observed substantial increases in muscle strength, with 1RM leg extension and leg press being increased by $27 \pm 3$ and $24 \pm 3 \%$ (PLA) vs $38 \pm 4$ and $24 \pm 2 \%$ (PRO). Previously, similar increases in strength, ranging between $25-45 \%$, have been reported $(26,33)$.

The loss of skeletal muscle mass with aging is associated with specific type II muscle fiber atrophy $(27,30,48)$. In accordance, type II muscle fiber CSA 
was significantly smaller than type I fiber CSA prior to intervention. Consistent with previous observations $(9,26,33,44)$, the exercise induced increase in muscle fiber size was greater in the type II vs type I muscle fibers in both groups (Figure 6.2). As a consequence, differences in muscle fiber type size prior to intervention were no longer apparent after the 12 week exercise intervention program. Taken together, these data confirm the efficacy of resistance type exercise training to improve skeletal muscle mass and strength and reverse type II muscle fiber atrophy in the elderly.

Studies assessing the acute muscle protein synthetic response following exercise have provided ample data to suggest that muscle protein balance can be substantially increased by ingesting protein and/or amino acids prior to and/or immediately after exercise $(2,4,23,24,35,40,45,46)$. However, long-term nutritional intervention studies generally fail to observe additional benefits of increasing protein intake during exercise intervention in the elderly $(5,13,15,20)$. The latter is in line with Campbell et al. (7) who recently concluded that resistance exercise training induced improvements in muscle mass and strength are not enhanced when older people who consume adequate dietary protein (in excess of $0.8 \mathrm{~g} / \mathrm{kg} / \mathrm{d}$ ) further increase their protein intake. The absence of any additional benefits of nutritional cointervention during more prolonged exercise intervention programs might be attributed to an inadequate timing of the protein supplementation after each exercise bout (10). Furthermore, ingesting dietary protein prior to and/or during exercise has been shown to further improve the post-exercise net muscle protein balance $(2,46)$. Therefore, we hypothesized that the intake of $10 \mathrm{~g}$ protein prior to and $10 \mathrm{~g}$ protein immediately after resistance exercise would increase muscle mass and strength gains during prolonged resistance type exercise training in healthy, elderly males who habitually consume adequate dietary protein. Even though we observed large increases in muscle mass and strength on a whole-body, limb, and myocellular level, no differences were observed between the groups supplemented with (PRO) or without (PLA) additional protein (Figures 6.1-6.3). The latter despite the fact that with a power of 0.80 , we would have been able to detect group differences as small as $3.5 \%, 2.5 \%$ and $11 \%$ for the changes in quadriceps CSA, leg lean mass, and muscle fiber size, respectively. The latter would have been more than sufficient to detect even the smallest clinically relevant differences compared with previous findings (10).

The present data seem to be in contrast with Esmarck et al. (10), who found that the acute post-exercise ingestion of a protein containing supplement is prerequisite for muscle hypertrophy to occur in the elderly. It might be suggested that the apparent discrepancy can be explained by differences between the supplements that were provided in these studies. In the present study we provided $20 \mathrm{~g}$ protein, whereas Esmarck et al. (10) provided their subjects with supplements containing $10 \mathrm{~g}$ protein, $7 \mathrm{~g}$ carbohydrate and $3 \mathrm{~g}$ 
fat. However, the lack of carbohydrate in the supplements provided in the present study would unlikely have modulated the muscle protein anabolic response, as recent work from our group (22) as well as others (35) has shown that post-exercise carbohydrate ingestion is not warranted when ample protein is ingested. The apparent discrepancy between studies is more likely attributed to differences in the outcome of the control groups. In the present study, we observed a substantial increase in muscle mass and strength following resistance type exercise training without nutritional cointervention (PLA). In contrast, Esmarck et al. (10) reported no increase in leg muscle CSA and muscle fiber size when protein supplements were provided $2 \mathrm{~h}$ after cessation of exercise. The latter tends to disagree with the plethora of studies that report substantial increases in muscle mass and strength following 2-4 months of resistance type exercise training in the elderly without any dietary modulation $(9,12-15,17,26,33,44)$. In short, timed protein supplementation prior to and immediately after exercise does not seem to further augment the benefits of prolonged resistance type exercise training on muscle mass and strength in healthy, elderly males.

In the present study, dietary intake remained stable throughout the intervention period (Table 6.3). Even without additional protein supplementation, habitual dietary protein intake averaged $1.1 \pm 0.1 \mathrm{~g} / \mathrm{kg} / \mathrm{d}$ in both groups. This value is well in excess of the current RDA values of 0.8 $\mathrm{g} / \mathrm{kg} / \mathrm{d}(39,47)$. The latter values have been suggested to be marginal or even insufficient for muscle mass maintenance (8) and/or for allowing lean mass accrual following resistance training in the elderly (6). However, when older people habitually consume adequate dietary protein (i.e. $>0.9 \mathrm{~g} / \mathrm{kg} / \mathrm{d}$ ), improvements in muscle mass and strength following long-term resistance exercise training do not seem to be further enhanced by increasing dietary protein intake (20). Yet, in line with recent observations by Campbell et al. (7), we also observed a positive correlation between daily dietary protein intake and the increase in lean mass with training. We can only speculate on the physiological relevance of these correlations, which show that the regulation of the skeletal muscle adaptive response to exercise and nutritional supplementation remains far from being established.

The additional protein ingested before and after each exercise session resulted in an average additional protein intake of $0.1 \pm 0.0 \mathrm{~g} / \mathrm{kg} / \mathrm{d}$. The latter induced no side effects and did not induce any changes in markers of renal function or $24 \mathrm{~h}$ nitrogen balance. Though we could not detect any benefits of timed protein supplementation during exercise intervention in healthy, well-nourished elderly males, it remains to be determined whether the proposed benefits of timed protein supplementation are restricted to specific elderly subpopulations, like malnourished or frail elderly.

We conclude that prolonged resistance type exercise training substantially improves skeletal muscle mass and strength in healthy, elderly males. Timed 
protein supplementation immediately prior to and after each exercise session does not further enhance skeletal muscle mass and strength gains following prolonged resistance type exercise training in healthy, elderly males who habitually consume adequate dietary protein.

\section{Acknowledgements}

We gratefully acknowledge the expert technical assistance of Joan Senden, Dominique Moermans, Geert Souverijns and Luk Corluy, and the enthusiastic support of the subjects who volunteered to participate in this study. This study was partly supported by grants from The Anna Foundation, Leiden, The Netherlands, and DSM Food Specialties, Delft, The Netherlands. 


\section{References}

1. Diagnosis and classification of diabetes mellitus. Diabetes Care 2006;29 Suppl 1:S43-8.

2. Beelen M, Koopman R, Gijsen AP, et al. Protein coingestion stimulates muscle protein synthesis during resistance-type exercise. Am J Physiol Endocrinol Metab 2008;295:E70-7.

3. Bergstrom J. Percutaneous needle biopsy of skeletal muscle in physiological and clinical research. Scand J Clin Lab Invest 1975;35:609-16.

4. Biolo G, Tipton KD, Klein S, Wolfe RR. An abundant supply of amino acids enhances the metabolic effect of exercise on muscle protein. Am J Physiol 1997;273:E122-9.

5. Campbell WW, Crim MC, Young VR, Evans WJ. Increased energy requirements and changes in body composition with resistance training in older adults. Am J Clin Nutr 1994;60:167-75.

6. Campbell WW, Kruskall LJ, Evans WJ. Lower body versus whole body resistive exercise training and energy requirements of older men and women. Metabolism 2002;51:989-97.

7. Campbell WW, Leidy HJ. Dietary protein and resistance training effects on muscle and body composition in older persons. J Am Coll Nutr 2007;26:696S-703S.

8. Campbell WW, Trappe TA, Wolfe RR, Evans WJ. The recommended dietary allowance for protein may not be adequate for older people to maintain skeletal muscle. J Gerontol A Biol Sci Med Sci 2001;56:M373-80.

9. Charette SL, McEvoy L, Pyka G, et al. Muscle hypertrophy response to resistance training in older women. J Appl Physiol 1991;70:1912-6.

10. Esmarck B, Andersen JL, Olsen S, Richter EA, Mizuno M, Kjaer M. Timing of postexercise protein intake is important for muscle hypertrophy with resistance training in elderly humans. J Physiol 2001;535:301-11.

11. Evans W. Functional and metabolic consequences of sarcopenia. J Nutr 1997;127:998S$1003 \mathrm{~S}$.

12. Fiatarone MA, Marks EC, Ryan ND, Meredith CN, Lipsitz LA, Evans WJ. Highintensity strength training in nonagenarians. Effects on skeletal muscle. Jama 1990;263:3029-34.

13. Fiatarone MA, O'Neill EF, Ryan ND, et al. Exercise training and nutritional supplementation for physical frailty in very elderly people. $\mathrm{N}$ Engl $\mathrm{J}$ Med 1994;330:1769-75.

14. Frontera WR, Meredith CN, O'Reilly KP, Knuttgen HG, Evans WJ. Strength conditioning in older men: skeletal muscle hypertrophy and improved function. J Appl Physiol 1988;64:1038-44.

15. Godard MP, Williamson DL, Trappe SW. Oral amino-acid provision does not affect muscle strength or size gains in older men. Med Sci Sports Exerc 2002;34:1126-31.

16. Hasten DL, Pak-Loduca J, Obert KA, Yarasheski KE. Resistance exercise acutely increases MHC and mixed muscle protein synthesis rates in 78-84 and 23-32 yr olds. Am J Physiol Endocrinol Metab 2000;278:E620-6.

17. Hikida RS, Staron RS, Hagerman FC, et al. Effects of high-intensity resistance training on untrained older men. II. Muscle fiber characteristics and nucleo-cytoplasmic relationships. J Gerontol A Biol Sci Med Sci 2000;55:B347-54.

18. Holm L, Esmarck B, Mizuno M, et al. The effect of protein and carbohydrate supplementation on strength training outcome of rehabilitation in ACL patients. J Orthop Res 2006;24:2114-23.

19. Holm L, Olesen JL, Matsumoto K, et al. Protein-containing nutrient supplementation following strength training enhances the effect on muscle mass, strength, and bone formation in postmenopausal women. J Appl Physiol 2008;105:274-81. 
20. Iglay HB, Thyfault JP, Apolzan JW, Campbell WW. Resistance training and dietary protein: effects on glucose tolerance and contents of skeletal muscle insulin signaling proteins in older persons. Am J Clin Nutr 2007;85:1005-13.

21. Jones PR, Pearson J. Anthropometric determination of leg fat and muscle plus bone volumes in young male and female adults. J Physiol 1969;204:63P-66P.

22. Koopman R, Beelen M, Stellingwerff T, et al. Coingestion of carbohydrate with protein does not further augment postexercise muscle protein synthesis. Am J Physiol Endocrinol Metab 2007;293:E833-42.

23. Koopman R, Verdijk L, Manders RJ, et al. Co-ingestion of protein and leucine stimulates muscle protein synthesis rates to the same extent in young and elderly lean men. Am J Clin Nutr 2006;84:623-32.

24. Koopman R, Verdijk LB, Beelen M, et al. Co-ingestion of leucine with protein does not further augment post-exercise muscle protein synthesis rates in elderly men. Br J Nutr 2008;99:571-80.

25. Koopman R, Zorenc AH, Gransier RJ, Cameron-Smith D, van Loon LJ. Increase in S6K1 phosphorylation in human skeletal muscle following resistance exercise occurs mainly in type II muscle fibers. Am J Physiol Endocrinol Metab 2006;290:E1245-52.

26. Kosek DJ, Kim JS, Petrella JK, Cross JM, Bamman MM. Efficacy of 3 days/wk resistance training on myofiber hypertrophy and myogenic mechanisms in young vs. older adults. J Appl Physiol 2006;101:531-44.

27. Larsson L, Sjodin B, Karlsson J. Histochemical and biochemical changes in human skeletal muscle with age in sedentary males, age 22--65 years. Acta Physiol Scand 1978;103:31-9.

28. Levenhagen DK, Gresham JD, Carlson MG, Maron DJ, Borel MJ, Flakoll PJ. Postexercise nutrient intake timing in humans is critical to recovery of leg glucose and protein homeostasis. Am J Physiol Endocrinol Metab 2001;280:E982-93.

29. Levey AS, Bosch JP, Lewis JB, Greene T, Rogers N, Roth D. A more accurate method to estimate glomerular filtration rate from serum creatinine: a new prediction equation. Modification of Diet in Renal Disease Study Group. Ann Intern Med 1999;130:461-70.

30. Lexell J, Taylor CC, Sjostrom M. What is the cause of the ageing atrophy? Total number, size and proportion of different fiber types studied in whole vastus lateralis muscle from 15- to 83-year-old men. J Neurol Sci 1988;84:275-94.

31. Mari A, Pacini G, Murphy E, Ludvik B, Nolan JJ. A model-based method for assessing insulin sensitivity from the oral glucose tolerance test. Diabetes Care 2001;24:539-48.

32. Maroni BJ, Steinman TI, Mitch WE. A method for estimating nitrogen intake of patients with chronic renal failure. Kidney Int 1985;27:58-65.

33. Martel GF, Roth SM, Ivey FM, et al. Age and sex affect human muscle fibre adaptations to heavy-resistance strength training. Exp Physiol 2006;91:457-64.

34. Mayhew JL, Prinster JL, Ware JS, Zimmer DL, Arabas JR, Bemben MG. Muscular endurance repetitions to predict bench press strength in men of different training levels. J Sports Med Phys Fitness 1995;35:108-13.

35. Miller SL, Tipton KD, Chinkes DL, Wolf SE, Wolfe RR. Independent and combined effects of amino acids and glucose after resistance exercise. Med Sci Sports Exerc 2003;35:449-55.

36. Mitsiopoulos N, Baumgartner RN, Heymsfield SB, Lyons W, Gallagher D, Ross R. Cadaver validation of skeletal muscle measurement by magnetic resonance imaging and computerized tomography. J Appl Physiol 1998;85:115-22.

37. Park SW, Goodpaster BH, Strotmeyer ES, et al. Decreased muscle strength and quality in older adults with type 2 diabetes: the health, aging, and body composition study. Diabetes 2006;55:1813-8.

38. Phillips SM, Tipton KD, Aarsland A, Wolf SE, Wolfe RR. Mixed muscle protein synthesis and breakdown after resistance exercise in humans. Am J Physiol 1997;273:E99-107. 
39. Rand WM, Pellett PL, Young VR. Meta-analysis of nitrogen balance studies for estimating protein requirements in healthy adults. Am J Clin Nutr 2003;77:109-27.

40. Rasmussen BB, Tipton KD, Miller SL, Wolf SE, Wolfe RR. An oral essential amino acid-carbohydrate supplement enhances muscle protein anabolism after resistance exercise. J Appl Physiol 2000;88:386-92.

41. Roy BD, Tarnopolsky MA, MacDougall JD, Fowles J, Yarasheski KE. Effect of glucose supplement timing on protein metabolism after resistance training. J Appl Physiol 1997;82:1882-8.

42. Sheffield-Moore M, Yeckel CW, Volpi E, et al. Postexercise protein metabolism in older and younger men following moderate-intensity aerobic exercise. Am J Physiol Endocrinol Metab 2004;287:E513-22.

43. Short KR, Vittone JL, Bigelow ML, Proctor DN, Nair KS. Age and aerobic exercise training effects on whole body and muscle protein metabolism. Am J Physiol Endocrinol Metab 2004;286:E92-101.

44. Singh MA, Ding W, Manfredi TJ, et al. Insulin-like growth factor I in skeletal muscle after weight-lifting exercise in frail elders. Am J Physiol 1999;277:E135-43.

45. Tipton KD, Ferrando AA, Phillips SM, Doyle D, Jr., Wolfe RR. Postexercise net protein synthesis in human muscle from orally administered amino acids. Am J Physiol 1999;276:E628-34.

46. Tipton KD, Rasmussen BB, Miller SL, et al. Timing of amino acid-carbohydrate ingestion alters anabolic response of muscle to resistance exercise. Am J Physiol Endocrinol Metab 2001;281:E197-206.

47. Trumbo P, Schlicker S, Yates AA, Poos M. Dietary reference intakes for energy, carbohydrate, fiber, fat, fatty acids, cholesterol, protein and amino acids. J Am Diet Assoc 2002;102:1621-30.

48. Verdijk LB, Koopman R, Schaart G, Meijer K, Savelberg HH, van Loon LJ. Satellite cell content is specifically reduced in type II skeletal muscle fibers in the elderly. Am J Physiol Endocrinol Metab 2007;292:E151-7.

49. Verdijk LB, van Loon L, Meijer K, Savelberg HH. One-repetition maximum strength test represents a valid means to assess leg strength in vivo in humans. J Sports Sci 2009;27:59-68.

50. Welle S, Thornton C, Statt M. Myofibrillar protein synthesis in young and old human subjects after three months of resistance training. Am J Physiol 1995;268:E422-7.

51. Yarasheski KE, Zachwieja JJ, Bier DM. Acute effects of resistance exercise on muscle protein synthesis rate in young and elderly men and women. Am J Physiol 1993;265:E210-4. 



\title{
Chapter 7
}

\author{
General discussion
}



The loss of skeletal muscle mass and strength with aging is currently recognized as one of the major determinants affecting functional capacity in the elderly and, as such, the ability to live independently. Skeletal muscle satellite cells have been implicated as a key factor in the process of sarcopenia. In the present thesis, we studied the age-related changes in muscle fiber type-specific satellite cell content and the skeletal muscle adaptive response to resistance type exercise training in the elderly. In this final chapter, we will address the implications of the findings presented in this thesis, and discuss them in a broader perspective. In addition, specific areas on which future research should focus will be identified.

\section{Satellite cells and sarcopenia}

Sarcopenia has been characterized by the specific loss and atrophy of type II muscle fibers. In this thesis, we consistently show that type II muscle fiber atrophy in the elderly is accompanied by a type II muscle fiber specific decline in satellite cell content (chapters 3-5). These results are now confirmed by recent findings from other labs (59). Furthermore, we observed a positive correlation between muscle fiber type-specific size and satellite cell content within the elderly population (chapter 4). Satellite cells play a key role in muscle fiber maintenance, growth, and repair (25), and the regenerative capacity of skeletal muscle tissue seems to depend on the abundance of these satellite cells (55). Therefore, we suggest that the agerelated decline in type II muscle fiber satellite cell content leads to impaired muscle fiber maintenance, resulting in the specific type II muscle fiber atrophy that is observed with aging. In accordance, the age-related fiber type-specific decline in satellite cell content in rodents $(4,55)$ has been shown to precede muscle fiber atrophy (4). However, longitudinal studies in humans are warranted to elucidate the timeline of changes in satellite cell content and muscle fiber atrophy during aging. The latter could provide evidence on a cause or effect relationship between a decline in satellite cell content and specific type II muscle fiber atrophy with aging. Another strategy to address this topic would be to assess the timeline for changes in muscle fiber size and satellite cell content during muscle hypertrophy. As such, in chapter 5 we assessed changes in muscle fiber size and satellite cell content following 3 months of resistance type exercise training in healthy elderly men. We observed a type II muscle fiber specific hypertrophy that was accompanied by a fiber type-specific increase in satellite cell content. Furthermore, the increase in muscle fiber size following testosterone supplementation (56) and resistance type exercise training (48) has been shown to be proportional to the increase in satellite cell content. Although all these studies lack a specific timeline, the findings support the idea that satellite cell content forms a key factor in the regulation of muscle fiber size and, as such, the maintenance of skeletal muscle mass. Prolonged 
intervention studies with a more regular assessment of skeletal muscle fiber size and satellite cell content over time may provide more definite evidence to support the hypothesis that an increase in satellite cell content is required to allow substantial muscle fiber hypertrophy.

Apart from the age-related decline in satellite cell content, satellite cell dysfunction has been suggested to contribute to the loss of skeletal muscle mass with aging. In both animal $(8,9)$ and human studies $(12)$, satellite cell activation and/or proliferation have been shown to be attenuated at a more advanced age. The progression of satellite cells through the stages of activation, proliferation and/or differentiation is mediated by the expression of myogenic growth factors, including insulin-like growth factor (IGF)-1, mechano growth factor (MGF), MyoD, Myf-5, myogenin, MRF4, and myostatin $(6,18,24,25,28,41,43,53)$. A rapid up- or down-regulation of intramuscular mRNA levels of these myogenic factors has been observed in response to a single bout of resistance type exercise in healthy young adults $(3,13,23,33,42,62)$. However, the latter response was shown to be attenuated in the elderly $(13,23,33)$, which might be indicative of impairments in satellite cell activation in elderly muscle (12). Interestingly, recent studies indicate that the muscle protein synthetic response to the main anabolic stimuli, i.e. physical activity and/or food intake, is blunted in the elderly when compared with young adults $(11,31,34,36)$. The latter is now believed to represent a key factor in the loss of muscle mass with aging. It remains to be determined whether the age-related decline in satellite cell content and/or function contributes to the proposed blunted muscle protein synthetic response to physical activity and/or food intake in the elderly.

In summary, aging is associated with a decline in type II muscle fiber size and satellite cell content. We speculate that the age-related fiber typespecific decline in satellite content and/or function represent key factors in the etiology of sarcopenia. A reduced satellite cell content and/or impaired satellite cell function might contribute to a reduced sensitivity of elderly muscle to the main anabolic stimuli, i.e. food intake and/or physical activity.

\section{Satellite cells, skeletal muscle wasting, and disuse atrophy}

The process of sarcopenia is not related to any specific disease state. Aside from sarcopenia, several clinical conditions are accompanied by a rapid decline in skeletal muscle mass, often referred to as muscle wasting. Studying the muscle fiber type-specific atrophy associated with muscle wasting in these disease states might provide more insight into the proposed role of skeletal muscle satellite cells in regulating muscle fiber atrophy/hypertrophy. Chronic obstructive pulmonary disease (COPD) represents one of the many pathologic conditions in which extensive muscle wasting is observed. Despite the fact that COPD is associated with muscle fiber atrophy, it was recently suggested that skeletal muscle satellite cell 
content in COPD patients is similar when compared with healthy, agematched subjects (14). However, these data were only based on mixed muscle fiber analyses. Muscle atrophy in COPD is characterized by a shift towards a higher proportion of type II muscle fibers, and specific type II muscle fiber atrophy $(14,20,21)$. Likewise, muscle wasting in human immunodeficiency virus (HIV) and chronic heart failure patients has been associated with specific type II muscle fiber atrophy $(37,44)$. Therefore, it would be interesting to assess whether type II muscle fiber atrophy in these disease states is accompanied by a muscle fiber type-specific decline in satellite cell content. In contrast to sarcopenia, the presence of a chronic inflammatory state (with increased circulating and/or intramuscular levels of tumor necrosis factor $[\mathrm{TNF}] \alpha$, interleukin [IL]-1ß, IL-6, Interferon- $\gamma$, and potentially myostatin) has been suggested to be responsible for skeletal muscle wasting associated with COPD, cancer cachexia, chronic heart failure, and $\operatorname{HIV}(2,15,19,22,61)$. The chronic presence of an inflammatory state might impair the activation, proliferation, and differentiation of satellite cells. Furthermore, greater oxidative stress observed in these pathologic conditions might lead to the apoptotic loss of myonuclei and satellite cells, triggering atrophy and further reducing skeletal muscle regenerative capacity. Although data in humans are currently lacking, we speculate that fiber type-specific changes in skeletal muscle satellite cells might also play a key role in skeletal muscle wasting. More research is warranted to investigate the mechanisms responsible for muscle atrophy in both sarcopenia and muscle wasting conditions, and the potential role for satellite cells in these processes.

The loss of muscle mass with aging is, at least partly, attributed to the skeletal muscle adaptive response to a more sedentary lifestyle. In accordance, various models of physical inactivity have been associated with substantial skeletal muscle atrophy. Such models of disuse/inactivity include space flight, bed rest, denervation, and immobilization. It is currently unknown what the impact of these different models of physical inactivity is on skeletal muscle fiber type-specific satellite cell content and/or function. The loss of muscle mass with physical inactivity is an exceptionally fast physiological adaptive response, with substantial skeletal muscle atrophy (10-12\%) already occurring following 10-14 days of immobilization (26, 57). The latter has been attributed to the absence of mechanical loading as a potent anabolic stimulus and a reduced skeletal muscle responsiveness to the main anabolic stimuli (17). The changes in muscle fiber size with short-term disuse atrophy are remarkably similar to those observed in sarcopenia (58). Therefore, it is interesting to assess the changes in satellite cell content and/or function with short-term disuse atrophy. The latter might provide a more practical model to study the timeline of the changes in muscle fiber size and the concomitant changes in satellite cell content and/or function. 
The absence of major anabolic stimuli might negatively affect the capacity of satellite cells to activate, proliferate and/or differentiate. In addition, longterm inactivity or disuse, as observed in spinal cord injury, has been associated with an increased rate of apoptosis which is likely induced by the lack of neurogenic input (29). It would be interesting to assess whether the latter is also accompanied by a loss of skeletal muscle satellite cell content and/or function. Yet, given the observed hypertrophy following electrical stimulation of muscle tissue in patients with spinal cord injury (54), it is tempting to speculate that a substantial pool of quiescent satellite cells remains present, waiting to be activated to reboot myogenesis. Muscle fiber type-specific analyses of satellite cell content and/or function in both shortand long-term models of 'disuse' atrophy will be instrumental to obtain evidence on the impact of physical inactivity as a key factor in the etiology of sarcopenia.

Taken together, data on the potential changes in satellite cell content in various human models of skeletal muscle atrophy and/or wasting is presently lacking. Studying the skeletal muscle fiber type-specific characteristics in different models of skeletal muscle atrophy will further elucidate the role of satellite cells in the maintenance of skeletal muscle fiber size and provide the framework needed to establish the physiological role of skeletal muscle fiber satellite cell content and function in the progressive loss of muscle mass with aging.

\section{Satellite cells and skeletal muscle hypertrophy}

Given the general function of satellite cells to provide new myonuclei to skeletal muscle tissue, their contribution to skeletal muscle growth during postnatal development seems obvious. However, whether satellite cells are also required for muscle growth in adults remains a matter of debate. We report that specific type II muscle fiber hypertrophy following resistance type exercise training is accompanied by an increase in type II muscle fiber satellite cell content in elderly men (chapter 5). Other interventions in this population that have been shown to induce muscle fiber hypertrophy generally also report an increase in satellite cell content $(7,56)$. These findings imply a functional role of satellite cells in allowing skeletal muscle fiber hypertrophy in the elderly. In response to acute resistance type exercise, muscle protein synthesis rates are rapidly increased, improving protein balance during immediate post-exercise recovery (49). Because satellite cell proliferation takes at least 24 hours to become evident (50), it seems obvious to speculate that the acute post-exercise increase in muscle protein synthesis is not directly mediated and/or facilitated by the skeletal muscle satellite cells. Thus, it can be questioned whether satellite cells are prerequisite to allow skeletal muscle hypertrophy; a topic that was recently discussed in the Journal of Applied Physiology $(40,45)$. One of the main 
issues relating to this question is whether there is a ceiling in the myonuclear domain size that can be reached. The myonuclear domain theory suggests that each myonucleus controls the metabolic processes (e.g. gene expression, protein synthesis) for a certain volume of cytoplasm. Consequently, to allow substantial muscle fiber hypertrophy without an increase in myonuclear domain size, more nuclei are needed. In accordance, we observed substantial muscle fiber hypertrophy without any changes in myonuclear domain size following 3 months of resistance type exercise training (chapter 5). Our findings tend to be in line with other studies and suggest that hypertrophy can only take place to a certain extent beyond which additional, newly formed, myonuclei are required $(30,47,48)$. Several animal studies have used X-ray irradiation as a technique to completely block skeletal muscle satellite cell function and, as such, prevent the incorporation of new myonuclei. The latter results in the lack of overload-induced muscle hypertrophy when compared with animals not exposed to irradiation $(1,38$, 51). Therefore, those findings also support the idea that satellite cells are essential to allow skeletal muscle hypertrophy. Furthermore, myonuclei are probably lost with normal muscle use during routine daily activities, due to subtle myofiber injuries and/or apoptosis induced by cumulative DNA damage $(27,55)$. This myonuclear loss might be increased by more exhaustive physical activity, necessitating the continuous incorporation of newly formed nuclei into skeletal muscle tissue. Evidence to date indicates that the contribution of other stem cells (such as derived from the brain or bone marrow) to muscle repair and/or growth is minimal and that skeletal muscle satellite cells are required for the incorporation of new myonuclei during normal physiological muscle growth, such as induced by exercise $(38,46,63,64)$. Though modest, temporary increases in muscle fiber size may be possible without satellite cell involvement, the successful incorporation of new myonuclei eventually determines the extent to which hypertrophy can occur, supporting a key role for skeletal muscle satellite cells in reversing sarcopenia.

From chapters 5 and 6 , it is concluded that skeletal muscle tissue in the elderly is still responsive to the anabolic stimuli induced by prolonged resistance type exercise training, reflected in a substantial increase in muscle mass, strength, and type II muscle fiber size and satellite cell content after 3 months of exercise training. However, the long-term skeletal muscle adaptive response to exercise training seems to be reduced in the elderly when compared with healthy young adults $(27,35,60)$. Shefer et al. (55) argued that a reduced satellite cell pool size might negatively affect the myogenic response induced by growth stimuli. This hypothesis was supported by Petrella et al. (48), who observed greater hypertrophy in response to resistance type exercise training when baseline, pre-intervention satellite cell content was larger. However, the latter findings may have been 
confounded by including both young and elderly men and women in the analysis. In chapter 5 , only healthy elderly males were subjected to 3 months of resistance type exercise training. Unfortunately, we cannot provide sufficient data to support the proposed relation between baseline satellite cell content and the extent of muscle hypertrophy during subsequent resistance type exercise training due to the limited number of subjects $(n=13)$ in this study. Nonetheless, we speculate that the specific decline in type II muscle fiber satellite cell content with aging (chapter 3) negatively affects the capacity of the muscle to hypertrophy. Future studies should assess whether differences in baseline satellite cell content can explain inter-individual differences in the skeletal muscle adaptive response to exercise intervention in healthy elderly, as well as in more clinical populations suffering from skeletal muscle wasting.

In addition to satellite cell content, muscle hypertrophy following prolonged exercise intervention might also depend on the potential of these satellite cells to activate, proliferate, and differentiate. Results from animal studies suggest that the systemic environment plays an important role in inducing satellite cell activation/proliferation and, as such, in determining the regenerative potential of skeletal muscle tissue with aging $(5,9)$. However, as mentioned earlier in this chapter, attenuated satellite cell activation, proliferation and/or differentiation in response to the main anabolic stimuli (i.e. food intake and physical activity) in the elderly may be functionally coupled to the blunted exercise-induced response in intramuscular growth factor mRNA expression. In contrast with the proposed importance of systemically circulating factors $(5,9)$, the latter may underline the importance of local processes (i.e. local growth factor expression) in regulating satellite cell function. In accordance, unilateral loading induces an increase in satellite cell content in the exercised muscle tissue only $(10,52)$. Likewise, skeletal muscle hypertrophy following resistance type exercise training is only observed in the exercised muscle groups and not throughout the entire body (chapters 5-6) $(18,24)$. Therefore, even though systemic factors might play a permissive role, local myocellular factors seem to regulate the skeletal muscle adaptive response to exercise. However, it remains to be established if and how different aspects of satellite cell function are specifically regulated by local growth factor expression. For example, cell culture and animal experiments have suggested that specific growth factors (i.e. MyoD, myogenin, myf-5, MRF4, MGF, and myostatin) mediate satellite cell activation, proliferation and differentiation. Although exercise induces an increase in intramuscular mRNA expression of these growth factors, a direct link with in vivo satellite cell activation, proliferation, and/or differentiation remains to be established. Furthermore, previous research has shown that intramuscular expression of myogenic growth factors at the transcript (i.e. mRNA) level may have limited 
predictive value for the actual growth factor expression at the protein level. The latter is apparent for MyoD and myogenin in the basal state (13), and for MyoD, myogenin and MRF4 in response to resistance loading (35). Therefore, in vivo studies are warranted to establish a direct relation between the upregulation of specific myogenic factors, the activation, proliferation and differentiation of satellite cells, and the subsequent incorporation of newly formed myonuclei into skeletal muscle tissue in humans. To assess potential age-related impairments in these processes, both young and elderly subjects should be studied. A combination of immunoblotting and/or histochemical analyses should be performed on skeletal muscle biopsy samples collected at regular intervals to investigate both the short and longterm skeletal muscle adaptive response to exercise. The latter will give further insight into the timeline of myogenic pathways induced by anabolic stimuli, the specific role of different growth factors in regulating satellite cell function, and the age-related changes that might cause the skeletal muscle anabolic response to be attenuated in the elderly.

In conclusion, satellite cells seem to play a key role in regulating the skeletal muscle adaptive response to anabolic stimuli. Although substantial skeletal muscle hypertrophy can be achieved by prolonged resistance type exercise training in the elderly, an age-related decline in satellite cell content and/or impaired satellite cell function seem to attenuate the skeletal muscle adaptive response to prolonged exercise intervention. Determining the regulation of satellite cell content and/or function in vivo will provide many new targets for the development of interventional strategies to more effectively counteract the progressive loss of muscle mass with aging.

\section{Maximizing the skeletal muscle adaptive response}

Given the age-related blunted activation, proliferation and/or differentiation of satellite cells, as well as the attenuated skeletal muscle protein synthetic response to food intake and/or physical activity in the elderly, it appears that aged muscle tissue is generally less sensitive to the main anabolic stimuli. It would be interesting to assess whether the reduced sensitivity can be reversed by prolonged exercise, nutritional and/or pharmacological intervention. We hypothesize that resistance type exercise training can rejuvenate aging muscle, thereby restoring the attenuated skeletal muscle adaptive response in the elderly. Such an increased sensitivity to anabolic stimuli would improve skeletal muscle maintenance and, as such, skeletal muscle strength and function. To assess potential changes in the sensitivity and/or responsiveness of skeletal muscle tissue to the main anabolic stimuli, future studies should investigate the muscle protein synthetic and/or proteolytic response to food intake and/or physical activity as well as satellite cell content and/or function, both before and after prolonged resistance type exercise training. 
Resistance type exercise training has been well established as the most effective strategy to increase muscle mass and strength in the elderly. As the long-term skeletal muscle adaptive response to resistance type exercise training appears to be attenuated with aging, it is imperative to define more effective exercise, nutritional and/or pharmacological interventions to further augment skeletal muscle mass and strength in the elderly. Given the proposed insensitivity of aged skeletal muscle tissue to the main anabolic stimuli, the time required to allow skeletal muscle hypertrophy might be different in the elderly when compared with young subjects. As such, more prolonged resistance type exercise training in the elderly will further augment muscle mass and strength when compared with only 3 months of training. In short, resistance type exercise training should be implemented as a standard component of lifestyle intervention programs aiming to improve general health in the elderly population.

Furthermore, previous studies have suggested that specific nutritional and/or pharmacological interventions may augment the increase in skeletal muscle mass and strength following resistance type exercise training. For example, protein and/or specific amino acid (e.g. leucine) supplementation has been shown to substantially augment muscle protein synthesis rates at rest and/or following a single session of resistance type exercise $(32,34)$. In chapter 6 , we report no benefits of timed protein supplementation before and after each exercise session on the increase in muscle mass, strength, and muscle fiber size following 12 weeks of resistance type exercise training in healthy, elderly men consuming ample amounts of protein in their habitual diet. Yet, we still speculate that (timed) protein supplementation can improve the skeletal muscle adaptive response to exercise training in more compromised subpopulations such as frail and/or malnourished elderly. In addition, certain nutritional and/or pharmacological compounds (e.g. leucine, testosterone, IGF-1) may have specific anabolic properties, e.g. increasing muscle protein synthesis rates, and/or directly stimulating satellite cell activation, proliferation and/or differentiation $(16,32,56)$. Administration of these compounds may further boost myogenesis, increase satellite cell content and, as such, improve the long-term skeletal muscle adaptive response to resistance type exercise training in the elderly. Future research should pursue the development of more effective interventional strategies to maximize the skeletal muscle adaptive response to exercise in the elderly.

\section{Conclusions and future research}

Since the discovery of skeletal muscle satellite cells in 1961 (39), a substantial body of scientific research has been devoted to the properties and function of these satellite cells. The results of these studies have prompted Zammit et al. (64) to state that the satellite cell has earned its place at the very centre of adult myogenesis. In this thesis, we provide the first evidence 
for a muscle fiber type-specific decline in satellite content with human aging. We have shown that the age-related muscle fiber type-specific changes are accompanied by and functionally related to the loss of muscle mass and strength. Furthermore, the loss of muscle mass and strength with aging can, at least partly, be reversed by prolonged resistance type exercise training. The latter is associated with an increase in type II muscle fiber size and satellite cell content. Based on these findings, we suggest that skeletal muscle satellite cells play a key role in both age-related muscle atrophy and in the hypertrophic response to exercise intervention programs aiming to counteract sarcopenia.

Although resistance type exercise represents a potent stimulus for the recruitment of satellite cells in humans, the molecular regulation of satellite cell activation, proliferation and differentiation in vivo is still poorly understood. It remains to be determined which specific satellite cell processes are involved in the differential adaptive response of skeletal muscle tissue to aging and/or anabolic stimuli. Whereas the use of cell culture systems and animal models may answer specific questions on the signaling pathways involved in muscle maintenance and growth, only human in vivo research will provide information on whether these pathways are still functional in the elderly and/or how they can be stimulated by exercise or other interventions. To gain further insight into the role of satellite cells in age-related skeletal muscle atrophy and hypertrophy, future studies should address the following questions:

- Which pathways are involved in, and what is the timeline for the in vivo regulation of satellite cell activation, proliferation, and differentiation? Are these processes impaired in aged muscle?

-What are the fiber type-specific changes in muscle fiber size, composition, and satellite cell content in various conditions of skeletal muscle wasting and/or disuse atrophy?

- Is it possible to reverse the age-related blunted skeletal muscle adaptive response to anabolic stimuli (i.e. both satellite cell proliferation and/or muscle protein synthesis) and, as such, rejuvenate aging muscle by prolonged resistance type exercise training?

- To what extent does baseline satellite cell content and/or function, restrict the skeletal muscle adaptive response to resistance type exercise training in the elderly? 
- What distinguishes the relative importance of an increase in myonuclear domain versus an increase in the number of myonuclei for skeletal muscle hypertrophy?

- Which nutritional and/or pharmacological compounds stimulate satellite cell activation, proliferation and/or differentiation?

- How can we optimize the skeletal muscle adaptive response to combined exercise, nutritional, and pharmacological intervention in the elderly?

The increasing number of elderly in today's society faces us with the challenging task of developing effective interventional strategies to prevent and/or treat the progressive loss of skeletal muscle mass and function associated with aging. The latter would delay the onset of functional limitation and improve quality of life in the elderly population. Although much work has already been devoted to this area, a more comprehensive insight into the mechanisms underlying the loss of muscle mass and the factors that determine the skeletal muscle adaptive response to intervention is urgently warranted. Fortunately, the remarkable capacity of skeletal muscle tissue to adapt to exercise intervention provides a solid foundation for future research in this interesting field. 


\section{References}

1. Adams GR, Caiozzo VJ, Haddad F, Baldwin KM. Cellular and molecular responses to increased skeletal muscle loading after irradiation. Am J Physiol Cell Physiol 2002;283:C1182-95.

2. Baracos VE. Cancer-associated cachexia and underlying biological mechanisms. Annu Rev Nutr 2006;26:435-61.

3. Bickel CS, Slade J, Mahoney E, Haddad F, Dudley GA, Adams GR. Time course of molecular responses of human skeletal muscle to acute bouts of resistance exercise. J Appl Physiol 2005;98:482-8.

4. Brack AS, Bildsoe H, Hughes SM. Evidence that satellite cell decrement contributes to preferential decline in nuclear number from large fibres during murine age-related muscle atrophy. J Cell Sci 2005;118:4813-21.

5. Carlson BM, Faulkner JA. Muscle transplantation between young and old rats: age of host determines recovery. Am J Physiol 1989;256:C1262-6.

6. Chakravarthy MV, Davis BS, Booth FW. IGF-I restores satellite cell proliferative potential in immobilized old skeletal muscle. J Appl Physiol 2000;89:1365-79.

7. Charifi N, Kadi F, Feasson L, Denis C. Effects of endurance training on satellite cell frequency in skeletal muscle of old men. Muscle Nerve 2003;28:87-92.

8. Conboy IM, Conboy MJ, Smythe GM, Rando TA. Notch-mediated restoration of regenerative potential to aged muscle. Science 2003;302:1575-7.

9. Conboy IM, Conboy MJ, Wagers AJ, Girma ER, Weissman IL, Rando TA. Rejuvenation of aged progenitor cells by exposure to a young systemic environment. Nature 2005;433:760-4.

10. Crameri RM, Langberg H, Magnusson P, et al. Changes in satellite cells in human skeletal muscle after a single bout of high intensity exercise. J Physiol 2004;558:33340.

11. Cuthbertson D, Smith K, Babraj J, et al. Anabolic signaling deficits underlie amino acid resistance of wasting, aging muscle. Faseb J 2005;19:422-4.

12. Dreyer HC, Blanco CE, Sattler FR, Schroeder ET, Wiswell RA. Satellite cell numbers in young and older men 24 hours after eccentric exercise. Muscle Nerve 2006;33:24253.

13. Drummond MJ, Miyazaki M, Dreyer HC, et al. Expression of growth-related genes in young and older human skeletal muscle following an acute stimulation of protein synthesis. J Appl Physiol 2009;106:1403-11.

14. Eliason G, Abdel-Halim S, Arvidsson B, Kadi F, Piehl-Aulin K. Physical performance and muscular characteristics in different stages of COPD. Scand J Med Sci Sports 2008.

15. Filippatos GS, Anker SD, Kremastinos DT. Pathophysiology of peripheral muscle wasting in cardiac cachexia. Curr Opin Clin Nutr Metab Care 2005;8:249-54.

16. Giovannini S, Marzetti E, Borst SE, Leeuwenburgh C. Modulation of GH/IGF-1 axis: Potential strategies to counteract sarcopenia in older adults. Mech Ageing Dev 2008.

17. Glover EI, Phillips SM, Oates BR, et al. Immobilization induces anabolic resistance in human myofibrillar protein synthesis with low and high dose amino acid infusion. J Physiol 2008;586:6049-61.

18. Goldspink G. Age-related muscle loss and progressive dysfunction in mechanosensitive growth factor signaling. Ann N Y Acad Sci 2004;1019:294-8.

19. Gonzalez-Cadavid NF, Taylor WE, Yarasheski K, et al. Organization of the human myostatin gene and expression in healthy men and HIV-infected men with muscle wasting. Proc Natl Acad Sci U S A 1998;95:14938-43.

20. Gosker HR, Engelen MP, van Mameren H, et al. Muscle fiber type IIX atrophy is involved in the loss of fat-free mass in chronic obstructive pulmonary disease. Am J Clin Nutr 2002;76:113-9. 
21. Gosker HR, van Mameren H, van Dijk PJ, et al. Skeletal muscle fibre-type shifting and metabolic profile in patients with chronic obstructive pulmonary disease. Eur Respir J 2002;19:617-25.

22. Gosker HR, Wouters EF, van der Vusse GJ, Schols AM. Skeletal muscle dysfunction in chronic obstructive pulmonary disease and chronic heart failure: underlying mechanisms and therapy perspectives. Am J Clin Nutr 2000;71:1033-47.

23. Hameed M, Orrell RW, Cobbold M, Goldspink G, Harridge SD. Expression of IGF-I splice variants in young and old human skeletal muscle after high resistance exercise. J Physiol 2003;547:247-54.

24. Harridge SD. Plasticity of human skeletal muscle: gene expression to in vivo function. Exp Physiol 2007;92:783-97.

25. Hawke TJ, Garry DJ. Myogenic satellite cells: physiology to molecular biology. J Appl Physiol 2001;91:534-51.

26. Hespel P, Op't Eijnde B, Van Leemputte M, et al. Oral creatine supplementation facilitates the rehabilitation of disuse atrophy and alters the expression of muscle myogenic factors in humans. J Physiol 2001;536:625-33.

27. Hunter GR, McCarthy JP, Bamman MM. Effects of resistance training on older adults. Sports Med 2004;34:329-48.

28. Ishido M, Kami K, Masuhara M. Localization of MyoD, myogenin and cell cycle regulatory factors in hypertrophying rat skeletal muscles. Acta Physiol Scand 2004;180:281-9.

29. Jejurikar SS, Kuzon WM, Jr. Satellite cell depletion in degenerative skeletal muscle. Apoptosis 2003;8:573-8.

30. Kadi F, Schjerling P, Andersen LL, et al. The effects of heavy resistance training and detraining on satellite cells in human skeletal muscles. J Physiol 2004;558:1005-12.

31. Katsanos CS, Kobayashi H, Sheffield-Moore M, Aarsland A, Wolfe RR. Aging is associated with diminished accretion of muscle proteins after the ingestion of a small bolus of essential amino acids. Am J Clin Nutr 2005;82:1065-73.

32. Katsanos CS, Kobayashi H, Sheffield-Moore M, Aarsland A, Wolfe RR. A high proportion of leucine is required for optimal stimulation of the rate of muscle protein synthesis by essential amino acids in the elderly. Am J Physiol Endocrinol Metab 2006;291:E381-7.

33. Kim JS, Cross JM, Bamman MM. Impact of resistance loading on myostatin expression and cell cycle regulation in young and older men and women. Am J Physiol Endocrinol Metab 2005;288:E1110-9.

34. Koopman R, Verdijk L, Manders RJ, et al. Co-ingestion of protein and leucine stimulates muscle protein synthesis rates to the same extent in young and elderly lean men. Am J Clin Nutr 2006;84:623-32.

35. Kosek DJ, Kim JS, Petrella JK, Cross JM, Bamman MM. Efficacy of 3 days/wk resistance training on myofiber hypertrophy and myogenic mechanisms in young vs. older adults. J Appl Physiol 2006;101:531-44.

36. Kumar V, Selby A, Rankin D, et al. Age-related differences in the dose-response relationship of muscle protein synthesis to resistance exercise in young and old men. $\mathrm{J}$ Physiol 2009;587:211-7.

37. Larsen AI, Lindal S, Aukrust P, Toft I, Aarsland T, Dickstein K. Effect of exercise training on skeletal muscle fibre characteristics in men with chronic heart failure. Correlation between skeletal muscle alterations, cytokines and exercise capacity. Int $\mathrm{J}$ Cardiol 2002;83:25-32.

38. Li P, Akimoto T, Zhang M, Williams RS, Yan Z. Resident stem cells are not required for exercise-induced fiber-type switching and angiogenesis but are necessary for activity-dependent muscle growth. Am J Physiol Cell Physiol 2006;290:C1461-8.

39. Mauro A. Satellite cell of skeletal muscle fibers. J Biophys Biochem Cytol 1961;9:4935 . 
40. McCarthy JJ, Esser KA. Counterpoint: Satellite cell addition is not obligatory for skeletal muscle hypertrophy. J Appl Physiol 2007;103:1100-2; discussion 1102-3.

41. McCroskery S, Thomas M, Maxwell L, Sharma M, Kambadur R. Myostatin negatively regulates satellite cell activation and self-renewal. J Cell Biol 2003;162:1135-47.

42. McKay BR, O'Reilly CE, Phillips SM, Tarnopolsky MA, Parise G. Co-expression of IGF-1 family members with myogenic regulatory factors following acute damaging muscle-lengthening contractions in humans. J Physiol 2008;586:5549-60.

43. Megeney LA, Rudnicki MA. Determination versus differentiation and the MyoD family of transcription factors. Biochem Cell Biol 1995;73:723-32.

44. Miro O, Pedrol E, Cebrian M, et al. Skeletal muscle studies in patients with HIV-related wasting syndrome. J Neurol Sci 1997;150:153-9.

45. O'Connor RS, Pavlath GK. Point:Counterpoint: Satellite cell addition is/is not obligatory for skeletal muscle hypertrophy. J Appl Physiol 2007;103:1099-100.

46. Parise G, McKinnell IW, Rudnicki MA. Muscle satellite cell and atypical myogenic progenitor response following exercise. Muscle Nerve 2008;37:611-9.

47. Petrella JK, Kim JS, Cross JM, Kosek DJ, Bamman MM. Efficacy of myonuclear addition may explain differential myofiber growth among resistance-trained young and older men and women. Am J Physiol Endocrinol Metab 2006;291:E937-46.

48. Petrella JK, Kim JS, Mayhew DL, Cross JM, Bamman MM. Potent myofiber hypertrophy during resistance training in humans is associated with satellite cellmediated myonuclear addition: a cluster analysis. J Appl Physiol 2008;104:1736-42.

49. Phillips SM, Tipton KD, Aarsland A, Wolf SE, Wolfe RR. Mixed muscle protein synthesis and breakdown after resistance exercise in humans. Am J Physiol 1997;273:E99-107.

50. Rantanen J, Hurme T, Lukka R, Heino J, Kalimo H. Satellite cell proliferation and the expression of myogenin and desmin in regenerating skeletal muscle: evidence for two different populations of satellite cells. Lab Invest 1995;72:341-7.

51. Rosenblatt JD, Yong D, Parry DJ. Satellite cell activity is required for hypertrophy of overloaded adult rat muscle. Muscle Nerve 1994;17:608-13.

52. Roth SM, Martel GF, Ivey FM, et al. Skeletal muscle satellite cell characteristics in young and older men and women after heavy resistance strength training. J Gerontol A Biol Sci Med Sci 2001;56:B240-7.

53. Sartorelli V, Fulco M. Molecular and cellular determinants of skeletal muscle atrophy and hypertrophy. Sci STKE 2004;2004:re11.

54. Scremin AM, Kurta L, Gentili A, et al. Increasing muscle mass in spinal cord injured persons with a functional electrical stimulation exercise program. Arch Phys Med Rehabil 1999;80:1531-6.

55. Shefer G, Van de Mark DP, Richardson JB, Yablonka-Reuveni Z. Satellite-cell pool size does matter: Defining the myogenic potency of aging skeletal muscle. Dev Biol 2006;294:50-66.

56. Sinha-Hikim I, Cornford M, Gaytan H, Lee ML, Bhasin S. Effects of testosterone supplementation on skeletal muscle fiber hypertrophy and satellite cells in communitydwelling older men. J Clin Endocrinol Metab 2006;91:3024-33.

57. Thom JM, Thompson MW, Ruell PA, et al. Effect of 10-day cast immobilization on sarcoplasmic reticulum calcium regulation in humans. Acta Physiol Scand 2001;172:141-7.

58. Veldhuizen JW, Verstappen FT, Vroemen JP, Kuipers H, Greep JM. Functional and morphological adaptations following four weeks of knee immobilization. Int J Sports Med 1993;14:283-7.

59. Verney J, Kadi F, Charifi N, et al. Effects of combined lower body endurance and upper body resistance training on the satellite cell pool in elderly subjects. Muscle Nerve 2008;38:1147-54. 
60. Welle S, Totterman S, Thornton C. Effect of age on muscle hypertrophy induced by resistance training. J Gerontol A Biol Sci Med Sci 1996;51:M270-5.

61. Wouters EF, Creutzberg EC, Schols AM. Systemic effects in COPD. Chest 2002;121:127S-130S.

62. Yang Y, Creer A, Jemiolo B, Trappe S. Time course of myogenic and metabolic gene expression in response to acute exercise in human skeletal muscle. J Appl Physiol 2005;98:1745-52.

63. Zammit PS, Golding JP, Nagata Y, Hudon V, Partridge TA, Beauchamp JR. Muscle satellite cells adopt divergent fates: a mechanism for self-renewal? J Cell Biol 2004;166:347-57.

64. Zammit PS, Partridge TA, Yablonka-Reuveni Z. The skeletal muscle satellite cell: the stem cell that came in from the cold. J Histochem Cytochem 2006;54:1177-91. 
Summary 
The progressive loss of skeletal muscle mass and strength with aging, sarcopenia, is associated with functional impairments in daily life activities, the loss of independence, an increased risk of developing chronic metabolic diseases, and an overall decrease in the quality of life. Satellite cells (muscle stem cells) play a key role in the maintenance, repair and regeneration of skeletal muscle tissue. Therefore, age-related changes in satellite cell content and/or function might represent a key factor in the etiology of sarcopenia. In this thesis, we assess the age-related changes in skeletal muscle mass, strength, and muscle fiber type characteristics. We specifically focus on the changes in muscle fiber type-specific satellite cell content with aging and the impact of resistance type exercise training in the elderly.

In chapter 2, we assess the validity of one-repetition maximum (1RM) strength testing by comparing it with gold standard dynamometry testing in a population healthy adult men and women of varying ages $(n=55: 19-84 \mathrm{y})$. Both 1RM leg extension and leg press correlate strongly with dynamometer results $(0.72 \leq r \leq 0.88)$, and these correlations do not differ between young and old, or male and female subgroups. We conclude that 1RM testing represents a valid means to assess leg muscle strength in both young and elderly men and women. As such, we used 1RM testing in subsequent studies to assess age-related changes in muscle strength and to evaluate the impact of prolonged exercise intervention on muscle strength in the elderly. In chapter 3, 1RM leg muscle strength is shown to be $25-30 \%$ lower in healthy elderly versus young men. Histochemical analyses of muscle biopsies show that the latter is accompanied by a reduced proportion of type II muscle fibers and specific type II muscle fiber atrophy in the elderly. Furthermore, the number of skeletal muscle satellite cells is substantially reduced in the type II muscle fibers in the elderly. No differences in type I muscle fiber characteristicss are observed between elderly versus young men. We speculate that a decline in type II muscle fiber satellite cell content with aging might play a key role in the etiology of sarcopenia. In chapter 4, 41 healthy elderly men were included in a cross-sectional analysis to show that type I and II muscle fiber myonuclear content and satellite cell content correlate with muscle fiber size $(0.50 \leq r \leq 0.56)$. In addition, type I and II muscle fiber size correlate with quadriceps muscle size (measured with CT scans). Furthermore, muscle fiber size, quadriceps muscle size, and leg lean mass (measured with DXA scans) are shown to correlate strongly with leg muscle strength. These findings support the idea that muscle fiber typespecific changes in satellite cell content, myonuclear content and muscle fiber size are associated with the age-related loss of skeletal muscle mass and strength.

Although resistance type exercise training represents an effective strategy to counteract the loss of skeletal muscle mass and strength with aging, the mechanisms underlying the skeletal muscle adaptive response to exercise 
remain poorly understood. Therefore, chapter 5 focuses on the role that satellite cells might play in the skeletal muscle adaptive response to exercise. Three months of resistance type exercise training in the elderly is shown to result in a $6 \%$ increase in lean tissue in the legs, a $9 \%$ increase in quadriceps muscle size, and a concomitant $25-30 \%$ increase in 1RM leg extension and leg press strength. Furthermore, a substantial increase in type II muscle fiber size is observed, accompanied by a $\sim 70 \%$ increase in type II muscle fiber satellite cell content. No changes are observed in myonuclear domain size. In addition, no changes are observed in type I muscle fiber size or satellite cell content. These findings imply that skeletal muscle tissue in the elderly is still capable of inducing satellite cell activation, proliferation, and differentiation, and fusion of new myonuclei into existing muscle fibers, allowing type II muscle fiber hypertrophy.

Previous studies have suggested that timed protein supplementation may further augment the skeletal muscle adaptive response to exercise in the elderly. Therefore, in chapter 6 we assessed the effects of timed protein supplementation on the increase in skeletal muscle mass and strength following 3 months of resistance type exercise training. Progressive resistance type exercise training is shown to result in similar increases in leg muscle mass and strength in healthy elderly men provided with either placebo or protein supplements immediately before and after each exercise session. In accordance, muscle fiber hypertrophy is shown to be similar in both groups for both the type I $(\sim 10 \%)$ and type II $(\sim 28 \%)$ muscle fibers. Dietary protein intake in these elderly men is shown to be above current dietary guidelines, with an intake $1.1 \pm 0.1 \mathrm{~g}$ protein per kg body weight per day. We conclude that timed protein supplementation does not further augment skeletal muscle hypertrophy after 3 months of resistance type exercise training in well-nourished, healthy, elderly males.

The final chapter addresses the implications of the findings presented in this thesis, and provides key topics for future research. This thesis shows that sarcopenia is associated with a muscle fiber type-specific decline in satellite content. Resistance type exercise training can, at least partly, reverse the loss of muscle mass and strength with aging. The latter is associated with an increase in type II muscle fiber size and satellite cell content. We suggest that skeletal muscle satellite cells play a key role in both age-related muscle atrophy and in the skeletal muscle adaptive response to exercise intervention programs aiming to counteract sarcopenia. 



\section{Samenvatting}


Veroudering gaat gepaard met een progressief verlies van spiermassa en spierkracht, ook wel sarcopenie genoemd. Dit leidt tot functionele beperkingen in het dagelijkse leven, verminderde zelfredzaamheid, een verhoogde kans op de ontwikkeling van chronisch metabole ziekten, en een afname in de kwaliteit van leven. Satellietcellen (de zogenaamde "spierstamcellen") zijn van essentieel belang voor het onderhoud en de regeneratieprocessen van skeletspierweefsel. Een daling in het aantal satellietcellen en/of een afname in hun functioneren zou een belangrijke factor kunnen zijn in de ontstaansgeschiedenis van sarcopenie. In dit proefschrift richten we ons op leeftijdsgerelateerde veranderingen in spiermassa, spierkracht, en spiervezelkarakteristieken. Speciale aandacht wordt besteed aan de spiervezelspecifieke veranderingen in het aantal satellietcellen in relatie tot veroudering en de effecten van krachttraining in oudere mensen.

In hoofdstuk 2 bepalen we de validiteit van 1-RM ("one-repetition maximum") testen voor het meten van spierkracht, door deze te vergelijken met dynamometrie als de gouden standaard. Dit doen we in een groep van 55 gezonde mannen en vrouwen (19-84 jaar). Zowel de 1RM resultaten van de "leg press" als de "leg extension" fitness toestellen correleren goed met de dynamometer resultaten $(0,72 \leq r \leq 0,88)$, en dit geldt eveneens voor aparte subgroepen (man versus vrouw als ook jong versus oud). Het gebruik van 1RM testen blijkt een valide manier om spierkracht te meten in zowel jonge als oudere mannen en vrouwen. Daarom werden 1RM testen in de overige studies gebruikt om leeftijdsgerelateerde veranderingen in spierkracht te onderzoeken en om de toename in spierkracht na krachttraining in oudere mensen te bepalen. Hoofdstuk 3 laat zien dat de 1RM kracht in de benen 25$30 \%$ lager is in gezonde oudere mannen in vergelijking met gezonde jonge mannen. Histochemische analyses van spierbiopten tonen aan dat dit gepaard gaat met een lager percentage type II spiervezels en specifieke atrofie (afname in grootte) van de type II spiervezels in oudere mannen. Bovendien is het aantal satellietcellen in type II spiervezels aanmerkelijk lager in de ouderen dan in de jongeren. De afname van het aantal satellietcellen in type II spiervezels met veroudering zou een belangrijke rol kunnen spelen bij het ontstaan van sarcopenie. In hoofdstuk 4 tonen we bij 41 gezonde oudere mannen aan dat voor zowel de type I als de type II spiervezels het aantal kernen en satellietcellen per spiervezel positief correleert met spiervezelgrootte $(0,50 \leq r \leq 0,56)$. Spiervezelgrootte correleert daarnaast positief met de grootte van de quadriceps spier (gemeten met CT scans). Spiervezelgrootte, quadriceps grootte en totale beenspiermassa (gemeten met DXA scans) zijn bovendien sterk gecorreleerd met spierkracht. Deze resultaten ondersteunen de gedachte dat spiervezelspecifieke veranderingen in het aantal satellietcellen, het aantal kernen, en de spiervezelgrootte geassocieerd zijn met verlies van spiermassa en spierkracht bij veroudering. 
Hoewel krachttraining het verlies van spiermassa en spierkracht met veroudering tegen kan gaan, zijn de onderliggende mechanismen van de positieve effecten van lichamelijk inspanning nog grotendeels onduidelijk. Daarom onderzoeken we in hoofdstuk 5 de rol die satellietcellen zouden kunnen spelen in de respons op inspanning bij ouderen. Na drie maanden krachttraining wordt een $6 \%$ toename in spiermassa in het been, een $9 \%$ toename in de grootte van de quadriceps spier, en een $25-30 \%$ toename in spierkracht waargenomen. Er wordt een substantiële toename in type II spiervezelgrootte aangetoond, die bovendien gepaard gaat met een $70 \%$ toename in het aantal satellietcellen per type II spiervezel. Er worden geen veranderingen aangetoond in de spiervezeloppervlakte per kern. Ook worden er geen veranderingen aangetoond in de spiervezelgrootte en/of het aantal satellietcellen per type I spiervezel. Deze bevindingen geven aan dat skeletspierweefsel in oudere mensen nog steeds in staat is om activatie, proliferatie en differentiatie van satellietcellen te induceren en nieuwe kernen te laten fuseren met bestaande spiervezels, wat uiteindelijk bijdraagt aan hypertrofie (toename in grootte) van de type II spiervezels.

Eerder onderzoek heeft gesuggereerd dat de inname van eiwitsupplementen de effecten van inspanningsinterventie bij oudere mensen verder zou kunnen verhogen. In hoofdstuk 6 onderzoeken we daarom de additionele effecten van eiwitsuppletie in combinatie met langdurige krachttraining. De toename in spiermassa en spierkracht na een krachttrainingsprogramma bij gezonde oudere mannen blijkt onafhankelijk te zijn van het al dan niet innemen van een eiwitsupplement direct voor en na iedere trainingssessie. Ook voor hypertrofie van de type I ( $\sim 10 \%)$ en type II spiervezels ( $\sim 28 \%)$ worden geen verschillen aangetoond tussen de eiwit- en placebogroep. De gemiddelde dagelijkse eiwitinname in deze gezonde oudere mannen blijkt met een inname van $1,1 \mathrm{~g}$ eiwit per $\mathrm{kg}$ lichaamsgewicht per dag ruim boven de geldende richtlijn te liggen. Deze studie toont aan dat eiwitsuppletie voor en onmiddellijk na elke training geen additioneel effect heeft op de toename in spiermassa en spierkracht gedurende een krachttrainingsprogramma in gezonde oudere mannen met voldoende eiwitinname.

In het laatste hoofdstuk worden de onderzoeksresultaten uit dit proefschrift nader bediscussieerd en worden specifieke doelen voor toekomstig onderzoek gedefinieerd. Dit proefschrift toont aan dat veroudering gepaard gaat met een specifieke afname van het aantal satellietcellen in de type II spiervezels. Krachttraining kan het verlies van spiermassa en spierkracht (deels) tegengaan. Dit laatste gaat gepaard met een toename van type II spiervezelgrootte en het aantal satellietcellen. Op basis van onze bevindingen suggereren wij dat satellietcellen een primaire rol spelen bij het verlies van spiermassa tijdens veroudering en bij de adaptieve respons van de skeletspieren op krachttraining in ouderen. 



\section{Dankwoord}





\section{Dankwoord}

Ik heb lang zitten twijfelen over wat te doen met dit dankwoord. Wordt het een lijst met namen, met als onvermijdelijk gevolg dat ik mensen ga vergeten? Wordt het een lijst met clichés, wat de originaliteit van het proefschrift wellicht geen goed zou doen? Of wordt het een kort en bondige opsomming van rake one-liners (helaas, was een collega mij net even voor)? Mijn sterke neiging tot wollige schrijfstijl uiteindelijk volledig negerend (...) , heb ik besloten om het nog simpeler te houden, en me hier tot één pagina met een algemeen "bedankt" te beperken.

De meeste dingen die je in je leven doet, kun je niet alleen. En als je het al alleen zou kunnen, dan is er niet veel aan als je het niet met anderen kunt delen of beleven. Dankbaarheid is voor mij dan ook de waardering die je voelt voor iets wat je overkomt, voor iets wat je met hulp van anderen bereikt, of simpelweg voor iets wat anderen voor je doen. Zonder al te lyrisch te worden, kan ik in alle eerlijkheid zeggen dat ik bijzonder gelukkig ben met de dingen die ik dagelijks doe, de dingen die ik bereikt heb en de mensen die me daarbij geholpen hebben. En dat geldt uiteraard specifiek voor de periode die uiteindelijk heeft geleid tot de totstandkoming van dit boekje. Mijn dank gaat dan ook simpelweg uit naar iedereen die iets - groot of klein - voor mij betekend heeft, nog steeds betekent, en hopelijk ook blijft betekenen; van thuisfront tot werkplek, en van familie tot vrienden en collega's (gelukkig sluit het een het ander niet uit). Degenen die mij goed kennen, weten waarschijnlijk dat ik mijn dankbaarheid niet te pas en te onpas hardop uit. Maar hopelijk weten zij wel dat ik veel waardering heb voor: de diepe of juist lekker oppervlakkige alledaagse gesprekken; de momenten waarop blijkt dat je (bijna tot op het enge af) wel heel erg op dezelfde golflengte met elkaar zit; het "Brabantse thuisgevoel"; een uitgebreid diner in een van die fijne restaurants die Maastricht rijk is, of gewoon lekker thuis; een simpele eierkoek bij de (senseo) koffie; een biertje in de kroeg of juist het borreltje op de bank; de groene matten op vrijdag (en de rest van de week), het "Brabantse werkgevoel", enzovoorts.

Ik hoop dan ook dat dit soort aangelegenheden zich in de toekomst veelvuldig mogen blijven voordoen. En hopelijk met dezelfde mensen die mij de afgelopen jaren hebben geholpen, bijgestaan, en begeleid; kortom, met wie ik alles heb mogen delen en beleven, en die mijn tijd in Maastricht tot nu toe tot een heel fijne tijd hebben gemaakt.

Dank jullie wel!! 



\section{Curriculum vitae}



Lex Verdijk was born on February 10, 1979 in Vierlingsbeek, the Netherlands. He attended secondary school at the Elzendaalcollege in Boxmeer and graduated from the VWO in 1997. He then studied Physical Therapy at the Hogeschool van Arnhem and Nijmegen and received his diploma as a physical therapist in 2001. In the same year, he started a 2 year master's program at the Faculty of Health Sciences at Maastricht University. He obtained his Master's degree in Human Movement Sciences in 2003, after working as an intern on the age-related changes in the human walking pattern, and on the self-stabilizing function of intrinsic muscle properties. For his Master thesis, he received the SWUM award (2003).

After working as a research assistant at Human Movement Sciences (Maastricht University), Lex started his $\mathrm{PhD}$ project entitled "structural and metabolic basis of sarcopenia" at the same department in July 2004. During the first years as a PhD student, he received a Young Investigators Award from the European College of Sport Science (2006), for his presentation on age-related fiber type-specific differences in satellite cell content.

Currently, Lex Verdijk works as a Post Doctoral fellow at the Human Movement Sciences Department of the Maastricht University Medical Centre+, on the TIFN project entitled "dietary strategies to augment muscle mass and function in the elderly". He continues his work in the field of sarcopenia, with special focus on the role of satellite cells in the atrophy and hypertrophy of senescent skeletal muscle, and the benefits of exercise and nutritional interventions to improve muscle mass and strength in the elderly. 



\section{List of publications}



Koopman R, Verdijk L, Manders RJ, Gijsen AP, Gorselink M, Pijpers E, Wagenmakers AJ, and van Loon LJ. Co-ingestion of protein and leucine stimulates muscle protein synthesis rates to the same extent in young and elderly lean men. Am J Clin Nutr 2006;84:623-32.

Koopman R, Verdijk LB, Beelen M, Gorselink M, Kruseman AN, Wagenmakers AJ, Kuipers H, and van Loon LJ. Co-ingestion of leucine with protein does not further augment post-exercise muscle protein synthesis rates in elderly men. Br J Nutr 2008;99:571-80.

Savelberg HH, Verdijk LB, Willems PJ, Meijer K. The robustness of agerelated gait adaptations: can running counterbalance the consequences of ageing? Gait Posture 2007;25:259-66.

Snijders T, Verdijk LB, and van Loon LJ. The impact of sarcopenia and exercise training on skeletal muscle satellite cells. Ageing Res Rev 2009.

Vanschoonbeek K, Lansink M, van Laere KM, Senden JM, Verdijk LB, and van Loon LJ. Slowly Digestible Carbohydrate Sources Can Be Used to Attenuate the Postprandial Glycemic Response to the Ingestion of DiabetesSpecific Enteral Formulas. Diabetes Educ 2009.

Verdijk LB, Gleeson BG, Jonkers RA, Meijer K, Savelberg HH, Dendale P, and van Loon LJ. Skeletal muscle hypertrophy following resistance training is accompanied by a fiber type-specific increase in satellite cell content in elderly men. J Gerontol A Biol Sci Med Sci 2009;64:332-9.

Verdijk LB, Jonkers RA, Gleeson BG, Beelen M, Meijer K, Savelberg HH, Wodzig WK, Dendala P, and van Loon LJ. Protein supplementation before and after exercise does not further augment skeletal muscle hypertrophy after resistance training in elderly men. Am J Clin Nutr 2009;89:608-16.

Verdijk LB, Koopman R, Schaart G, Meijer K, Savelberg HH, and van Loon LJ. Satellite cell content is specifically reduced in type II skeletal muscle fibers in the elderly. Am J Physiol Endocrinol Metab 2007;292:E151-7. 
Verdijk LB, van Loon L, Meijer K, and Savelberg HH. One-repetition maximum strength test represents a valid means to assess leg strength in vivo in humans. J Sports Sci 2009;27:59-68.

Verhoeven S, Vanschoonbeek K, Verdijk LB, Koopman R, Wodzig WK, Dendale P, and van Loon LJ. Long-term leucine supplementation does not increase muscle mass or strength in healthy elderly men. Am J Clin Nutr 2009;89:1468-75. 